\title{
Recent developments of nanocarbon based supports for PEMFCs electrocatalysts
}

\author{
Junwei Chen, Zuqiao Ou, Haixin Chen, Shuqin Song, Kun Wang, Yi Wang * \\ The Key Laboratory of Low-carbon Chemistry \& Energy Conservation of Guangdong Province, School of Chemical Engineering and Technology, School of \\ Materials Science and Engineering, Sun Yat-sen University, Guangzhou 510275, Guangdong, China
}

\section{A R T I C L E I N F O}

Article history:

Received 5 October 2020

Accepted 29 November 2020

Available online 5 April 2021

\section{Keywords:}

Nanocarbon support

Proton exchange membrane fuel cell

Electrocatalyst

Oxygen reduction reaction

Methanol oxidation reaction

\begin{abstract}
A B S T R A C T
Nanocarbons, widely and commonly used as supports for supported Pt-based electrocatalysts in PEMFCs, play a significant role in Pt dispersion and accessibility, further determining their corresponding electrocatalytic performance. This paper provides an overview of the nanoarchitectures and surface physicochemical properties of nanocarbons affecting the electrocatalyst performance, with an emphasis on both physical characteristics, including pore structure, and chemical properties, including heteroatom doping and functional carbon-based supports. This review discusses the recent progress in nanocarbon supports, guides the future development direction of PEMFC supports, and provides our own viewpoints for the future research and design of PEMFCs catalysts, advancing the commercialization of PEMFCs.
\end{abstract}

(C) 2021, Dalian Institute of Chemical Physics, Chinese Academy of Sciences. Published by Elsevier B.V. All rights reserved.

\section{Introduction}

Proton exchange membrane fuel cells (PEMFCs) are currently one of the most popular new energy devices, possessing the advantages of quick start-up owing to their low working temperature, compactness, no corrosion problems, and flexibility in any orientation [1,2]. In this operational system, either hydrogen, methanol (direct methanol fuel cells, DMFCs), or ethanol (direct ethanol fuel cells, DEFCs) can be directly used as the fuel. Using liquid alcohols as fuel avoids the complicated process of hydrogen preparation, storage, and transportation, and DMFCs and DEFCs have considerable weight and volume advantages over $\mathrm{H}_{2}$-PEMFCs. Consequently, $\mathrm{H}_{2}$-PEMFCs are generally used for power station and vehicle applications, while direct alcohol fuel cells (DAFCs), including DMFCs and DEFCs, are mainly used as portable power sources $[1,3]$.

PEMFCs are mainly composed of a membrane electrode assembly (MEA), bipolar plates, and sealing gaskets, in a typical sandwich structure [3]. MEA is the heart of PEMFCS, with reactions occurring in the catalyst layer [4]. For PEMFCs, the reactions occurring at the cathode is the oxygen reduction reaction (ORR) while the oxidation reaction occurs at the anode (dependent on the fuel type, it could be the hydrogen oxidation reaction (HOR), methanol oxidation reaction (MOR), or ethanol oxidation reaction (EOR)) [5]. Among them, ORR proceeds through two reaction mechanisms by $2 \mathrm{e}^{-}$or $4 \mathrm{e}^{-}$pathways. Under the $2 \mathrm{e}^{-}$reaction mechanism, $\mathrm{O}_{2}$ is first reduced to produce $\mathrm{H}_{2} \mathrm{O}_{2}$, and then further reduced to $\mathrm{H}_{2} \mathrm{O}$ (Eqs. $(1,2)$ ), while under

\footnotetext{
* Corresponding author. Tel/Fax: +86-20-84113253; E-mail: wangyi76@mail.sysu.edu.cn

This work was supported by the National Natural Science Foundation of China (21978331, 21975292, 21905311), Guangdong Basic and Applied Basic Research Foundation (2020A1515010343) ,Tip-top Scientific and Technical Innovative Youth Talents of Guangdong Special Support Program (2016TQ03N322), Guangzhou Science and Technology Project (201707010079), the National Key Research and Development Program of China (2016YFB0101200), and the fundamental Research Funds for Central Universities (19lgpy136, 19lgpy116), and the China Postdoctoral Science Foundation (2019M653142). DOI: 10.1016/S1872-2067(20)63736-6 | http://www.sciencedirect.com/journal/chinese-journal-of-catalysis | Chin. J. Catal., Vol. 42, No. 8, August 2021
} 
the $4 \mathrm{e}^{-}$reaction mechanism, $\mathrm{O}_{2}$ is directly reduced to $\mathrm{H}_{2} \mathrm{O}$ without $\mathrm{H}_{2} \mathrm{O}_{2}$ (Eq. (3)) [6,7]. MOR usually undergoes the adsorption dehydrogenation process of $\mathrm{CH}_{3} \mathrm{OH}$ first and then is oxidized to $\mathrm{CO}_{2}$, which is a typical $6 \mathrm{e}^{-}$reaction mechanism (Eq. (4)) [8]. However, it must be noted that the dehydrogenation of $\mathrm{CH}_{3} \mathrm{OH}$ during the MOR reaction produces $\mathrm{CO}$ intermediates. When there is insufficient $\mathrm{OH}_{\text {ads }}$ on the catalyst surface to react with $\mathrm{CO}$ and convert it into $\mathrm{CO}_{2}$, it will cause $\mathrm{CO}$ poisoning and deactivation of the catalyst, which should be avoided as much as possible [9]. EOR has two reaction pathways, namely, a $12 \mathrm{e}^{-}$ reaction mechanism in which $\mathrm{CH}_{3} \mathrm{CH}_{2} \mathrm{OH}$ is oxidized to $\mathrm{CO}_{2}$ (Eq. (5)) and a $4 \mathrm{e}^{-}$reaction mechanism in which $\mathrm{CH}_{3} \mathrm{CH}_{2} \mathrm{OH}$ is oxidized to $\mathrm{CH}_{3} \mathrm{COOH}$ (Eq. (6)). The former reaction is more thorough, but due to cleavage of the $\mathrm{C}-\mathrm{C}$ bond, the reaction rate is significantly slower than that of the latter reaction [9].

$2 \mathrm{e}^{-}$ORR:

$$
\begin{gathered}
\mathrm{O}_{2}+2 \mathrm{H}^{+}+2 \mathrm{e}^{-} \rightarrow \mathrm{H}_{2} \mathrm{O}_{2} \\
\mathrm{H}_{2} \mathrm{O}_{2}+2 \mathrm{H}^{+}+2 \mathrm{e}^{-} \rightarrow 2 \mathrm{H}_{2} \mathrm{O}
\end{gathered}
$$

$4 \mathrm{e}^{-}$ORR:

$$
\mathrm{O}_{2}+4 \mathrm{H}^{+}+4 \mathrm{e}^{-} \rightarrow 2 \mathrm{H}_{2} \mathrm{O}
$$

MOR:

$$
\mathrm{CH}_{3} \mathrm{OH}+\mathrm{H}_{2} \mathrm{O} \rightarrow \mathrm{CO}_{2}+6 \mathrm{H}^{+}+6 \mathrm{e}^{-}
$$

EOR:

$$
\begin{gathered}
\mathrm{CH}_{3} \mathrm{CH}_{2} \mathrm{OH}+3 \mathrm{H}_{2} \mathrm{O} \rightarrow 2 \mathrm{CO}_{2}+12 \mathrm{H}^{+}+12 \mathrm{e}^{-} \\
\mathrm{CH}_{3} \mathrm{CH}_{2} \mathrm{OH}+\mathrm{H}_{2} \mathrm{O} \rightarrow \mathrm{CH}_{3} \mathrm{COOH}+4 \mathrm{H}^{+}+4 \mathrm{e}^{-}
\end{gathered}
$$

Because of the sluggish kinetics and complexity of the ORR, MOR, EOR, and $\mathrm{CO}$ poison in the case of $\mathrm{H}_{2}$-rich gas as fuel, $\mathrm{Pt}$ or Pt-based catalysts are exclusively adopted to obtain desirable electrode reactions, and undesirably, high Pt loading is always needed [1,10-13]. This results in the high cost of the electrocatalysts and PEMFCs.

To improve Pt utilization, Pt nanoparticles are generally supported on a supporting material, which could produce Pt electrocatalysts with high dispersion and utilization efficiency [14]. As an essential component of PEMFCs, the electrocatalyst support can affect various physical properties (such as particle size, dispersion, and specific surface area) and electrochemical properties (such as activity and stability) of the electrocatalysts. Moreover, support materials can also influence both the electron and proton transfer processes; therefore, they will appreciably correlate with the catalyst performance [15]. Suitable support is beneficial for dispersing and anchoring catalyst nanoparticles, increasing the effective active area, improving the catalyst activity and stability, constructing an efficient electrocatalytic reaction interface, and reducing the cost of PEMFCs [16-19]. An ideal catalyst support needs to possess the following properties, namely, (1) suitable pore structure, (2) high active specific surface area, (3) high conductivity, and (4) good thermal and electrochemical stability $[15,16,20]$. Among all the promising supporting materials, carbon is the most desirable and widely adopted one because of its distinguishing features, namely, (1) high stability (in both acidic and basic media, even at high temperature), (2) controllable pore structure, (3) tractable physical form, (4) modifiable surface chemistry, and (5) low cost [21,22]. Moreover, its high electronic conductivity is also a prerequisite for the high performance of electrocatalysts. To date, the most widely used carbon support in PEMFCs is

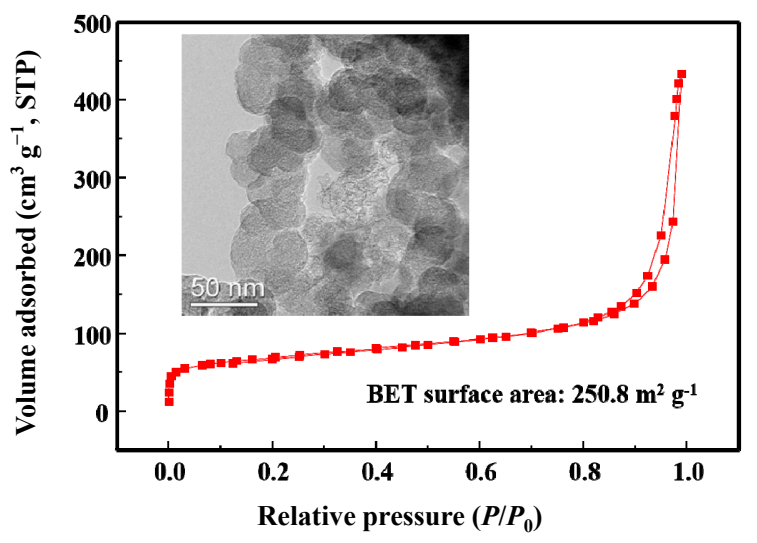

Fig. 1. $\mathrm{N}_{2}$ adsorption-desorption isotherms and TEM image of XC72R CB.

carbon black (CB), especially commercial XC72R CB (Cabot Corp.) with a surface area of $\sim 250 \mathrm{~m}^{2} \mathrm{~g}^{-1}$ and a particle size of $\sim 30 \mathrm{~nm}$. Fig. 1 presents the corresponding $\mathrm{N}_{2}$ adoption-desorption curves and transmission electron microscope (TEM) images.

The surface of XC72R CB does not contain sufficient anchoring sites for metal particles due to the lack of functional groups, and thus the metal particles, such as Pt, are easily shifted and further agglomerated together. Consequently, the activity and stability of the electrocatalysts deteriorates [20]. Additionally, the catalysts with XC72R CB as the support easily corrode, especially at the cathode with the high potential and high oxygen content, leading to a significant decrease in their electrocatalytic performance. Although high graphitization can increase its stability, it also reduces the surface area and porosity, thereby deeply affecting the mass transfer process [23,24].

To address the above issues and improve the electrocatalyst performance, novel carbon materials (such as carbon nanotubes (CNTs), carbon nanofibers (CNFs), graphene, carbon aerogels (CAs), and others) have been introduced as supporting materials for Pt-based electrocatalysts to improve Pt dispersion and accessibility, catalytic activity, stability, and CO resistance [12,25-27] (Fig. 2). Table 1 lists the characteristics of various nanocarbon material types. These novel carbon materials are quite different based on not only the macro-scale, in terms of the physical form (microspheres, tubes, fibers, etc.), but also on the micro-, nano-, and even molecular-scale, in terms of pore nanoarchitectures and surface chemistry [28]. Moreover, re-

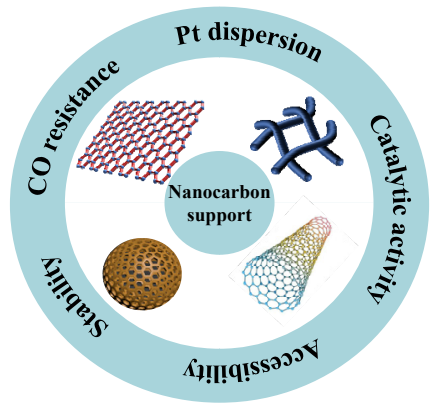

Fig. 2. Novel nanocarbon materials as the support for PEMFCs. 
Table 1

Nanocarbons as the support for PEMFC electrocatalysts.

\begin{tabular}{|c|c|c|c|c|c|}
\hline $\begin{array}{l}\text { Nano carbon- } \\
\text { based materials }\end{array}$ & Preparation methods & Material characteristics & Application fields & $\begin{array}{c}\text { Problems to be } \\
\text { solved as a catalyst } \\
\text { support }\end{array}$ & Solutions \\
\hline CNTs & $\begin{array}{l}\text { 1. Arc discharge method } \\
\text { 2. Laser ablation } \\
\text { 3. Solid phase pyrolysis } \\
\text { 4. Ion or laser sputtering } \\
\text { 5. Catalytic cracking }\end{array}$ & $\begin{array}{l}\text { 1. Hexagonal arrangement of } \\
\text { carbon atom layers } \\
\text { 2. One-dimensional nanostruc- } \\
\text { ture } \\
\text { 3. Low impedance } \\
\text { 4. Good conductivity and stability } \\
\text { 5. Excellent resistance to electro- } \\
\text { chemical corrosion }\end{array}$ & $\begin{array}{l}\text { 1. Composite materials } \\
\text { 2. Electronic devices } \\
\text { 3. Fluorescent labels }\end{array}$ & $\begin{array}{l}\text { 1. Small active specific } \\
\text { surface area } \\
\text { 2. Surface inertness } \\
\text { 3. High price }\end{array}$ & $\begin{array}{l}\text { 1. Form hybrid ma- } \\
\text { terials with other } \\
\text { carbon materials; } \\
\text { 2. Dope metal or } \\
\text { nonmetal to form } \\
\text { composite materials }\end{array}$ \\
\hline Graphene (GP) & $\begin{array}{l}\text { 1. Mechanical peeling } \\
\text { 2. Redox method } \\
\text { 3. Chemical vapor depo- } \\
\text { sition (CVD) } \\
\text { 4. Oriented epiphysis }\end{array}$ & $\begin{array}{l}\text { 1. Two-dimensional planar } \\
\text { structure } \\
\text { 2. Large theoretical specific sur- } \\
\text { face area }\left(2630 \mathrm{~m}^{2} \mathrm{~g}^{-1}\right) \\
\text { 3. High electrical conductivity } \\
\left(106 \mathrm{~S} \mathrm{~cm}^{-1}\right) \\
\text { 4. Good resistance to electro- } \\
\text { chemical corrosion }\end{array}$ & $\begin{array}{l}\text { 1. Physics } \\
\text { 2. Materials } \\
\text { 3. Electronic information } \\
\text { 4. Computers }\end{array}$ & $\begin{array}{l}\text { 1. Metal nanoparticles } \\
\text { are easily reunited } \\
\text { 2. Surface is chemically } \\
\text { inert }\end{array}$ & $\begin{array}{l}\text { 1. Structured into 3D } \\
\text { material } \\
\text { 2. Heteroatom dop- } \\
\text { ing } \\
\text { 3. Surface defect } \\
\text { engineering }\end{array}$ \\
\hline $\begin{array}{l}\text { Ordered } \\
\text { mesoporous } \\
\text { carbon (OMC) }\end{array}$ & $\begin{array}{l}\text { 1. Hard template method } \\
\text { 2. Soft template method }\end{array}$ & $\begin{array}{l}\text { 1. Uniformly adjustable pore } \\
\text { diameter } \\
\text { 2. Good conductivity } \\
\text { 3. Good stability } \\
\text { 4. Large specific surface area } \\
\text { 5. Large pore volume }\end{array}$ & $\begin{array}{l}\text { 1. Adsorption } \\
\text { 2. Electrochemistry } \\
\text { 3. Biology } \\
\text { 4. Catalysis }\end{array}$ & $\begin{array}{l}\text { 1. Complex manufac- } \\
\text { turing process } \\
\text { 2. Orderly structure is } \\
\text { easily broken }\end{array}$ & $\begin{array}{l}\text { Surface functionali- } \\
\text { zation with acid }\end{array}$ \\
\hline $\begin{array}{l}\text { Carbon aerogel } \\
\text { (CA) }\end{array}$ & $\begin{array}{l}\text { 1. Organogel formation } \\
\text { 2. Super-critical drying } \\
\text { 3. Carbonization process }\end{array}$ & $\begin{array}{l}\text { 1. Amorphous carbon materials } \\
\text { 2. Controllable nanoporous 3D } \\
\text { network structure } \\
\text { 3. High specific surface area } \\
\left(600-1100 \mathrm{~m}^{2} \mathrm{~g}^{-1}\right) \\
\text { 4. High porosity ( } 80 \%-98 \%) \\
\text { 5. High stability }\end{array}$ & $\begin{array}{l}\text { 1. Catalyst } \\
\text { 2. Electrochemistry } \\
\text { 3. Hydrogen storage } \\
\text { 4. Template }\end{array}$ & $\begin{array}{l}\text { 1. Low graphitization } \\
\text { degree } \\
\text { 2. Poor electrochemica } \\
\text { corrosion resistance }\end{array}$ & $\begin{array}{l}\text { 1. Surface modifica- } \\
\text { tion } \\
\text { l2. Improving the } \\
\text { graphitization de- } \\
\text { gree }\end{array}$ \\
\hline $\begin{array}{l}\text { Carbon nano- } \\
\text { fiber }(\mathrm{CNF})\end{array}$ & $\begin{array}{l}\text { 1. CVD } \\
\text { 2. Solid phase synthesis } \\
\text { 3. Electrospinning }\end{array}$ & $\begin{array}{l}\text { 1. Large specific surface area } \\
\text { 2. Good electrical conductivity } \\
\text { 3. Good chemical stability } \\
\text { 4. High single strength } \\
\text { 5. Low cost }\end{array}$ & $\begin{array}{l}\text { 1. Chemical engineering } \\
\text { 2. Medicine } \\
\text { 3. Sewage prevention }\end{array}$ & $\begin{array}{l}\text { 1. Difficult to control } \\
\text { shape } \\
\text { 2. Uneven perfor- } \\
\text { mance }\end{array}$ & $\begin{array}{l}\text { 1. Surface stabiliza- } \\
\text { tion } \\
\text { 2. Element doping }\end{array}$ \\
\hline $\mathrm{CB}$ & $\begin{array}{l}\text { 1. Spray method } \\
\text { 2. Lamp smoke method } \\
\text { 3. Drum method } \\
\text { 4. Plasma method }\end{array}$ & $\begin{array}{l}\text { 1. Good electrochemical perfor- } \\
\text { mance } \\
\text { 2. BET specific surface area is } \\
\text { approximately } 250 \mathrm{~m}^{2} \mathrm{~g}^{-1} \\
\text { 3. The proportion of mesopores } \\
\text { and macropores exceeds } 54 \% \\
\text { 4. Electrical conductivity is ap- } \\
\text { proximately } 2.77 \mathrm{~S} \mathrm{~cm}^{-1}\end{array}$ & $\begin{array}{l}\text { 1. Chemical engineering } \\
\text { 2. Transportation } \\
\text { 3. Textile }\end{array}$ & $\begin{array}{l}\text { 1. Poor resistance to } \\
\text { electrochemical corro- } \\
\text { sion } \\
\text { 2. The proportion of } \\
\text { micropores is still very } \\
\text { high }\end{array}$ & $\begin{array}{l}\text { 1. Improve the de- } \\
\text { gree of graphitiza- } \\
\text { tion } \\
\text { 2. Doping heteroa- } \\
\text { toms }\end{array}$ \\
\hline
\end{tabular}

searchers have recognized the nano-effect of nanomaterials and have applied it to the design of nanomaterials.

Nanomaterials have different characteristics from traditional materials, including conductivity, melting point, and adsorption energy. Under the nano-effect, nanomaterials are adjustable, that is, the composition, morphology, structure, and electronic state of nanomaterials can be controlled [29-31]. Although the current control technology is still not very precise, precise control can only be achieved on the sub-nanometer scale. Accordingly, the development of various nanomaterials and nanotechnology is very promising for its application prospects [30]. Therefore, compared with CB (XC72R), the nano-effects of the novel nanocarbon materials may be able to achieve "tailoring catalysis" according to the target reaction requirements $[30,32,33]$, which is of great significance for studying the catalytic reaction mechanism of catalysts [34]. The introduction of nanocarbon supports into catalysts has proven to have a positive effect on a variety of catalytic reactions (such as MOR, EOR, selective hydrogenation/dehydrogenation reactions, acetylene hydrochlorination, hydrogen/oxygen evolution reactions, and others) [35-41]. Maillard et al. [42] investigated the effects of different carbon supports, including CB, CNTs, GP nanosheets, and carbon xerogels, on the ORR activity and stability of PtNi nanocatalysts in PEMFCs. It was also found that the difference in the specific surface area, graphitization degree, and surface functionalization degree of the carbon support affected the size of the PtNi nanoparticles, which in turn led to differences in electrocatalytic performance. Before now, some researchers [43-45] reviewed the effects of different support materials on the performance of catalysts in fuel cells, 
but they focused more on discussing the differences in the performance of different material types and seldom discussed how catalyst supports affected the catalyst performance from the perspective of the physical and chemical properties of materials themselves. Although in a follow-up, Hatton et al. [46] discussed the influence of the structural changes of the nanocarbon material as supports on the electrochemical performance and Meng et al. [47] reported that the interface effect between $\mathrm{Pt}$ and the carbon support affected the catalyst activity and durability; these are only one aspect of the physical or chemical properties of the support. For the first time, this paper provides a review on the recent development of nanocarbon supports for PEMFC electrocatalysts from the perspective of both physical and chemical properties of nanocarbons, especially with an emphasis on the effect of both physical characteristics, including pore structure, and chemical properties, including heteroatom doping and functional carbon-based supports, on the electrocatalytic performance of the supported Pt-based catalysts at the micro- and nano-scale level.

\section{Pore structure}

Efficient electrocatalysts are closely related to the structure of the support. With the development of electrocatalysts, carbon materials, which are among the most ideal supports for electrocatalysts, have also evolved from ordinary carbon to nanocarbon with defective structures, heterostructures, and 3D porous structures [48]. In particular, porous carbon has the most prominent application for electrocatalysts, which mainly includes GP, CNTs, OMC, and CAs. They can be "tailored" for specific electrocatalytic reactions, and their pore size and distribution can be adjusted through treatments, such as acid oxidation and hydrogen reduction. This can provide convenience to study the influence of the support pore structure on the electrocatalyst performance [49].

Additionally, the pore structure of porous carbon is a key factor for improving the accessibility of the active centers and promoting the mass transfer of reactive molecules and products. Moreover, it is well known that the catalytically active components are distributed on the inner surface of the support with a porous structure. Consequently, when porous carbon is used as the electrocatalyst support, during reactions the reactant molecules need to be diffused to the inner surface to combine with the catalytically active components. Understandably, this diffusion process is closely related to the pore structure of the electrocatalyst support. Accordingly, electrocatalysts with supports possessing different pore structures exhibit different diffusion behaviors, physicochemical characteristics, apparent reaction kinetics, and catalytic performances [49-54] (Fig. 3). This section discusses in detail how the pore structure, mainly the pore morphology and pore size of the porous carbon supports, affects the catalytic performance of PEMFC electrocatalysts.

\subsection{Pore morphology}

The pore morphology of carbon support has a significant

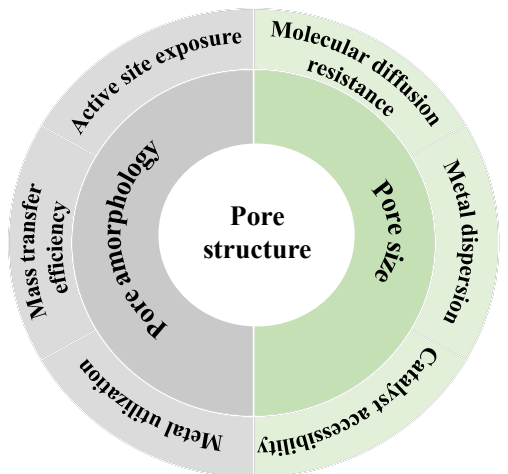

Fig. 3. The effect of the pore structure of nanocarbon support on the supported metal catalysts.

effect on the performance of the supported electrocatalyst. It is reasonable to assume that the pore morphology of carbon support could affect the physical properties of the supported metal particles to some extent. That is, only the metal particles with a suitable morphology and particle size could play a catalytic role in the pores of the carbon support, in a relationship similar to a "lock and key". When the pore morphology is disorderly and the pore distribution is not uniform, only some metal nanoparticles with a suitable morphology can enter the inner surface of the support to play the catalytic role, which greatly affects the active site distribution of the catalysts. Additionally, the diffusion process of the reactant molecules in the pores is heavily dependent on the pore morphology. Existing studies have demonstrated that the catalyst morphology is very significant for the ORR performance [55], so it is indisputable that studying the pore morphology of carbon support is critical for improving the electrocatalyst performance.

Previously, due to the lack of a suitable carbon support model as the research object, few studies focused on the effect of the pore morphology of carbon nanomaterials on the electrocatalyst performance. By using two kinds of mesoporous carbon materials as the support for the electrocatalysts, our investigations have demonstrated that the pore morphology of the support has a decisive effect on the electrocatalytic activity of Pt nanoparticles [56]. These two carbon models were obtained through the same carbonization process, with the pore morphology being the only significant difference between them, and all other pore parameters (including pore volume, BET surface area, and mesopore size) were similar. These two aforementioned carbon models were CMK-3 with a hexagonal arrangement and a highly ordered structure and the other is a wormhole-like mesoporous carbon (WMC) with a disordered 3D network structure (Fig. 4(a)) [57]. Therefore, it is desirable to probe the effect of pore morphology by adopting CMK-3 and WMC as typical carbon models.

The porous morphology affects the Pt electrocatalytic activity in the fuel cell reactions by affecting the PEMFC mass transfer process [58]. The ordered pore morphology is similar to a neat road where the reactant molecules can be more easily transported through the pores to the inner surface of the support to react at the surface of metal nanoparticles, and the reaction products can also be easily transported to the outer sur- 
(a)

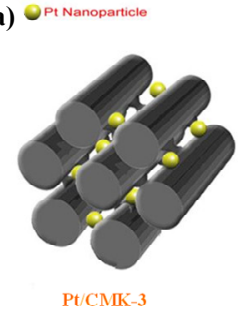

(d)

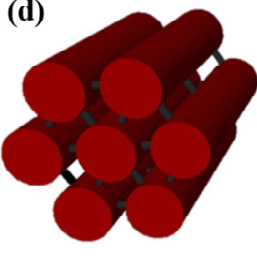

CMK-3

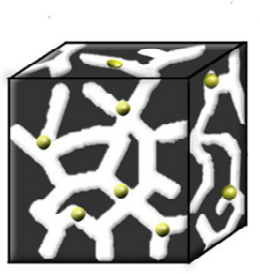

PtWMCs (b)

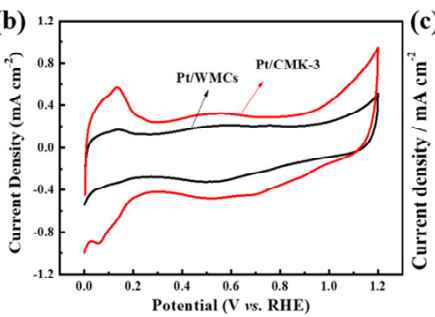

(e)
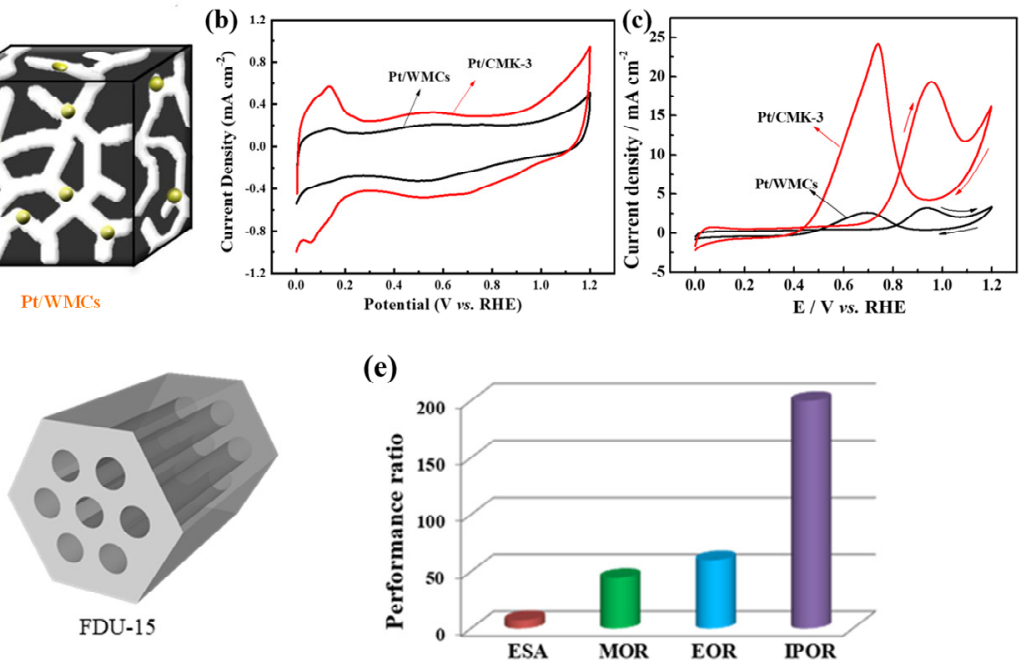

Fig. 4. (a) Schematic illustration for the effect of the structural regularity of the carbon support on the activity of Pt and (b) cyclic voltagrammograms of ethanol oxidation on Pt/WMCs and Pt/CMK-3. Reproduced with permission from Ref. [57], Copyright 2010 Elsevier. (c) Cyclic voltammetry curves of the as-prepared Pt/WMCs and Pt/CMK-3; (d) schematic diagram of highly OMC (CMK-3 and FDU-15) with different nanopore arrays and (e) comparison of electrochemical performance of Pt/CMK-3 and Pt/FDU-15. Reproduced with permission from Ref. [59], Copyright 2011 Royal Society of Chemistry.

face of the support. Consequently, Pt/CMK-3 exhibits a higher activity towards ORR than Pt/WMC. This advantage becomes more prominent for EOR, where the reactant molecules are larger than that of $\mathrm{O}_{2}$ and exist in the liquid form (Figs. 4(b,c)) [59]. This indicates that a highly ordered structured and good 3D networked array can increase the accessibility of Pt nanoparticles, thereby significantly enhancing the mass transfer rate.

A previous study by our group found that even in terms of an ordered mesoporous structure, the pore array in the carbon support is also an important determinant of the Pt accessibility and electrocatalytic activity [59]. Two different types of OMCs, CMK-3 and FDU-15, which possess completely reverse ordered hexagonal mesostructures but almost the same pore size, were used as supports for Pt nanoparticles (Fig. 4(d)) [59]. It was shown that the Pt nanoparticles supported on OMC (CMK-3) with connected pores exhibited a better Pt utilization efficiency and alcohol electrooxidation activity than Pt nanoparticles supported on OMC (FDU-15) with isolated pore channels by carbon wall. The advantage of CMK-3 became more prominent when the molecular size of the reaction probers increased, while the molecular polarization decreased from $\mathrm{H}_{2}$ to methanol, ethanol, and isopropanol (Fig. 4(e)). Additionally, it was found that the $\mathrm{FeO}_{x} @ \mathrm{GC}-\mathrm{NOMC}$ catalyst supported on OMC supports exhibited better catalytic activity and stability than $\mathrm{Pt} / \mathrm{C}$. This was mainly attributed to the fact that the OMC support not only promoted the rapid mass transfer and exposed more active centers, but also limited the agglomeration of embedded nanoparticles [60]. Evidently, it provides an indicator that the ordered and 3D interconnected pore morphology of carbon support materials contributes to easier mass transfer and higher Pt utilization efficiency and thus exhibits superior electrocatalytic activity. This suggests that there should be greater focus on the control of pore morphology in the design of novel carbon materials. Moreover, we believe that there will be many opportunities to improve the electrocatalytic properties of nanocarbon-supported catalysts once the pore morphology dependence of the catalyst is revealed, considering that modern nanocarbons have various pore morphologies, for example, ranging from disordered to ordered [61], from spherical to tubular [62], or from isolated to continuous [15].

\subsection{Pore size}

The pore size of carbon supports, another important physical parameter of the pore structure, could also significantly affect the performance of PEMFC electrocatalysts because the pore size has an obvious effect on mass transfer channels. Moreover, a suitable pore size can well-disperse metal nanoparticles and simultaneously promote the mass transfer process [63]. It is well known that electrochemical reactions occur at the three-phase interface between reactants, catalysts, and electrolyte. It requires an ionically conductive medium for charge balance. Accordingly, only those catalysts, that is, $\mathrm{Pt}$ nanoparticles, that are well distributed on the pore surface of the supports, where both the reactants and electrolyte can access to them, are electrochemically active [24]. Based on this analysis, it is understandable that an ideal carbon support texture is expected to meet the demands for both fast mass transfer (including reactants, products, and electrolyte) and efficient mass-accessible surface area for electrochemical reactions, except for high electrical conductivity. Considering that micropores and mesopores can increase the specific surface area, macropores can reduce the mass transfer resistance. A support material with a rational pore size can promote the metal utilization efficiency and electrocatalytic activity of the catalysts 
$[64,65]$.

Much progress has been made in demonstrating the influence of pore size on the catalyst activity towards HOR. However, in the past, most of the available carbon-based support materials, such as activated carbon and $\mathrm{CB}$, displayed a wide pore size distribution and it was very difficult to reveal the specific relationship between pore size and electrochemical behaviors. Accordingly, CA can be introduced as promising investigation objects because of their relatively narrow and adjustable pore size distribution $[63,66,67]$. Moreover, CA can be a promising support for PEMFC electrocatalysts mainly because of their unique 3D network structure formed by 3D linked carbon nanoparticles $[53,68,69]$. Their porous structure can be easily tailored by adjusting the sol-gel synthesis parameters, for example, reactant concentration, catalyst amount, reaction temperature, and time [67]. Yi et al. [70] prepared CA microsphere supports with an adjustable pore size using PEG-200 as a template. When $0.75 \mathrm{wt} \%$ PEG-200 was added, the pore size of the CA was 10-35 nm, and its supported Pt catalyst showed excellent electrochemical activity and stability with an electrochemically active surface area of $56 \mathrm{~m}^{2} \mathrm{~g}^{-1}$ and mass activity of 0.11 A mg-1 both of which exceeded those of commercial Pt/C catalysts. Furthermore, the obtained Pt/CA had good stability with no significant change after a $5000 \mathrm{~s}$ accelerated durability test (ADT). Achard et al. [71] prepared CAs with different pore size distributions as a support and the best PEMFC performance was found when the support pore size was $25-30 \mathrm{~nm}$, while when the pore size was $>40 \mathrm{~nm}$, the pore structure was blocked by conductive polymers and the mass transfer resistance increased. Interestingly, Han et al. [63] developed an expanded-like study but obtained an inconsistent conclusion from Achard et al. [71]. They designed a variety of CAs with different pore sizes as PtRu catalyst supports for DMFCs, but they found that the catalytic performance of CAs was greater than others when the pore size was $>40 \mathrm{~nm}$. In this case, the onset potential of CO stripping was lower than $387 \mathrm{mV}$ and the electrochemical surface area was higher than $85.8 \mathrm{~m}^{2} \mathrm{~g}^{-1}$. They inferred that owing to the large pore size of the carbon support, even if the outer surface of the carbon support had anchored PtRu nanoparticles, it still had enough specific surface area to anchor smaller metal particles. In contrast, it is generally believed that the smaller the pore size of the support, the larger its specific surface area and the larger the pore size of the support, the easier the diffusion of gas molecules. When the pore size of the carbon support is $<2 \mathrm{~nm}$, although more reaction sites are provided for the metal catalyst nanoparticles, the diffusion of $\mathrm{O}_{2}$ molecules is hindered by the pore walls, hindering contact with the catalyst nanoparticles through the pores. When the pore size of the carbon support is $>50 \mathrm{~nm}$, the diffusion of $\mathrm{O}_{2}$ molecules is scarcely affected by the pore size, but the small specific surface area of the carbon support is not sufficient for the fine dispersion of metal particles. Therefore, coordinating the advantages and disadvantages of different pore sizes of porous carbons, when the pore size of the carbon support is $20-30 \mathrm{~nm}$, not only provides sufficient anchoring sites for the catalyst nanoparticles, but also ensures that there is no obstacle to the diffusion process [65].
Furthermore, to obtain an excellent catalytic performance for the supported metals by taking advantage of the different pore sizes of the carbon supports, hierarchical porous carbons with micropores, mesopores, and/or macropores could be a good choice for PEMFC electrocatalysts [72,73]. This hierarchical pore structure not only provides sufficient specific surface area but also abundant mass transfer channels, which are both necessary for desirable catalytic reactions. Lust et al. [73] used a temperature control method to prepare novel hierarchical microporous-mesoporous carbon supports with different pore size distributions and loaded the same content of $\mathrm{Pt}$ nanoparticles. Interestingly, these catalysts exhibited different electrochemical properties, including the maximum power density of the single cell and the Pt degradation rate, meaning that different pore size distributions had an effect on the electrocatalytic performance of the hierarchically porous carbon-supported $\mathrm{Pt}$, and the ratio of micropores to mesopores was an important influencing factor. Unfortunately, they did not conduct further exploration, including a comparison with carbon supports without an hierarchical pore structure, so the effect of hierarchical micropore-mesoporous structure in carbon supports on electrocatalytic performance is not very clear. $\mathrm{Xu}$ et al. [74] prepared a hierarchical porous graphitic carbon-Fe/N metal-organic framework (MOF) catalyst. Through
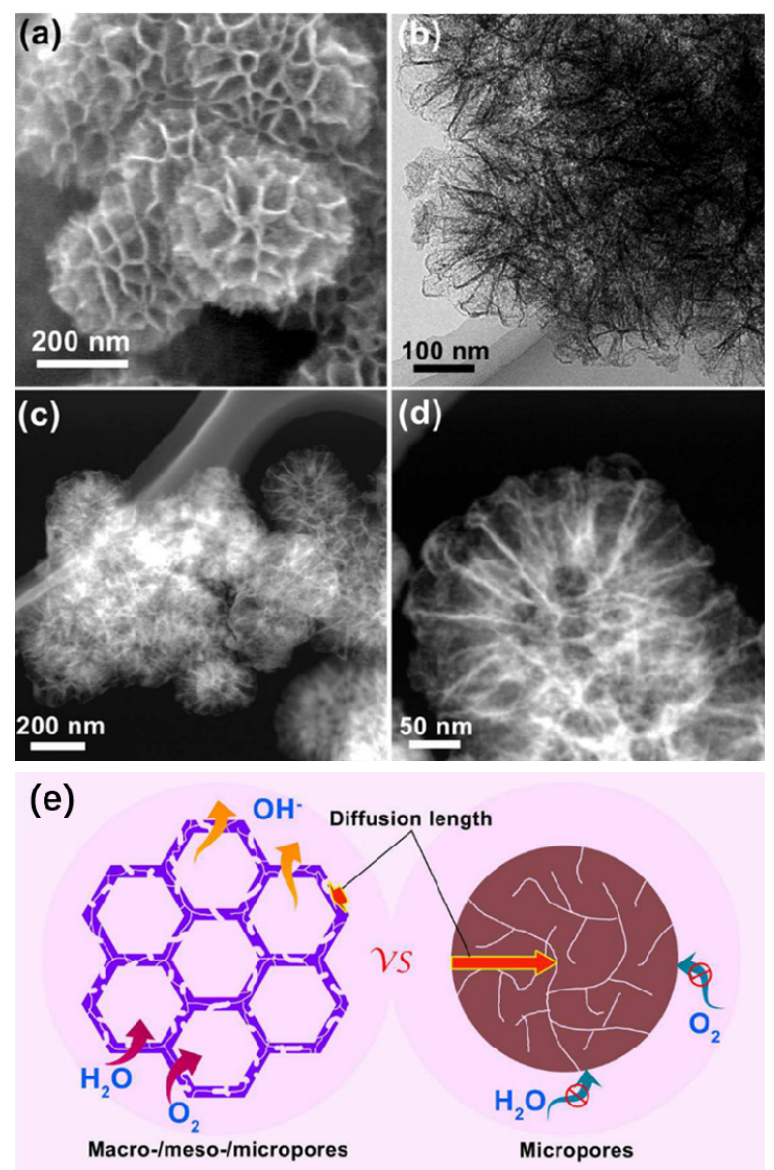

Fig. 5. SEM (a), TEM (b), and HAADF-STEM (c,d) images of Fe/N-GPC; (e) Schematic diagram of molecular diffusion in an hierarchical pore structure. Reproduced with permission from Ref. [74], Copyright 2017 American Chemical Society. 
scanning electron microscopy (SEM) and TEM images (Figs. $5(a-d))$, they found that the catalyst had a structure with macro-/mesopores-connected micropores and exhibited a better ORR performance than a $\mathrm{Pt} / \mathrm{C}$ catalyst under alkaline conditions. They considered that the hierarchical pore structure with the macro-/mesoporous-connected micropores of the catalyst could provide more accessible active surface sites and promote the mass diffusion of reactant molecules, thus improving the catalytic performance (Fig. 5(e)). On the one hand, their research subject was not porous carbon-supported Pt-based catalysts and it cannot be directly compared with other carbon without a hierarchical carbon structure as a Pt catalyst support. On the other hand, undoubtedly their research still has good reference value for exploring the influence of the carbon support pore structure and it is meaningful for the further exploration of hierarchical pore structure carbon supports. The merits of the hierarchical porous structure of carbon can also be reflected even after nitrogen doping. Zhang et al. [75] prepared nitrogen-doped ordered hierarchical porous carbon (N-OHPC) with ordered, interconnected macropores, abundant mesopores, and a large BET surface area. Owing to the fast diffusion channels provided by the 3D ordered macroporous structure and the larger specific surface area provided by the mesoporous structure, Pt/N-OHPC exhibited excellent MOR and ORR activities. Additionally, the Pt-N bond produced by the doped nitrogen reduced the Pt nanoparticle diameter and improved the stability. In summary, hierarchical porous carbons have significant effects on the performance of their supported or self-supported catalysts.

It is generally believed that a carbon support with more mesopores will show a better promoting effect on the catalyst performance and the presence of micropores and macropores provides the catalyst with more reaction sites and rapid mass transfer channels, respectively. Accordingly, to collaboratively take the above-mentioned advantages, hierarchical porous carbons with controllably tuned pore structures are desirable.

In recent years, with the rapid advancement in templating nanotechnology, many novel types of porous carbons with finely controllable mesoporous textures can be easily produced, providing a chance to better understand the relationship between the specific pore size and electrocatalytic performance. Generally, decreasing the pore size of carbons provides larger surface areas and larger pore volumes and thus facilitates a good dispersion of catalysts, consequently providing supported catalysts with better catalytic activity. However, unfortunately the catalyst dispersion deteriorates when the pore size of the carbon supports becomes too small because larger-sized catalyst nanoparticles cannot enter the pores, resulting in the agglomeration of catalysts to a high degree on the external surface of the carbon supports [76]. Therefore, mesoporous carbons with large mesopores can be adopted to increase the catalytic activity when the metal particle size is somewhat large, which can limit the particle size of metal NPs and hinder the aggregation of NPs during electrochemical reactions [77]. Understandably, porous carbons with very small pore sizes are not suitable for use as supports. These results agreed with those observed in the case of CA as model materi- als, but gave a more compelling result regarding the role of pore size in electrocatalytic effectiveness.

Our previous study provided convincing and direct evidence of how the pore size affected the accessibility and utilization efficiency of Pt nanoparticles and their electrocatalytic activity. Two types of WMCs with narrow pore size distributions were adopted as the porous carbon support model for Pt catalysts [78]. As shown in Figs. 6(a,b), pore size plays a decisive role in obtaining a larger electrochemical surface area and higher $\mathrm{Pt}$ utilization efficiency. When the pore size $\left(D_{\mathrm{P}}\right)$ is equal to the diameter of the Pt nanoparticles $\left(D_{\mathrm{Pt}}\right)$, the two Pt nanoparticles, located at the top and bottom of each nanopore, will block the pores and prevent the electrolyte and reactant $\left(\mathrm{H}_{2}\right)$ from contacting the inner Pt nanoparticles in this nanopore (Fig. 6(c)) [78].

Therefore, Pt nanoparticles on such a carbon support have poor accessibility, resulting in a small electrochemical surface area, low Pt utilization efficiency, and inferior hydrogen electrooxidation activity. In contrast, in the case of $D_{\mathrm{p}}>2 D_{\mathrm{Pt}}$, the Pt nanoparticle accessibility can be significantly improved and the Pt electrocatalyst exhibits an excellent electrochemically active surface area and Pt utilization (Figs. 6(a-c)) [78]. It is worth noting that compared with the case of the gaseous reactant $\left(\mathrm{H}_{2}\right)$, the positive impact of this rapid mass transfer through the appropriate support pore size on the performance of the electrocatalyst will be more prominent in the case of the liquid reactant (ethanol), especially at higher temperatures (Fig. 6(d)). This is because in the case of liquid fuel (ethanol), the mass transfer process becomes more important and the effective contribution of the large support pore size to the catalyst activity gets more significant $[79,80]$.

As previously highlighted, a suitable pore size range is a very important dynamic factor for electrocatalyst performance based on the different reaction probes. Accordingly, in the design of novel porous carbon materials for high-performance electrocatalysts, the pore size of carbon should also be considered from the reaction system perspective. Although much progress has been made in studying the role of pore size in the electrocatalytic activity, many important issues (for example, the optimum pore size value) remain unclear. It is believed that the development of nanotechnology will produce more suitable investigation objects with the desired precise pore size and then provide a platform to study fundamental aspects of electrochemical energy storage and conversion systems.

Furthermore, the density functional theory (DFT) model and statistical methods are significant for studying the intrinsic reasons for the influence of the support pore structure on the electrocatalyst performance. Based on the previous discussion, it has been shown that a suitable pore structure is beneficial for the reaction gas transportation process with reduced mass transfer resistance. Through DFT, Tao et al. [81] studied the effect of the carbon pore structure in the catalytic layer of the PEMFCs on Pt degradation, gas molecule transport, and electrochemical performance and confirmed that the gas mass transfer resistance was derived from Pt degradation of Pt calculated by DFT, which was a direct factor of the ECSA loss of the catalyst, and the pore structure and phase distribution of 


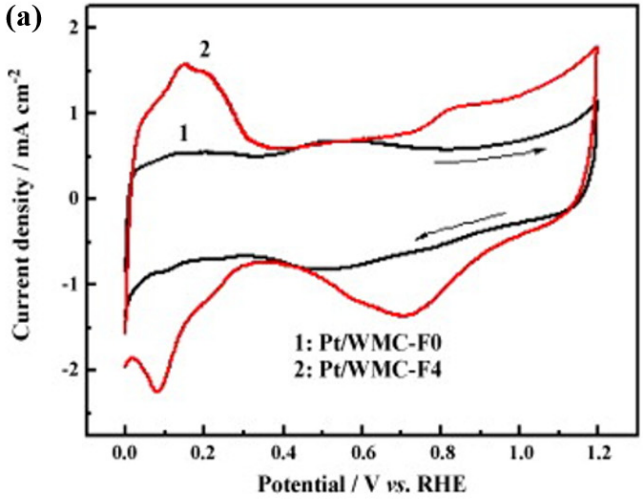

(c)

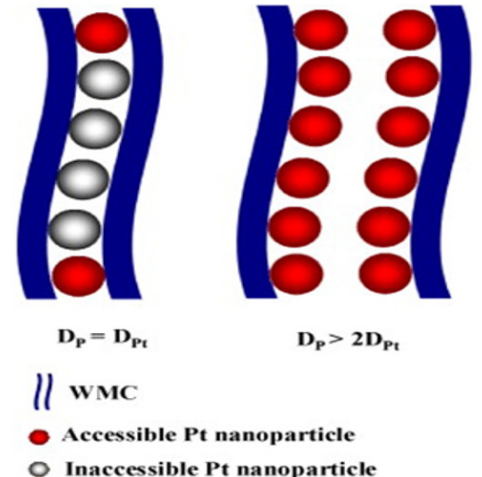

(b)

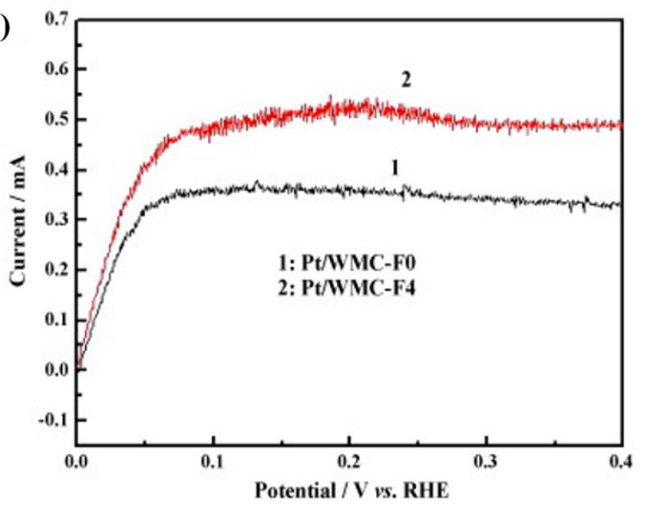

(d)

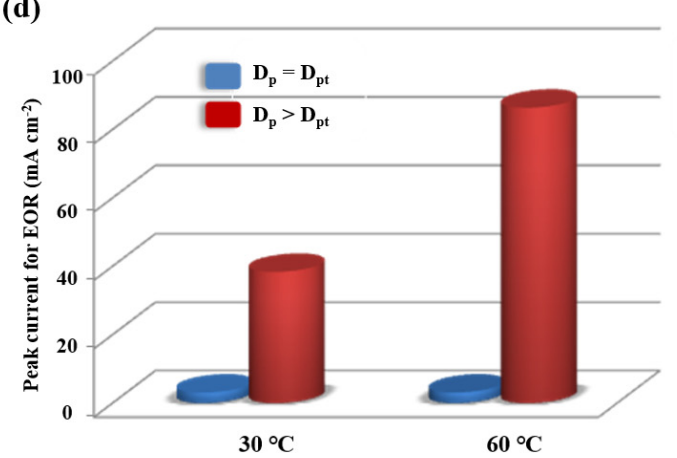

Fig. 6. CV curve (a) and polarization curve (b) of Pt/WMC-F0 and Pt/WMC-F4; (c) Schematic of the effect of pore diameter of WMCs on the accessibility of Pt nanoparticles; (d) Comparison of the peak current density for EOR of mesoporous carbon with different pore diameters under different temperatures. Reproduced with permission from Ref. [78], Copyright 2010 Elsevier.

carbon had a greater impact on the performance loss caused by Pt degradation. Although it is the behavior of the carbon in the PEMFC catalytic layer, it could be fully extended to the carbon support, meaning that the support pore structure may also improve the mass transfer efficiency by slowing down Pt degradation, which can also explain why the performance of fuel cells with low Pt-supported catalysts is undesirable, that is, owing to the low content of Pt being largely degraded, the gas transfer process cannot be normally performed. Additionally, they established a pore scale model based on oxygen diffusion, interfacial dissolution, and electrochemical reaction in the DFT calculation process to evaluate the influence of pore scale on Pt degradation, Pt utilization, ECSA, and limiting current density [81]. The simulation results confirmed that Pt was partially degraded at small pore scales, and because of Pt degradation the catalyst reaction rate was reduced by $20 \%$ while the mass transfer resistance increased by $25 \%$ when the Pt loading was lower. Divergently, extending their conclusion to the carbon support, it could be assumed that the carbon support pore size may also affect the catalytic performance of the catalysts in a similar way. This provides a new idea for the subsequent catalyst design, that is, reducing Pt degradation by controlling the pore structure to reduce Pt loading, thereby reducing the cost of PEMFCs.

Based on the above-mentioned viewpoints, it can be seen that the pore morphology and pore size of the nanocarbon supports clearly affect the performance of PEMFC electrocatalysts. In terms of pore morphology, the order of pores has a great beneficial influence on the mass transfer efficiency of reactant molecules so that the reactant molecules can better combine with the catalytically active sites in the support pores than in the case of disordered carbons, thereby accelerating the reaction activity. Moreover, the role of the pore array of the ordered carbons on the accessibility and catalytic activity of $\mathrm{Pt}$ should also be considered. CMK-3 with interconnected pore channels has a higher Pt utilization efficiency than FDU-15 with isolated pore channels. As far as the pore size of the carbon support is concerned, suitable mesopores have both large diffusion channels and large enough specific surface area, which are both meaningful for improving the catalytic performance of the catalysts. Combining their respective characteristics, ordered pore morphology can improve the mass transfer efficiency and better expose the active sites, thereby increasing the utilization rate of the supported metal. An appropriate mesoporous pore size is conducive to reducing the diffusion resistance of molecules and increasing the dispersibility of metal particles and accessibility of the catalysts. Accordingly, OMC is ideal as an electrocatalyst support, deserving more targeted research.

\section{Heteroatom doping}




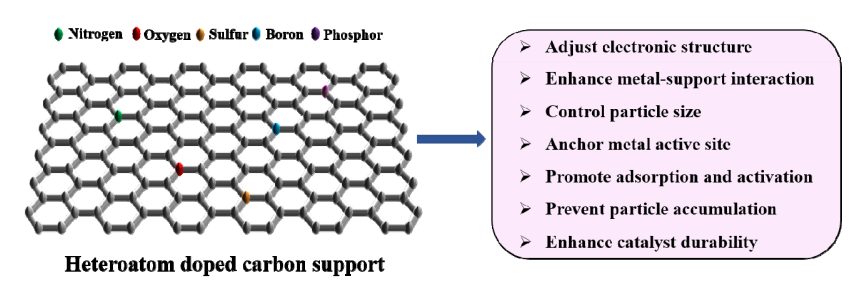

Fig. 7. The effect of the heteroatom doping of nanocarbon supports on the properties of supported metal catalysts.

In the recent years, using heteroatom doping to modify nanocarbon supports has been proposed to make nanostructured carbon materials an ideal electrocatalyst support for PEMFCs [82]. Heteroatoms commonly used for doping carbon materials mainly include nitrogen, oxygen, sulfur, boron, and phosphorus. Among the heteroatom-doped carbon materials, single-element-doped carbon, such as N-doped carbon, O-doped carbon, and S-doped carbon, have been widely investigated, while multi-atom co-doped carbon, such as N/S co-doped carbon, N/P co-doped carbon, N/S/P co-doped carbon, and others, have also gradually attracted the attention of researchers. As depicted in Fig. 7, heteroatom doping can stabilize the structure of carbon supports and increase the binding sites between the support surface and the metal precursor ions or metal nanoparticles. This is beneficial for dispersing metal nanoparticles on carbon supports to avoid nanoparticle agglomeration [83] as well as for improving the electrocatalyst performance by increasing the interaction between the metal and support and providing functional groups for the synergetic effect. The increase in metal-support interaction means that the geometric, electronic, and interface effects of the catalyst can be improved [84]. The particle size and morphology of metal nanoparticles are adjusted, the coordination environment and charge transfer of metal nanoparticles are improved, and a metal-support interface is constructed to provide a place for catalytic reactions [85]. Thus, the activity and stability of the catalysts could be greatly improved [86].

\subsection{Nitrogen-doping carbon}

Recently, with the significant enhancement of electrocatalytic activity and superior durability toward both MOR and ORR, nitrogen-doped carbons (NCs) have received widespread attention $[87,88]$. Nitrogen doping can effectively control the size of metal nanoparticles on carbon support and the interaction between nitrogen atoms and metal nanoparticles makes them uniformly be loaded in the pores of the support to fully anchor the catalytically active components $[36,89,90]$. Moreover, it can also adjust the electronic structure of the catalyst, enhance the conductivity, and exhibit better catalytic activity [91]. Carbon is scattered with free $\pi$ electrons and nitrogen has lone pair electrons [92]. Accordingly, when nitrogen is doped into carbon, the electron cloud is shifted and $\pi$ electrons can combine with the lone pair electrons [93]. Generally, the N species in NCs can be classified into four different types. The center binding energies from low to high are pyridinic $\mathrm{N}$, pyrrolic $\mathrm{N}$, quaternary $\mathrm{N}$, and pyridine- $\mathrm{N}-\mathrm{X}$, respectively, as shown in Fig. 8(a) $[94,95]$. Pyridinic $N$ refers to the $N$ atoms contributing to the $\pi$ system with one p electron, while pyrrolic $N$ refers to the $\mathrm{N}$ atoms with two p electrons in the system, but not necessarily coordinated in a pentagonal arrangement as pyrrole. Quaternary $\mathrm{N}$ refers to the $\mathrm{N}$ atoms incorporated inside the graphitic carbon layers and pyridine- $\mathrm{N}-\mathrm{X}$ is attributed to the $\mathrm{N}$ atoms included in the carbon structure and bonded to oxygen [96]. Different types of $\mathrm{N}$ species have different electron cloud densities and their effects on the catalytic activity and stability of catalysts supported on carbon supports are not completely consistent.

The influence of $\mathrm{N}$ content in the support on the performance of the electrocatalyst can be visually observed from Table 2 . It can be seen that the $\mathrm{N}$ content gradually declines with an increasing synthesis temperature, especially for the proportion of pyridinic N. Moreover, the ORR activity of the catalyst, including the onset potential and the limiting current density, both shows a roughly increasing trend because pyridinic $\mathrm{N}$
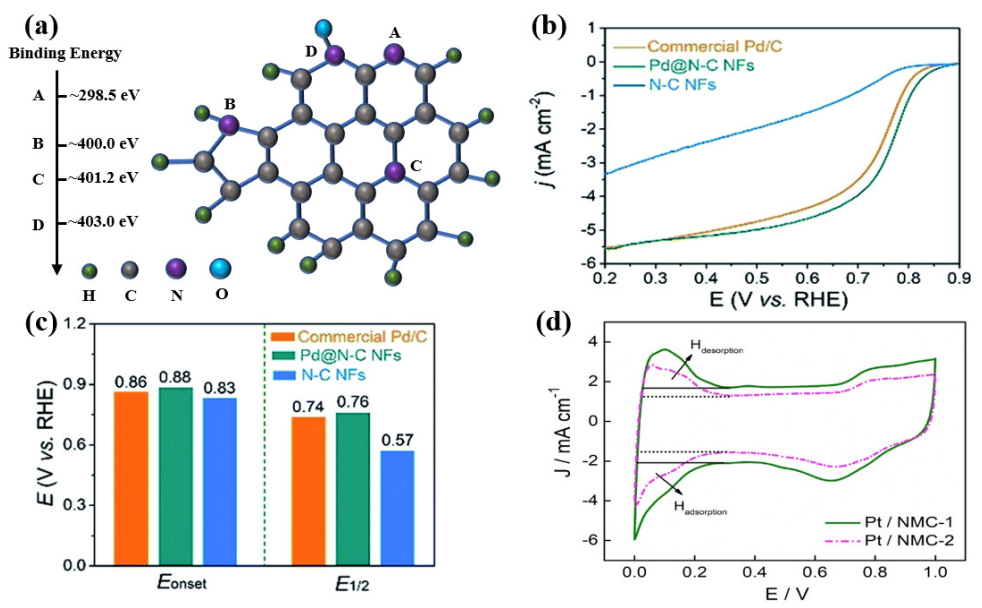

Fig. 8. (a) Schematic diagram of four types of N species in NCs, namely, pyridinic nitrogen (A), pyrrolic nitrogen (B), quaternary nitrogen (C), and pyridine-N-X (D); (b) Comparison of polarization curves; (c) Electrochemical performance of Pd/C, Pd@N-C NFs, and N-C NFs. Reproduced with permission from Ref. [97], Copyright 2019 Royal Society of Chemistry; (d) CV curves of Pt/NMC-1 and Pt/NMC-2 in an acid electrolyte. Reproduced with permission from Ref. [93], Copyright 2018 Elsevier. 
Table 2

Metal free NC as electrocatalysts.

\begin{tabular}{|c|c|c|c|c|c|c|c|c|c|c|c|c|c|}
\hline \multirow[b]{2}{*}{$\begin{array}{l}\text { Introduction } \\
\text { method }\end{array}$} & \multirow[b]{2}{*}{$\begin{array}{c}\text { Nanostructured } \\
\text { morphology }\end{array}$} & \multirow[b]{2}{*}{$\begin{array}{l}\text { N-precursor } \\
\text { /method }\end{array}$} & \multirow[b]{2}{*}{$T /{ }^{\circ} \mathrm{C}$} & \multirow[b]{2}{*}{$\begin{array}{l}\mathrm{N}_{\mathrm{A}^{\mathrm{a}}} \\
/ \mathrm{at} \%\end{array}$} & \multirow[b]{2}{*}{$\begin{array}{l}\mathrm{N} 6^{\mathrm{b}} \\
/ \%\end{array}$} & \multirow[b]{2}{*}{$\begin{array}{l}\mathrm{N} 5^{\mathrm{c}} \\
/ \%\end{array}$} & \multirow[b]{2}{*}{$\begin{array}{l}\mathrm{NQd}^{\mathrm{d}} \\
/ \%\end{array}$} & \multirow[b]{2}{*}{$\begin{array}{l}\mathrm{NX} \\
/ \%\end{array}$} & \multirow[b]{2}{*}{$\begin{array}{c}\text { AвET } \\
/ \mathrm{m}^{2} \mathrm{~g}^{-1}\end{array}$} & \multicolumn{3}{|c|}{ ORR } & \multirow[b]{2}{*}{ Ref. } \\
\hline & & & & & & & & & & $\mathrm{pH}$ & $\begin{array}{c}\text { Onset } \\
\text { potential }(\mathrm{V}) \\
\end{array}$ & $\begin{array}{c}\text { Limiting current } \\
\text { density }\left(\mathrm{mA} \mathrm{cm}^{-2}\right)\end{array}$ & \\
\hline \multirow{15}{*}{ 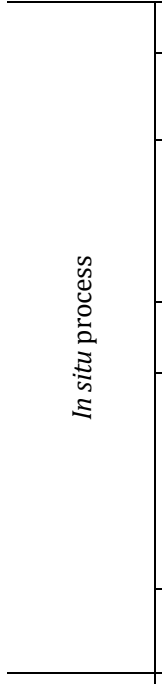 } & $\mathrm{N}-\mathrm{CNT}^{\mathrm{i}}$ & CCVD $^{i}$ & 1000 & 1.0 & 38.0 & 25.0 & $\sqrt{ }$ & $\sqrt{ }$ & 911.0 & 13.0 & - & - & {$[64]$} \\
\hline & \multirow{2}{*}{$\begin{array}{c}\mathrm{N} \text {-Carbon } \\
\text { nanocapsule }\end{array}$} & \multirow{2}{*}{$\begin{array}{c}\text { Gd-DTPAk }^{k} \\
\text { carbonization }\end{array}$} & 700 & 7.1 & 27.6 & 61.8 & 8.4 & 2.2 & - & 13.0 & $\sim-0.95^{\mathrm{fg}, \mathrm{g}}$ & 20.1 & [105] \\
\hline & & & 900 & 3.2 & 19.8 & 63.3 & 7.2 & 5.3 & - & 13.0 & $\sim-0.95^{\mathrm{fg}, \mathrm{g}}$ & 17.6 & [105] \\
\hline & \multirow{4}{*}{$\mathrm{N}-\mathrm{OMC}^{1}$} & \multirow{4}{*}{$\begin{array}{c}\text { Modified } \\
\text { nanocasting }\end{array}$} & 800 & 5.07 & 31.9 & $\sqrt{ }$ & $\sqrt{ }$ & 9.0 & 470.0 & 13.0 & $\sim 0.71^{\mathrm{h}}$ & 4.0 & [106] \\
\hline & & & 900 & 3.13 & 26.4 & $\sqrt{ }$ & $\sqrt{ }$ & 14.0 & 569.0 & 13.0 & $\sim 0.75^{\mathrm{h}}$ & 4.3 & [106] \\
\hline & & & 1000 & 2.20 & 20.9 & $\sqrt{ }$ & $\sqrt{ }$ & 18.5 & 629.0 & 13.0 & $\sim 0.78^{\mathrm{h}}$ & 4.5 & [106] \\
\hline & & & 1100 & 1.25 & 17.9 & $\sqrt{ }$ & $\sqrt{ }$ & 17.4 & 517.0 & 13.0 & $\sim 0.73^{\mathrm{h}}$ & 4.0 & [106] \\
\hline & \begin{tabular}{|c|}
$\begin{array}{c}\text { N-Nanoporous } \\
\text { carbon }\end{array}$ \\
\end{tabular} & $\begin{array}{c}\mathrm{NaCl} \text {-assisted } \\
\text { pyrolysis }\end{array}$ & 900 & 6.7 & 72.0 & 13.4 & 10.5 & 4.1 & 733.0 & 13.0 & $0.98^{g}$ & 33.8 & [107] \\
\hline & \multirow{5}{*}{$\begin{array}{l}\mathrm{N} \text {-ZIFl derived } \\
\text { carbon }\end{array}$} & \multirow{5}{*}{$\begin{array}{c}\mathrm{N}_{2}+\text { carboniza- } \\
\text { tion }\end{array}$} & 700 & - & 52.0 & 32.0 & 11.0 & 5.0 & 74.47 & 1.0 & - & - & [108] \\
\hline & & & 750 & - & 46.0 & 27.0 & 16.0 & 11.0 & 75.81 & 1.0 & - & - & [108] \\
\hline & & & 800 & - & 45.0 & 21.0 & 18.0 & 16.00 & 77.74 & 1.0 & - & - & [108] \\
\hline & & & 850 & - & 42.0 & 21.0 & 19.0 & 17.0 & 79.43 & 1.0 & $0.58^{\mathrm{h}}$ & 4.75 & [108] \\
\hline & & & 900 & - & 37.0 & 21.0 & 21.0 & 21.0 & 83.50 & 1.0 & - & - & [108] \\
\hline & \multirow{2}{*}{$\begin{array}{c}\mathrm{N} \text {-mesoporous } \\
\text { carbon }\end{array}$} & \multirow{2}{*}{$\begin{array}{c}\mathrm{SiO}_{2} \text {-assisted } \\
\text { sol-gel method }\end{array}$} & 800 & 11.0 & 18.0 & 58.0 & - & 24.0 & 609.0 & 2.0 & $\sim 0.80^{\mathrm{h}}$ & 1.44 & [93] \\
\hline & & & 800 & 6.0 & 12.0 & 61.0 & - & 27.0 & 736.0 & 2.0 & $\sim 0.75^{\mathrm{h}}$ & 1.18 & [93] \\
\hline \multirow{8}{*}{ 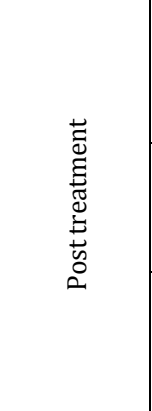 } & \multirow{3}{*}{$\mathrm{N}-\mathrm{GP}$} & \multirow{3}{*}{$\begin{array}{l}\text { Flake graphite } \\
+\mathrm{NH}_{3} \text { heat } \\
\text { treatment }\end{array}$} & 800 & 2.8 & 55.4 & 33.2 & 11.4 & - & - & 13.0 & $0.184 \mathrm{~g}$ & $\sim 2.7$ & [109] \\
\hline & & & 900 & 2.8 & 55.7 & 30.4 & 13.9 & - & - & 13.0 & $0.308^{g}$ & $\sim 2.9$ & [109] \\
\hline & & & 1000 & 2.0 & 51.0 & 33.0 & 16.0 & - & - & 13.0 & $0.204 \mathrm{~g}$ & $\sim 3.0$ & [109] \\
\hline & \multirow{3}{*}{$\mathrm{N}-\mathrm{OMC}$} & \multirow{3}{*}{$\begin{array}{l}\mathrm{NH}_{3} \text { heat } \\
\text { treatment }\end{array}$} & 950 & 6.0 & 44.0 & - & 8.6 & - & 690.0 & 2.0 & $0.67^{\mathrm{h}}$ & $\sim 3.7$ & [110] \\
\hline & & & 1000 & 3.6 & 45.2 & - & 9.0 & - & 482.0 & 2.0 & $0.7^{\mathrm{h}}$ & $\sim 4.0$ & [110] \\
\hline & & & 1050 & 4.6 & 46.9 & - & 10.0 & - & 229.0 & 2 & $0.72^{\mathrm{h}}$ & $\sim 4.2$ & [110] \\
\hline & N-MWCNTm & $\begin{array}{l}\mathrm{N}_{2} \text { plasma } \\
\text { sputtering }\end{array}$ & - & 4.0 & 9.99 & 58.6 & 18.28 & 13.13 & - & 2.0 & $0.90^{\mathrm{h}}$ & 6.0 & [111] \\
\hline & $\mathrm{N}-\mathrm{CNT}^{\mathrm{i}}$ & $\begin{array}{c}\text { CCVDi }+\mathrm{NH}_{3} \\
\text { heat treatment }\end{array}$ & 670 & 1.0 & 45.0 & 43.0 & 12.0 & - & 160.0 & 2.0 & $0.77^{\mathrm{h}}$ & 2.88 & [112] \\
\hline
\end{tabular}

${ }^{a} \mathrm{~N}_{\mathrm{A}}$ All nitrogen content, ${ }^{\mathrm{b}} \mathrm{N} 6$ pyridinic nitrogen, ${ }^{\mathrm{c}} \mathrm{N} 5$ pyrrolic/pyridone nitrogen, ${ }^{\mathrm{d}} \mathrm{NQ}$ quaternary nitrogen, e NX pyridine-N-oxide, ${ }^{\mathrm{f}} v \mathrm{~s}$. Ag/AgCl, $\mathrm{g}$ alkaline solution, ${ }^{\mathrm{h}}$ acid solution, ${ }^{\mathrm{i}}$ carbon nanotube, ${ }^{\mathrm{j}}$ Catalytic CVD, ${ }^{\mathrm{k}}$ Gadolinium(III) diethylene triaminepentaacetate, ${ }^{\mathrm{l}}$ zeolitic imidazolate frameworks, m Multi-walled CNTs, $\sqrt{ }$ existing.

affects the Lewis basicity of the connected $\mathrm{C}$ atoms and enhances their oxygen adsorption capacity [98]. Table 2 also demonstrates that there is a positive correlation between BET specific surface area and quaternary $\mathrm{N}$ content of the support. With an increase in quaternary $\mathrm{N}$ content, the BET specific surface area increases which invariably provides more reaction regions for the catalyst, thereby enhancing the ORR electrocatalytic activity. Therefore, there are different opinions about which $\mathrm{N}$ types are determinative for ORR activity. It is generally believed that pyridinic $\mathrm{N}$ and pyrrolic $\mathrm{N}$ are the main factors that improve the ORR electrocatalytic activity, forming a strong interaction with metal nanoparticles, while graphitic $\mathrm{N}$ has a positive effect on the improvement of the catalyst conductivity, and quaternary $\mathrm{N}$ can promote the adsorption and dissociation of $\mathrm{O}_{2}[95,96,99,100]$. In contrast, different perspectives are inevitable, Zhao et al. [101] and Hattig et al. [102] hold the opinion that pyridinic $\mathrm{N}$ was the key to enhancing ORR activity. As the preferential nanoparticle adsorption sites, pyridinic $\mathrm{N}$ interacts with metal nanoparticles through its lone pair of electrons, thereby changing the oxidation state of metal nanoparticles and its lone pair of electrons also promotes the electron transfer process, thereby significantly improving the ORR ac- tivity. Wang et al. [103] believed that different $\mathrm{N}$ groups could enhance the interaction between metal and support to varying extents, but only graphitic $\mathrm{N}$ was able to change the charge and spin densities of Pt nanoparticles and reduce the energy between the electron orbits, which played a major role in enhancing the Pt-based catalyst performance. Through DFT calculation results, Harris et al. [104] found that quaternary N was closely related to the bonding and breaking of 0-0 bonds, which indicated that it played an important role in the adsorption and dissociation of $\mathrm{O}_{2}$. Additionally, it has also been found that quaternary $\mathrm{N}$ has the lowest relative absorption energy as compared with pyridinic N and pyrrolic N (Fig. 9). Although these studies discussed the effects of different nitrogen types in NC supports on the performance of their supported catalysts from many aspects, until now there is no agreement on how NC supports affect the ORR performance of their supported catalysts. This section summarizes the development of NCs as support materials for fuel cell electrocatalysts.

As summarized in Table 2, NCs can be obtained by two methods, namely, in situ process and post-treatment. In the former case, N-containing materials, as both carbon and nitrogen sources, are often carbonized at high temperatures by py- 


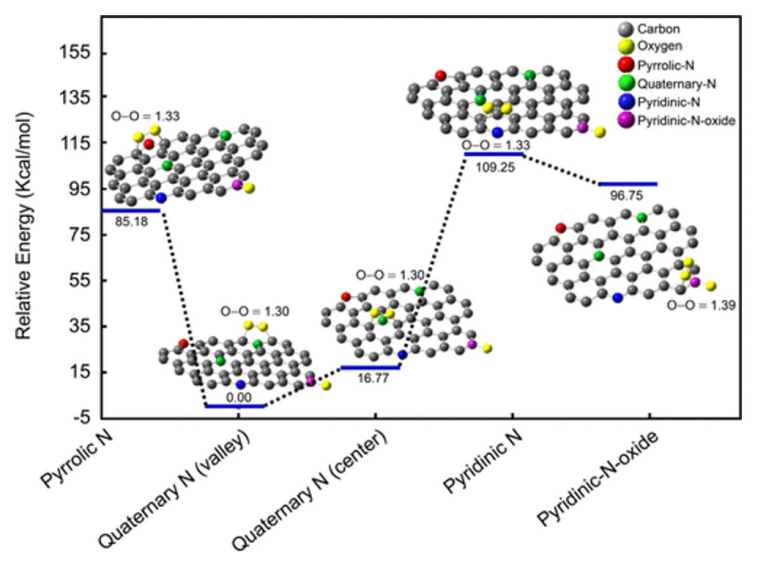

Fig. 9. Comparison of the relative potential surface energy of different types of $\mathrm{N}$ in nitrogen-doping graphitic carbon materials as calculated by DFT. Reproduced with permission from Ref. [104], Copyright 2020 American Chemical Society.

rolysis or CVD [64,107]. In this way, $\mathrm{N}$ can be introduced into both carbon skeleton and carbon surface [113]. In the latter case, the already existing carbon materials are frequently treated in $\mathrm{NH}_{3}$ atmosphere, nitrogen plasma, melamine, polybenzimidazole, or ethylene diamine with carbonization to fix nitrogen on the carbon surface $[110,112]$. In this case, $N$ was just introduced onto the carbon surface.

Nitrogen doping significantly affects the catalyst ORR performance. Owing to the extremely strong electron donating ability of nitrogen, doping it into carbon support can change the electronic structure of catalysts and affect the growth process of metal nanoparticles on carbon support [114,115]. Additionally, it also increases the chemical binding energy between the support and metal nanoparticles, thereby improving the catalytic activity and durability of catalysts [116]. Lee et al. [97] prepared a porous Pd@N-C NF catalyst using NC nanoframes (N-C NFs) as the support. The results showed that the Pd nanoparticles in the Pd@N-C NF catalyst had a small particle size and a narrow particle size distribution. Combined with the porous frame structure of the N-C NFs, the Pd@N-C NFs exhibited a higher ORR activity than Pd/C (Fig. 8(b,c)). Additionally, the chemical composition of nitrogen doping, including the concentration and dopant type, is also closely related to fuel cell performance [106]. Rao et al. [93] prepared nitrogen-doped mesoporous carbon (NMC)-supported Pt electrocatalysts (Pt/NMC) with different nitrogen contents (melamine as the nitrogen source) by the sol-gel method. They found that Pt/NMC-1 (11 wt\% N) possessed a larger specific surface area and electrochemical surface area, exhibiting higher ORR activity and power density, than those of Pt/NMC-2 (6 wt\% N). It was further found that the improved performance was attributed to a higher nitrogen content and more pyridine nitrogen centers, which promoted Pt dispersion and was more conducive to the adsorption and desorption of molecular oxygen (Fig. 8(d)). Kuznetsov et al. [112] prepared a Pt/MWCNT-MF catalyst using melamine-formaldehyde resin (MF) as nitrogen source to modify WMCNTs through nitrogen doping. The per- formance test results showed that the Pt/CNT-MF catalyst with a surface nitrogen content of 8.3 at $\%$ and a Pt loading of 0.1 wt $\%$ exhibited the best membrane electrode performance $\left(0.61 \mathrm{~W} \mathrm{~cm}^{-2}\right)$ and the highest Pt utilization coefficient (84\%). Tammeveski et al. [117] doped nitrogen into GP nanosheets by adopting dicyandiamide as the nitrogen source. The prepared nitrogen-doped GP nanosheet-supported Pt (Pt/NG) exhibited good Pt dispersibility. The as-obtained Pt/NG catalyst, with a nitrogen content of 6 at $\%$ and a Pt loading of $20 \mathrm{wt} \%$, exhibited the best ORR activity, with a half-wave potential as high as 0.80 $\mathrm{V}$ (vs. RHE), only $0.02 \mathrm{~V}$ lower than that of the Pt/C catalyst. Furthermore, it had been found that a higher nitrogen doping concentration did not result in a better performance of the catalyst and the best coordination environment could be obtained only if it is controlled within an appropriate range of 5-20 at\% $\mathrm{N}$ [118]. Selecting dopants with more pyridine $\mathrm{N}$ content tended to promote the dispersion of Pt and more easily adsorb $\mathrm{O}_{2}$ molecules [93].

Apart from the activity towards ORR, the stability and tolerance to MOR are also elementary requirements for cathode catalysts in DMFCs. Fortunately, the catalysts, in which NCs were adopted as the supports, exhibited excellent stability and high selectivity for ORR in the simultaneous presence of methanol and oxygen. Generally, for the fast but practical evaluation of electrocatalyst stability, the potential cycling test has been widely adopted as an accelerating degradation test (ADT) to model real cases and provide reference data [119]. Using this ADT method, Tak et al. [120] investigated the durability of N-doped $\mathrm{GP}^{-\mathrm{TiO}_{2}}$ supported Pt hybrid electrocatalysts (Pt/NG-TiON) and found that after 5000 ADT cycles the performance degradation rate of Pt/NG-TiON was only $9 \%$, significantly lower than that of Pt/C (83\%). Guo et al. [121] prepared a Pt@CN $\mathrm{x} / \mathrm{CNT}$ electrocatalyst (Pt-coated porous nitrogen-doped CNTs) and found that it exhibited significantly better stability than Pt/C after ADT with a very slow activity decay (Fig. 10). Some researchers have highlighted that the higher stability of catalysts with NCs as the support was attributed to the fact that the active nitrogen doping weakened the influence of carbon corrosion and other degradation mechanisms, such as Pt dissolution and migration on the supported Pt catalysts $[23,122]$. Additionally, Pt single-atom catalysts (SACs) are currently a popular research direction [123-126]. Generally, directly growing isolated metal atoms, such as $\mathrm{Pt}$, on a carbon support is an ideal method for synthesizing highly dispersed $\mathrm{Pt}$ SACs. However, due to the high surface energy, isolated Pt single atoms are unstable and prone to agglomeration, thus exhib-
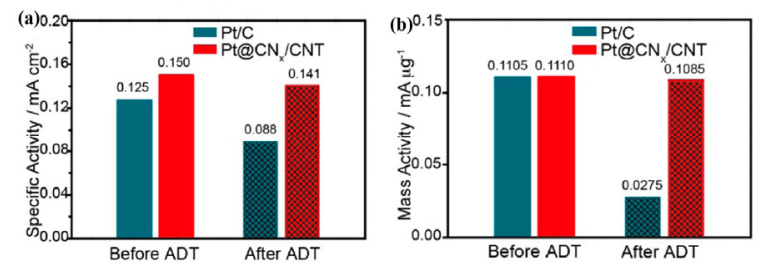

Fig. 10. Comparison of specific activity (a) and mass activity (b) of Pt/C and Pt@CN ${ }_{x} / \mathrm{CNT}$ before and after ADT. Reproduced with permission from Ref. [121], Copyright 2015 American Chemical Society. 
iting poor stability $[127,128]$. To address this issue, directly depositing Pt single atoms on the NC support may be a good solution to inhibit Pt SACs agglomeration [129-132]. Wu et al.[127] prepared an atom-dispersed Pt SAC (Pt/NMC-LT) on a NMC support by a one-pot synthesis method at $-40{ }^{\circ} \mathrm{C}$ and found that it exhibited better hydrogen evolution reaction activity and stability than Pt/C with no obvious change in current density after 5000 ADT cycles. Although there is no similar direct work on PEMFC electrocatalysts, their work has provided a strong evidence to prove the positive effect of nitrogen-doped carbon support on the stability of Pt SACs, which is worthy of further investigation by subsequent researchers. In contrast, this type of research is not particularly easy because research on SACs requires the assistance of more advanced characterization methods, such as synchrotron radiation in situ characterization techniques and so on [133-135].

Additionally, CO poisoning is a continuous issue for Pt-based electrocatalysts and determining whether NCs can be used as a support for Pt-based electrocatalysts to enhance the resistance to $\mathrm{CO}$ poisoning, which is a concern that requires further attention. GP, a two-dimensional carbon material, is a new material with a single-layer honeycomb structure formed by densely packing $s p^{2}$ hybridized carbon atoms and is widely used in the energy field owing to its excellent electrical, optical, and mechanical properties [136]. Moreover, modified GP treated by a series of modification methods, such as heteroatom doping, acid oxidation, hydrogen reduction, and others, has excellent characteristics and has also been proven to be a potential Pt catalyst support. Perez et al. [136] used N-doped GP nanoplates (N-GNPs) as the support for PtRu catalysts and found that $\mathrm{PtRu} / \mathrm{N}-\mathrm{GNP}$ exhibited better structural stability, higher CO tolerance, and higher electrochemical stability than $\mathrm{PtRu} / \mathrm{C}$. Regrettably, in this case, there was no clear understanding about the reason for the CO resistance improvement of the catalyst. This could be because nitrogen doping may change the pore size of the carbon support to facilitate the release of excess CO molecules, thereby reducing contact between the catalyst and CO [137]. Additionally, it may increase the oxidability of the catalyst, allowing $\mathrm{CO}$ to preferentially react with $\mathrm{O}_{2}$ molecules to avoid CO poisoning [138].

Overall, NCs as the catalyst support can significantly affect the performance of PEMFC electrocatalysts. This not only enables the catalysts to exhibit electrocatalytic activity comparable with or even beyond that of $\mathrm{Pt} / \mathrm{C}$, but also improves its long-term stability and resistance to alcohol oxidation and $\mathrm{CO}$ poisoning. Therefore, NCs are very promising nanocarbon materials as electrocatalyst supports for PEMFCs. When nitrogen atoms are doped into carbon support, their greater electronegativity can adjust the electronic properties and change the local electron density of adjacent carbon atoms, thereby promoting the adsorption of reactant oxygen molecules during the catalytic reaction $[139,140]$. Additionally, NC has a large specific surface area and abundant defects, which can disperse Pt metal nanoparticles and prevent their agglomeration [87]. Moreover, nitrogen doping enhances the interaction between Pt metal nanoparticles and carbon support to provide a synergistic effect and promotes the transfer of charges between Pt metal atoms and NC, generating new active sites [140,141]. Although there was ample evidence indicating that nitrogen doping into carbon supports could improve the catalyst performance significantly, its corresponding mechanism had not yet been confirmed. In particular, many researchers have observed that NCs without metal loading also exhibit performances comparable to that of Pt/C catalysts. Therefore, whether the increase in catalytic activity caused by nitrogen doping is a manifestation of the intrinsic activity of the NCs themselves or the result of the interaction enhancement between metal nanoparticles and support, still needs to be further confirmed.

\subsection{Oxygen-containing functional groups}

Without surface modification, most support materials for electrocatalysts, such as $\mathrm{CB}, \mathrm{CNTs}$, CNFs, and mesoporous carbon, lack sufficient binding sites to anchor precursor metal ions or metal nanoparticles. Consequently, this leads to poor metal nanoparticle dispersion and aggregation. To address this issue, carbon supports are usually decorated with oxygen-containing

Table 3

Type of groups and their decomposition temperatures in the TPD test [147].

\begin{tabular}{|c|c|c|c|}
\hline Type of group & Name & $\begin{array}{l}\text { Species } \\
\text { released }\end{array}$ & $\begin{array}{l}\text { Peak temperature } \\
\text { (K) }\end{array}$ \\
\hline & Carboxylic & $\mathrm{CO}_{2}$ & ca. 510 \\
\hline & Lactone & $\mathrm{CO}_{2}$ & ca. 940 \\
\hline & Anhydride & $\mathrm{CO}+\mathrm{CO}_{2}$ & ca. 820 \\
\hline & Phenol & $\mathrm{CO}$ & ca. 905 \\
\hline & Carbonyl & $\mathrm{CO}$ & са. 1080 \\
\hline & Ether & $\mathrm{CO}$ & ca. 973 \\
\hline & Quinone & $\mathrm{CO}$ & ca. 1080 \\
\hline
\end{tabular}


functional groups by an oxidative treatment, which can help to fix metal active sites on the support. It is an effective method to increase noble metal dispersion, anchor metal nanoparticles, and make good use of noble metals [142]. Furthermore, the decorated oxygen-containing groups can strengthen the interaction between metal and support and thus increase the stability of supported noble metal catalysts.

Generally, the main oxidative treatments are conducted with liquid oxidative agents, such as nitric acid, sulfuric acid, and hydrogen peroxide, which are simple to operate. The oxidation process is easy to control, and there are no severe reaction conditions such as those of the gaseous oxidation methods. Through the above treatment, based on the different oxidative abilities, different oxygen-containing functional groups (for example, carboxylic, hydroxyl, carbonyl, phenolic, and lactonic groups) could be introduced onto the carbon surface [143,144]. Temperature programmed desorption (TPD) is a feasible technique used to confirm the type and content of oxygen-containing groups on the carbon surface $[145,146]$. Table 3 summarizes the TPD results, which demonstrates that the strong and weak acidic groups evolve as $\mathrm{CO}_{2}$ and $\mathrm{CO}$, respectively [147]. It has been reported that $\mathrm{CO}_{2}$-evolving complexes, mainly carboxylic groups, seem to increase the hydrophilicity of carbon, and thus improve the accessibility of noble metal precursors during the impregnation synthesis procedure, resulting in high dispersion and activity [148]. In contrast, CO-evolving complexes, mainly ester and carbonyl groups, can provide anchoring sites that interact with metal particles and support, and thus increase catalyst stability [144].

As presented in Table 4, carbon support materials are successfully decorated with oxygen-containing groups through different oxidative treatments. Accordingly, the supported Pt NPs have a high dispersion and small particle size. Accordingly, the Pt electrochemical surface area is increased to a certain extent, meaning that the catalysts have a high Pt utilization coefficient and high electrocatalytic activity in PEMFCs. Moreover, oxygen-containing functional groups on the carbon support are crucial for the performance enhancement of Pt cata- lysts for MOR and CO poisoning. In the MOR cyclic voltammetric curves, the forward current peak is associated with methanol oxidation while the reverse current peak refers to the oxidation of intermediate poisonous CO species. Wang et al. [149] synthesized a Pt/OCS-X catalyst by heat-treating 3D carbon nanosheets (CS) loaded with Pt in an ozone atmosphere (where $\mathrm{X}$ was the temperature value during heat treatment). Electrochemical tests proved that the Pt/OCS-160 catalyst exhibited the best MOR activity during forward scanning and its peak current density was as high as $37.7 \mathrm{~mA} \mathrm{~cm}-2$. Additionally, the negative scan showed that the ozone-treated Pt/OCS-X catalysts exhibited better CO resistance than the original Pt/CS catalysts. Moreover, the BET and electron microscopy characterization results showed that the oxygen-containing carbon support after ozone treatment had a larger specific surface area and the Pt nanoparticles had a smaller particle size, which indicates that the oxygen-containing functional groups (including the carboxyl and hydroxyl groups) could provide more anchoring active sites for Pt nanoparticles. However, the difference in modified carbon supports obtained by different oxidation treatment methods cannot be ignored. Wu et al. [150] used a $\mathrm{H}_{2} \mathrm{SO}_{4} / \mathrm{HNO}_{3}$ mixed acid solution, 3-[2-(2-aminoethylamino) ethylamino]propyltrimethoxysilane (AEPTMS), and $\mathrm{H}_{2} \mathrm{O}_{2}$ to separately modify the surface of OMC (Fig. 11). All three surface-modified catalysts exhibited performances comparable to those of the $\mathrm{Pt} / \mathrm{C}$ catalysts. Among them, the distribution of $\mathrm{Pt}$ $\mathrm{NPs}$ on $\mathrm{Pt} / \mathrm{OMC}-\mathrm{H}_{2} \mathrm{SO}_{4} / \mathrm{HNO}_{3}$ was the widest and the average particle size was the smallest. Moreover, the loading of Pt NPs on Pt/OMC-AEPTMS was more uniform, but the conductivity was lower, and $\mathrm{Pt} / \mathrm{OMC}-\mathrm{H}_{2} \mathrm{O}_{2}$ was easily controlled and exhibited a good performance in most aspects (conductivity, dispersion, particle size, and others).

Stability is another key parameter for evaluating catalysts [151-153]. With the oxidative treatment of carbon supports, the agglomeration of Pt nanoparticles and the electrochemical surface area (ESA) loss slowed as compared to those of the original carbons, as shown in Table 4. It is known that the stability of Pt/C electrocatalysts is heavily dependent on the in-

Table 4

The effect of carbon support oxidative treatment on the electrocatalyst activity.

\begin{tabular}{|c|c|c|c|c|c|c|c|}
\hline $\begin{array}{l}\text { Carbon } \\
\text { materials }\end{array}$ & $\begin{array}{l}\text { Oxidative } \\
\text { treatment }\end{array}$ & Catalyst synthesis method & $\begin{array}{l}\text { Untreated Pt } \\
\text { particle } \\
\text { (nm) }\end{array}$ & $\begin{array}{l}\text { Treated Pt } \\
\text { particle } \\
\text { (nm) }\end{array}$ & $\begin{array}{c}\text { Untreated electro- } \\
\text { chemical surface area } \\
\left(\mathrm{m}^{2} \mathrm{~g}^{-1}\right)\end{array}$ & $\begin{array}{l}\text { Treated electro- } \\
\text { chemical surface } \\
\text { Area }\left(\mathrm{m}^{2} \mathrm{~g}^{-1}\right)\end{array}$ & Ref. \\
\hline OMC & $\mathrm{H}_{2} \mathrm{SO}_{4}: \mathrm{HNO}_{3}(1: 1)$ & Acid + refluxing + AEPTMS & 4.3 & 2.9 & - & - & [150] \\
\hline CB & $\mathrm{HNO}_{3}: \mathrm{HCl}(2: 1)$ & Impregnation $+\mathrm{H}_{2}$ reduction & $2.7 \mathrm{e}$ & $3.5^{\mathrm{e}}$ & $\begin{array}{l}63.0^{\mathrm{d}} \\
36.0^{\mathrm{e}}\end{array}$ & $\begin{array}{l}77.0^{\mathrm{b}} \\
34.9^{\mathrm{c}}\end{array}$ & [155] \\
\hline $\mathrm{CS}$ & Ozone & $\begin{array}{l}\text { Heat treatment }+25^{\circ} \mathrm{C}^{\mathrm{d}} \\
\text { Heat treatment }+90^{\circ} \mathrm{C}^{\mathrm{d}} \\
\text { Heat treatment }+160^{\circ} \mathrm{C}^{\mathrm{d}} \\
\text { Heat treatment }+200^{\circ} \mathrm{C}^{\mathrm{d}}\end{array}$ & $\begin{array}{l}- \\
- \\
- \\
-\end{array}$ & $\begin{array}{l}- \\
- \\
- \\
-\end{array}$ & $\begin{array}{l}24.4 \\
24.4 \\
24.4 \\
24.4 \\
\end{array}$ & $\begin{array}{c}2.9 \\
11.1 \\
87.1 \\
18.7 \\
\end{array}$ & $\begin{array}{l}{[149]} \\
{[149]} \\
{[149]} \\
{[149]}\end{array}$ \\
\hline MWCNTe & $\begin{array}{l}\mathrm{KOH}+\text { calcination } \\
\mathrm{H}_{2} \mathrm{SO}_{4}: \mathrm{HNO}_{3}(3: 1) \\
\mathrm{OH}^{-} \\
\mathrm{COOH}^{-} \\
\end{array}$ & $\begin{array}{l}\mathrm{EG}^{\mathrm{f}}+\text { microwave } \\
\text { Plasma sputtering } \\
\mathrm{H}_{2}\left(\mathrm{PtCl}_{6}\right)+\text { heat treatment }\end{array}$ & $\begin{array}{l}3.2 \\
3.2^{\mathrm{d}} \\
- \\
- \\
\end{array}$ & $\begin{array}{l}2.9 \\
4.9^{\mathrm{d}} \\
2.4 \\
2.6 \\
\end{array}$ & $\begin{array}{l}20.0 \\
61.4 \\
79.0 \\
79.0 \\
\end{array}$ & $\begin{array}{l}60.0 \\
90.4 \\
58.0 \\
73.0\end{array}$ & $\begin{array}{l}{[157]} \\
{[111]} \\
{[158]} \\
{[158]}\end{array}$ \\
\hline R-GOg & $\begin{array}{l}\text { Ozone } \\
\text { Fluorine }\end{array}$ & $\begin{array}{l}\text { High temperature adsorption } \\
\text { Soaking + freezing }\end{array}$ & $\begin{array}{l}2.0 \\
2.0\end{array}$ & $\begin{array}{l}3.0 \\
5.9 \\
\end{array}$ & $\begin{array}{l}48.0 \\
48.0\end{array}$ & $\begin{array}{l}51.0 \\
20.0\end{array}$ & $\begin{array}{l}{[159]} \\
{[159]}\end{array}$ \\
\hline
\end{tabular}

a 3-[2-(2-aminoethylamino)ethylamino]propyltrimethoxysilane, ${ }^{\mathrm{b}}$ before $\mathrm{CV}$ cycles test, $\mathrm{c}$ after $\mathrm{CV}$ cycles test, ${ }^{\mathrm{d}}$ heated to this temperature in a tube furnace under an ozone atmosphere, e multi-walled CNTs, ${ }^{\mathrm{f}}$ ethylene glycol, g GP oxide. Sulfur-doped carbon. 


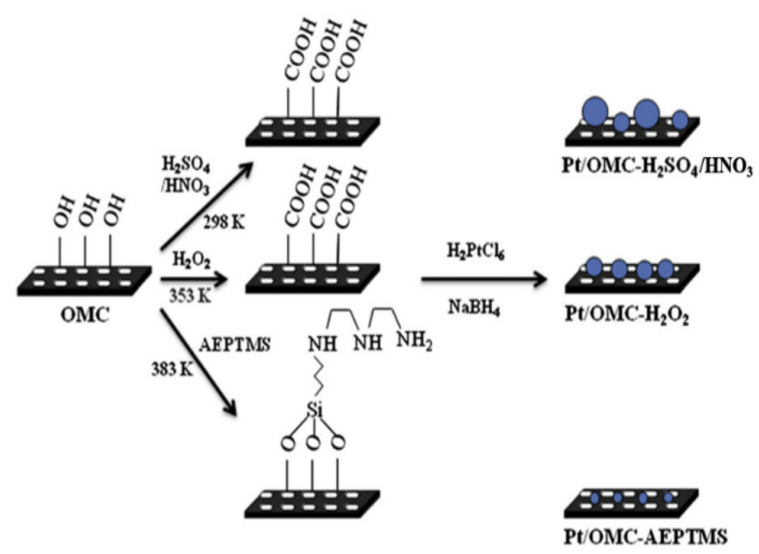

Fig. 11. Schematic diagram of $\mathrm{H}_{2} \mathrm{SO}_{4} / \mathrm{HNO}_{3}$, AEPTMS, and $\mathrm{H}_{2} \mathrm{O}_{2}$ oxidatively modifying the OMC surface. Reproduced with permission from Ref. [150], Copyright 2012 Elsevier.

teraction between the metal nanoparticles and the support materials, which influences the agglomeration and stability of $\mathrm{Pt} / \mathrm{C}$ catalysts during the electrochemical process. Zhao et al. [154] used the hydrothermal method to introduce oxygen atoms into multi-walled CNTs (MWCNTs) under the treatment of $\mathrm{H}_{2} \mathrm{SO}_{4}$ and $\mathrm{H}_{2} \mathrm{O}_{2}$ to generate O-MWCNTs, which were used as the support for metal catalysts. They found that due to the introduction of ketone and carboxyl groups, the content of $\mathrm{C}=0$ increased, resulting in the catalyst with a stronger electron-withdrawing ability, which showed not only excellent ORR activity, but also surprising stability. Additionally, Ramaprabhu et al. [111] studied the effects of oxygen and nitrogen functional groups on the ORR performance and stability of WMCNTs and low-layer GP hybrid structure catalysts. In the presence of pyrrole nitrogen and oxygen-containing functional groups, the supports exhibited highly oriented graphitization properties, resulting in a catalyst with approximately $30 \%$ improvement in carbon corrosion durability, and exhibited surprising ORR performance comparable to that of $\mathrm{Pt} / \mathrm{C}$.

On one hand, it has been well recognized that oxygen-containing functional groups on carbon surface can play some contributing role in enhancing the activity and stability of carbon supported Pt based catalysts in one form or the other. The more accepted view for this behavior is that the introduction of oxygen-containing functional groups into the carbon support is beneficial for anchoring metal Pt nanoparticles, controlling their particle size distribution and increasing their dispersibility. On the other hand, the corresponding mechanism and the specific relationship between oxygen-containing groups and the physicochemical characteristics and electrochemical properties of electrocatalysts have not been well established. Inevitably, different people often have different opinions. Some authors also argued that oxygen-containing functional groups had a negative effect on the dispersion $[155,156]$ and the functionalization of carbon supports resulted in a decrease in their activity and durability. Joo et al. [155] studied the effect of the oxygen functional group of carbon support on the catalytic activity and durability of Pt/C catalysts. They found that, compared with the original Pt/CB catalyst, the $\mathrm{Pt} / \mathrm{CB}$ _O catalyst, which is supported on CB with micro-oxygen functionalization, possessed similar physical parameters, including specific surface area, pore volume, and Pt particle size. However, in the electrochemical performance test, although the Pt/CB_O catalyst showed a better ECSA and ORR activity than $\mathrm{Pt} / \mathrm{CB}$, its durability was significantly worse than that of $\mathrm{Pt} / \mathrm{CB}$ (Fig. 12). The results of the spectral characterization indicated that the oxygen functionalization of carbon support promoted the surface oxidation of Pt nanoparticles, the dissolution of $\mathrm{Pt}$ nanoparticles on $\mathrm{CB}_{-} \mathrm{O}$, and Ostwald ripening resulting in severe agglomeration of Pt nanoparticles (Fig. 12). Therefore, the real effect of the oxygen-containing functional groups on the electrocatalyst performance is still disputed.

In addition to carbon doped with nitrogen and oxygen heteroatoms, sulfur-doped carbon has also been found to be an excellent support material for electrocatalysts (Table 5) $[160,161]$. Doping sulfur into carbon could create a C-S-C bond, activating adjacent carbon atoms to enable them to interact with the loaded Pt NPs. In the catalytic reaction process, the synergistic effect of $\mathrm{C}-\mathrm{S}-\mathrm{C}$ and adjacent Pt could promote the adsorption and activation of the reactants, thereby im-
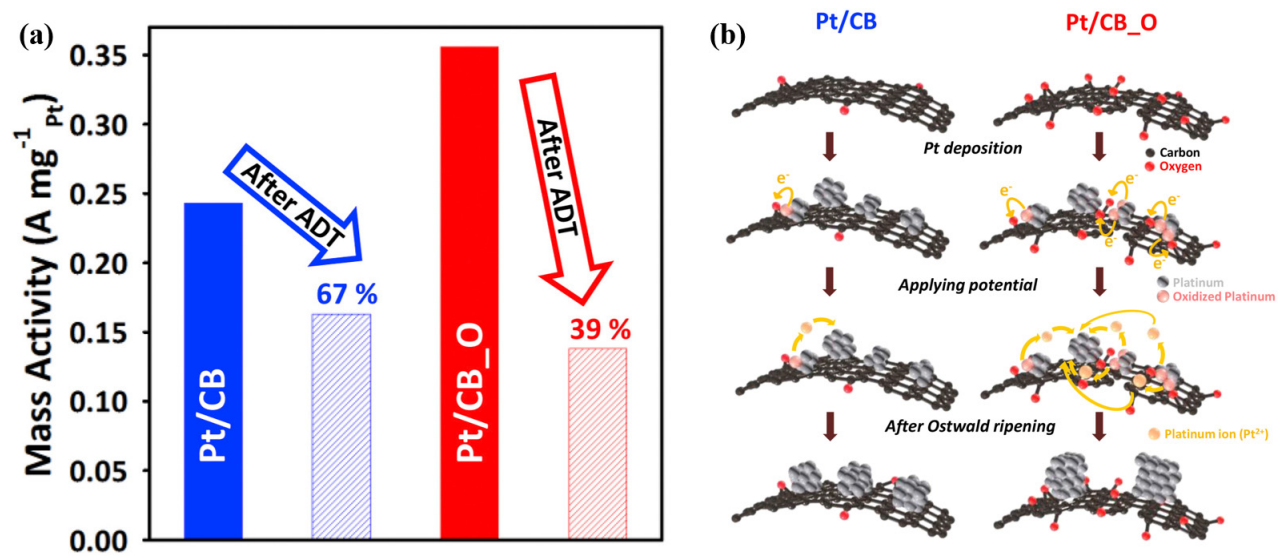

Fig. 12. (a) Mass activity comparison of Pt/CB and Pt/CB_O before and after the ADT test; (b) Schematic diagram of the particle size changes of Pt/CB and Pt/CB_O during ADT. Reproduced with permission from Ref. [155], Copyright 2016 Elsevier. 
Table 5

Sulfur-doped carbon as the PEMFC electrocatalyst support.

\begin{tabular}{|c|c|c|c|c|c|c|}
\hline $\begin{array}{l}\text { Introduction } \\
\text { method }\end{array}$ & Materials & Preparation methods & $\begin{array}{l}\text { Particles } \\
\text { size (nm) }\end{array}$ & $\begin{array}{c}\mathrm{pH} \\
\text { value }\end{array}$ & $\begin{array}{l}\text { Electrocatalytic } \\
\text { performance }\end{array}$ & Ref. \\
\hline \multirow{2}{*}{ In situ } & S-carbon shell & $\begin{array}{l}\text { Sodium dodecyl sulfate (SDS) + ethyleneglycol } \\
\text { (EG)-stirring + pyrolysis }\end{array}$ & 8.39 & 13.0 & 0.99 c (vs. RHE) & [162] \\
\hline & S-nanocarbon spheres & $\begin{array}{c}\text { Thioanisole (TOAS) + benzene-(solution plasma } \\
\text { synthesis) }\end{array}$ & 3.00 & 13.0 & $490^{d}$ & [167] \\
\hline \multirow{4}{*}{ Post-treatment } & \multirow[t]{2}{*}{ S-graphene } & GO + diethylene glycol methyl ether-refluxing & - & 13.0 & $\begin{array}{c}0.02^{\mathrm{c}}(v s . \mathrm{Hg} / \mathrm{HgO}) \\
-0.105^{\mathrm{e}}(\mathrm{vs} . \mathrm{Hg} / \mathrm{HgO})\end{array}$ & {$[163]$} \\
\hline & & $\mathrm{GP}+$ phenyl disulfide (PDS) + annealing & 4.00 & 2.0 & $182^{\mathrm{d}}$ & {$[164]$} \\
\hline & S-CNTa & Functionalized CNTa + PDS-heating & 6.20 & 2.0 & $\begin{array}{l}272^{\mathrm{d}} \\
17.2^{\mathrm{f}} \\
1.61^{\mathrm{g}}\end{array}$ & [165] \\
\hline & S-MWCNTb & $\begin{array}{c}\text { MWCNTs + SDS-ultrasonication } \\
\text { 3,4-ethylenedioxythiophene }+\left(\mathrm{NH}_{4}\right)_{2} \mathrm{~S}_{2} \mathrm{O}_{8} \text {-annealing }\end{array}$ & 2.37 & 1.0 & $\begin{array}{c}161.4^{\mathrm{f}} \\
0.16^{\mathrm{c}}\end{array}$ & [166] \\
\hline
\end{tabular}

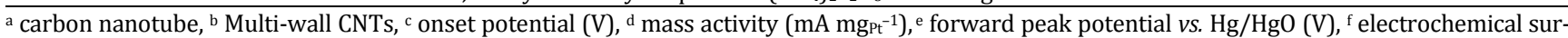
face area $\left(\mathrm{m}^{2} \mathrm{~g}^{-1}\right), \mathrm{g}$ specific activity $\left(\mathrm{mA} \mathrm{cm}^{-2}\right)$.

proving the electrocatalyst performance [160].

Lee et al. [162] prepared an S-doped carbon layer as the support for a Pt catalyst and found that under the synergistic effect of Pt and S-doped carbon, Pt nanoparticles showed good dispersibility on the C-S support, and the rate-determining step of ORR was promoted, so that the Pt/C-S catalyst exhibited excellent ORR activity and durability (Fig. 13). With that, the fuel cell power density reached $0.85 \mathrm{~W} \mathrm{~cm}^{-2}$ at $0.6 \mathrm{~V}$, and surprisingly, the Pt loading was only $0.05 \mathrm{mg} \mathrm{cm}^{-2}$. Although the S-doped carbon layer as a support was slightly different from conventional supports, Pt nanoparticles were wrapped by the S-doped carbon layer instead of the Pt nanoparticles on the support surface. This result still proved that S-doped carbon had a significant promoting effect on both improving Pt dispersibility and reducing Pt loading. Additionally, Tagmatarchis et al. [163] prepared Pd@Ni NPs/SG (sulfur-doped GP) catalysts by uniformly distributing the initially prepared Pd@Ni NPs without surfactants on the SG support. Compared with that of Pd/C, the MOR activity $\left(2.26 \mathrm{~mA} \mathrm{~cm}^{-2}\right)$ of Pd@Ni NPs/SG increased by $82 \%$ and its ORR activity $\left(1.5 \mathrm{~mA} \mathrm{~cm}^{-2}\right)$ increased by $67 \%$. Because the effect of Pd@Ni NPs on the improvement of catalytic performance could not be ruled out, only comparing the performance of Pd@Ni NPs/SG and Pd/C could not directly indicate that the performance improvement is caused by the S-doping of carbon support alone. However, the improved catalyst performance was indeed caused by the interaction between the core and shell nanostructure of Pd@Ni NPs and the SG support, proving that the sulfur-doped carbon supports could promote the catalytic performance of PEMFC electrocatalysts.

From the above discussion, indirect evidence proved that sulfur-doped carbon supports could influence PEMFC electrocatalysts and improve their electrocatalytic performance. Furthermore, Chen et al. [164] provided direct evidence to prove the significant effect. They prepared a series of SGs (with a sulfur content between 0.35-3.95 at\%) as the support for Pt nanowire (NW) catalysts to explore the sulfur effect on the electrochemical performance. They found that Pt NW/SG with a sulfur content of 1.40 at $\%$ showed the best performance and its

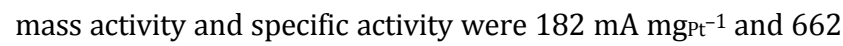
$\mu \mathrm{A} \mathrm{cmPt}{ }^{-2}$ (0.9 V vs. RHE), respectively. These results indicated that the sulfur content in the GP support significantly impacted the performance of the Pt NW catalysts. The physicochemical characterization results revealed that as the sulfur content in the GP support increased, the ratio of $s p^{2}$ and $s p^{3}$ carbon and the graphitization characteristics of SG decreased, while the band gap increased, and thus led to a decreased conductivity. Moreover, the DFT calculation results showed that due to the higher exchange current density and lower activation energy of Pt NW/SG with 1.40 at\% sulfur, the interaction between inactive oxygen species and Pt was weakened and the ORR kinetic was enhanced; thus, it exhibited a better electrocatalytic performance. Interestingly, they also performed another similar study by adopting a solvothermal method to synthesize a Pt nanowire catalyst supported on sulfur-doped CNTs (Pt NW/S-CNT) [165]. Pt NW/S-CNT exhibited better electrochemical activity and stability than Pt NW/CNT and Pt/C. Their corresponding mass activities were 1.61, 1.37, and $0.244 \mathrm{~mA}$ $\mathrm{CmPt}^{-2}$, and their ECSA was reduced by $7 \%, 38 \%$, and $99 \%$, respectively (compared with the initial value) after 3000 ADT cycles. Evidently, the sulfur-doped carbon, as Pt catalyst sup-

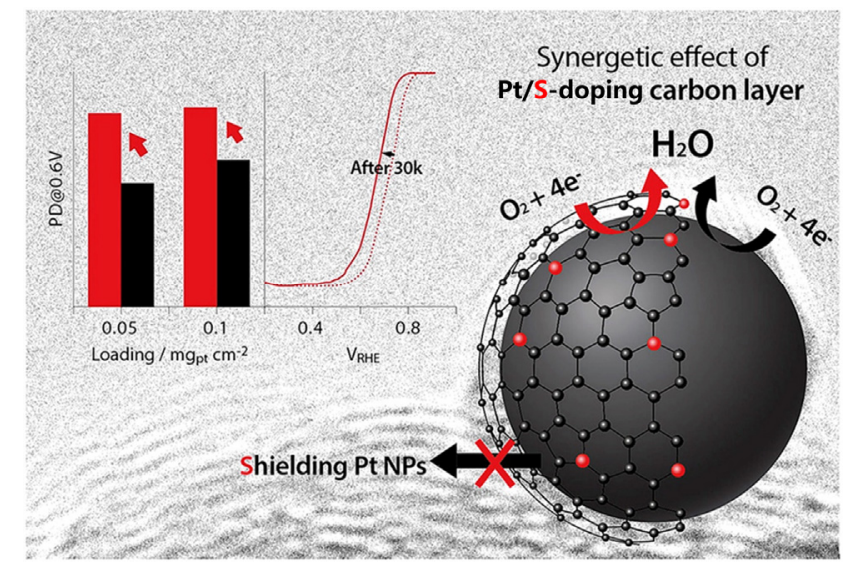

Fig. 13. Schematic diagram of the structure and performance of the Pt/S-C catalyst. Reproduced with permission from Ref. [162], Copyright 2020 Elsevier. 
port, plays a positive role in improving the catalyst performance, which is reflected in both catalytic activity and in the catalytic stability. Indeed, the above-mentioned research has proven the positive effect of sulfur-doped carbon supports on the performance improvement of Pt catalysts. In contrast, it should be highlighted that the Pt supported on sulfur-doped carbon support is in the form of NWs rather than a general nanoparticle, so the comparison with the $\mathrm{Pt} / \mathrm{C}$ catalyst cannot eliminate the influence of Pt morphology on their performance.

To eliminate the influence of Pt nanowires on the electrocatalytic performance and to correctly understand the effect of the sulfur-doped carbon support on the performance of Pt catalysts, Sun et al. [166] prepared sulfur-doped MWCNTs (S-MWCNTs) and undoped multi-walled CNTs (AO-MWCNT) as the support, and both were loaded on Pt nanoparticles (Fig. 14(a)). They found that the onset potential of MOR on the Pt/S-MWCNT catalyst was $0.16 \mathrm{~V}$, and the peak current density was $803.9 \mathrm{~mA} \mathrm{mgPt}^{-1}$. Moreover, the mass current density was only attenuated by $27.22 \%$ after $7000 \mathrm{~s}$ of electrochemical testing. The performance was considerably better than that of the Pt/AO-MWCNT and Pt/C catalysts (Figs. 14(b,c). By comparing them, the Pt nanoparticles on Pt/S-MWCNT had better dispersibility with an average particle size of $2.37 \mathrm{~nm}$ and larger ECSA (161.4 $\mathrm{m}^{2} \mathrm{~g}^{-1}$ ). This means that there were a large number of uniformly dispersed Pt anchor sites on the S-MWCNT support, and a strong electron transfer interaction was generated with $\mathrm{Pt}$ nanoparticles, enabling the Pt/S-MWCNTs to exhibit a high MOR activity, long-term durability, and CO resistance. Additionally, to explore the specific role of sulfur-doped carbon supports on Pt catalysts, Ishizaki et al. [167] synthesized sulfur-doped nanocarbon (TOAS) by plasma and compared it with pristine carbon (BZ) as a support for Pt catalysts. Sintering and electrochemical tests revealed that under a high temperature $\left(600^{\circ} \mathrm{C}\right)$ heat treatment, the $\mathrm{Pt}$ nanoparticle size increased less on the sulfur-doped nanocarbon support (Pt/TOAS: $0.3 \mathrm{~nm}$ and Pt/BZ: $5.2 \mathrm{~nm}$ ), and after 1500 ADT cycles, the mass activity of Pt/TOAS and Pt/BZ decreased by $10 \%$ ( 4.9 to $4.3 \mathrm{~A} \mathrm{gpt}^{-1}$ ) and $25 \%$ (5.8 to $4.3 \mathrm{~A} \mathrm{gat}^{-1}$ ), respectively. These results indicated that the sulfur-doped nanocarbon support increased the physical and electrochemical stability of Pt nanoparticles. This could be explained as follows: during the sulfur doping process, C-S-C bonds were formed, helping the formation of a strong metal-support interaction between Pt nanoparticles and nanocarbon support, so that Pt nanoparticles maintained an extremely strong stability. This result correlated with the conclusion by Lee et al. [162] and was essential to the commercialization of PEMFCs. Based on the above results, it can be concluded that when sulfur is doped into carbon support, the C-S-C bonds formed allow the carbon support to produce a strong metal-support interaction with Pt. Consequently, Pt nanoparticle dispersion improves and the particle size can be controlled, preventing further Pt nanoparticle agglomeration on the support to maintain an excellent catalytic performance. Furthermore, the amount of sulfur doping in carbon support also significantly affects the electrocatalytic performance, but a higher doping level does not translate to better electrocatalytic performance. This may be because the increase in the sulfur doping amount greatly changes the electronic configuration of the original carbon support, resulting in a decrease in electrical conductivity and an increase in the activation energy of the reaction, hindering the electrocatalytic performance.

\subsection{Multi-atoms co-doped carbon}

The previous section discussed the effect of $\mathrm{N}, \mathrm{O}$, and $\mathrm{S}$ het-

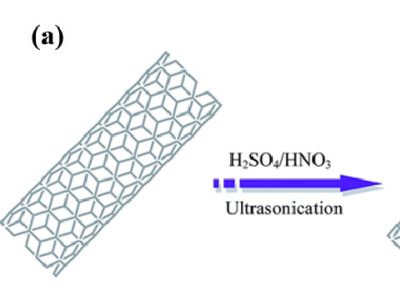

Raw MWCNTs

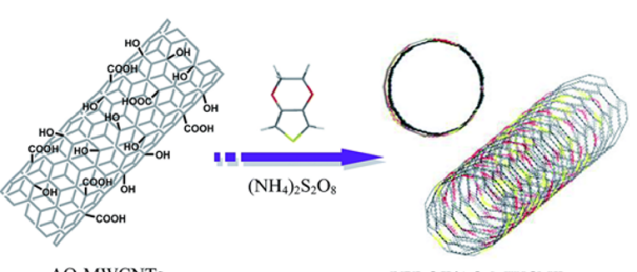

AO-MWCNTs
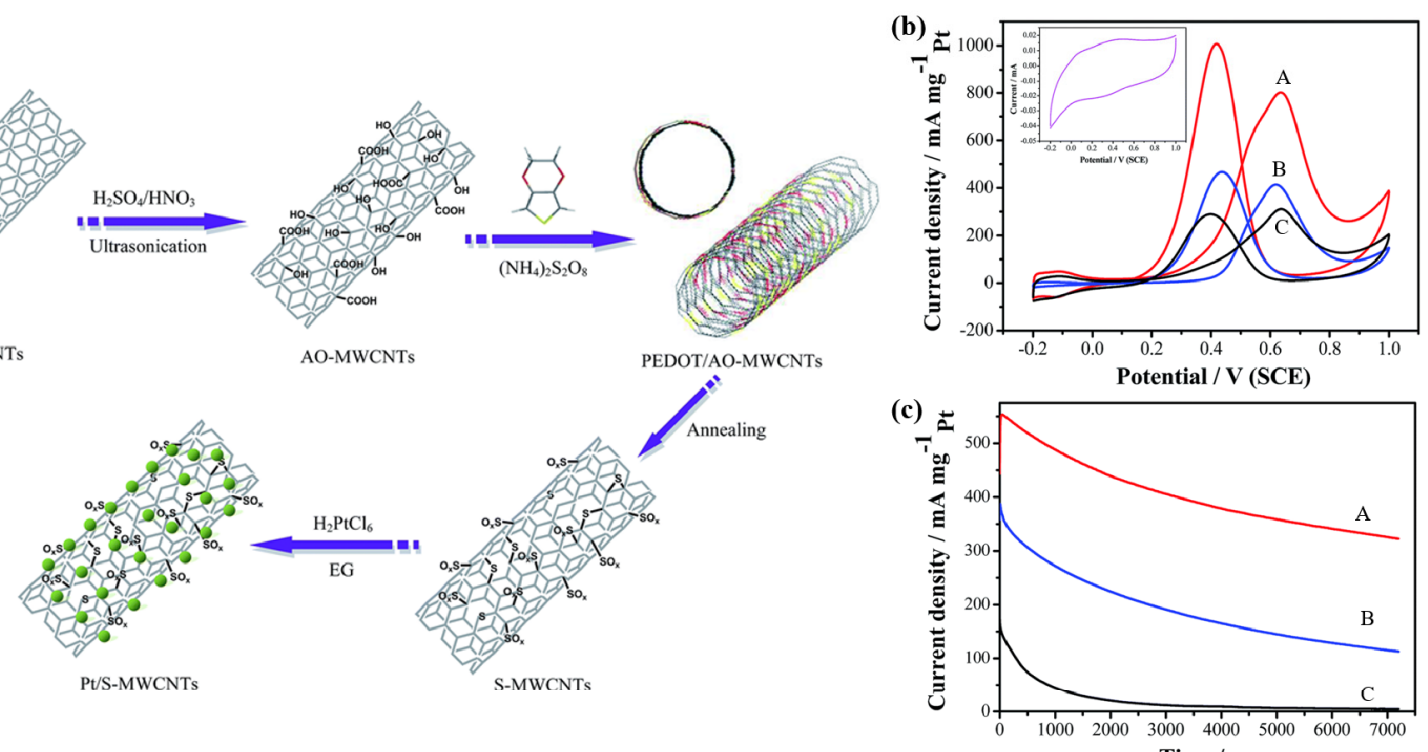

Time / $\mathbf{s}$

Fig. 14. (a) Schematic diagram for the preparation of the Pt/S-MWCNTs catalyst and (b,c) CV and current-time curves of Pt/S-MWCNT (A), Pt/AO-MWCNT (B), and commercial Pt/C (C) catalysts. Reproduced with permission from Ref. [166], Copyright 2017 Royal Society of Chemistry. 
Table 6

Multi-atom co-doped carbon as the PEMFC electrocatalyst support.

\begin{tabular}{|c|c|c|c|c|c|c|}
\hline $\begin{array}{l}\text { Introduction } \\
\text { method }\end{array}$ & Material & Method & $\begin{array}{l}\text { Metal particle } \\
\text { size }(\mathrm{nm})\end{array}$ & $\mathrm{pH}$ & $\begin{array}{c}\text { Catalytic } \\
\text { performance }\end{array}$ & Ref. \\
\hline \multirow{3}{*}{ In situ } & $\begin{array}{c}\mathrm{N} / \mathrm{S} \text { co-doped } \\
\text { honeycomb-ordered carbon }\end{array}$ & $\begin{array}{l}\text { 1. } \mathrm{SiO}_{2} \text { template + fluidic } \mathrm{ANT}^{\mathrm{c}} \text { cladding } \\
\text { 2. Carbonization } \\
\text { 3. } \mathrm{HF} \text { etching }\end{array}$ & 2.6 & 1 & $\begin{array}{l}100^{\mathrm{i}} \text { (for ORR) } \\
0.99^{\mathrm{j}} \text { (for ORR) }\end{array}$ & [168] \\
\hline & & & & & 528k (for ORR) & \\
\hline & N/S co-doped porous carbon & 1. Salt template method & 4.59 & 13 & $\begin{array}{l}112.34^{1} \text { (for ORR) } \\
\sim 0.8^{\mathrm{j}} \text { (for ORR) }\end{array}$ & [169] \\
\hline \multirow{4}{*}{$\begin{array}{l}\text { Post } \\
\text { treatment }\end{array}$} & N/P co-doped GP & $\begin{array}{l}\text { 1. Phosphoric acid + GP -hydrothermal synthesis } \\
\text { 2. } \mathrm{NH}_{4} \mathrm{OH}+\mathrm{P}-\mathrm{GO}^{\mathrm{d}} \text { hydrothermal synthesis }\end{array}$ & $2-4$ & 13 & $\begin{array}{l}108.6^{\mathrm{m}} \text { (for MOR) } \\
133.5^{\mathrm{l}} \text { (for MOR) }\end{array}$ & [170] \\
\hline & N/B co-doped SWCNH ${ }^{a}$ & $\begin{array}{l}\text { 1. } \mathrm{B}_{4} \mathrm{C}+\text { melamine composites }+ \text { carbon rod-DC } \\
\text { arc-vaporization }\end{array}$ & 5 & 1 & $100^{\mathrm{i}}$ (for ORR) & [171] \\
\hline & S/P co-doped GP & $\begin{array}{l}\text { 1. Phosphoric acid }+\mathrm{GO} \text { (ultrasonication-calcination) } \\
\text { 2. Sulfuric acid }+\mathrm{P}-\mathrm{GO}^{\mathrm{d}} \text { (ultrasonication-calcination) }\end{array}$ & 4.5 & 13 & $0.93^{\mathrm{i}}$ (for ORR) & [172] \\
\hline & N-S-P co-doped HCS ${ }^{b}$ & $\begin{array}{l}\text { 1. } \mathrm{HCCP}^{\mathrm{f}}+\mathrm{BPSg}+\mathrm{TEA}^{\mathrm{h}} \text { pyrolysis } \\
\text { 2. Etching }\end{array}$ & $4-6$ & 1 & $\begin{array}{l}1127^{n} \text { (for EOR) } \\
1.61^{\circ} \text { (for EOR) }\end{array}$ & [173] \\
\hline
\end{tabular}

a single-walled carbon nanohorns, ${ }^{\mathrm{b}}$ hollow carbon sphere, ${ }^{\mathrm{c}}$ acrylonitrile telomere, ${ }^{\mathrm{d}}$ GP oxide, e direct current, ${ }^{\mathrm{f}}$ hexachlorocyclotriphos, g 4,4-sulfonyldiphenol, ${ }^{\mathrm{h}}$ trimethylamine, ${ }^{\mathrm{i}}$ half-wave potential $(\mathrm{mV}),{ }^{\mathrm{j}}$ onset potential (V), ${ }^{\mathrm{k}}$ peak power density (mW $\left.\mathrm{cm}^{-2}\right),{ }^{1}$ electrochemical surface area $\left(\mathrm{m}^{2} \mathrm{~g}^{-1}\right)$, ${ }^{\mathrm{m}}$ peak current density $\left(\mathrm{mA} \mathrm{cm}^{-2}\right),{ }^{\mathrm{n}}$ mass peak current density $\left(\mathrm{mA} \mathrm{cm}{ }^{-2}\right),{ }^{\circ}$ specific current density $\left(\mathrm{mA} \mathrm{mg}{ }^{-1}\right)$.

eroatom-doped carbon as the support for PEMFC electrocatalysts on the electrocatalytic performance and discovered their positive role. Inspired by the above conclusions, many researchers have considered whether co-doping of two or more heteroatoms into the carbon support can further improve the electrocatalytic performance of PEMFC electrocatalysts.

Regarding the dual-atom co-doped carbon material as the electrocatalysts support, N/S co-doped carbon is feasible considering that both $\mathrm{N}$ - and S-doped carbon have been widely regarded as potential electrocatalysts support. As discussed above, the large electronegativity of $\mathrm{N}$-doped carbon can change the local electron density of adjacent carbon atoms and promote the adsorption of oxygen molecules during the catalytic reaction and its large specific surface area and abundant defects can increase the dispersion and prevent the agglomeration of catalyst particles. Additionally, S-doped carbon can form $\mathrm{C}-\mathrm{S}-\mathrm{C}$ bonds to strengthen the interaction between metal catalyst and carbon support, increase the dispersion of the catalyst particles, and inhibit the growth of the particles, which is very important for catalyst stability. The ideal goal is that the N/S co-doped carbon support can produce the synergistic effect of N/S so as to increase the electrocatalytic performance of their supported Pt catalysts, however, this is impossible and only a partial improvement can be obtained. Gao et al. [168] prepared a cellular ordered carbon (NS/C) co-doped with nitrogen and sulfur (3.23 at\% N and 4.35 at $\%$ S) as the support for PdNi catalyst. Electrochemical tests revealed that the ORR half-wave potential $\left(E_{1 / 2}\right)$ of the PdNi-NS/C catalyst was $100 \mathrm{mV}$ higher than that of $\mathrm{Pd} / \mathrm{C}$ and the current retention rate after a $10000 \mathrm{~s}$ chronopotentiometric test was 51\% higher than that of $\mathrm{Pd} / \mathrm{C}$, indicating that PdNi-NS/C exhibited better electrocatalytic activity and higher stability than $\mathrm{Pd} / \mathrm{C}$. However, it is obvious that the supported metal here is PtNi instead of pure Pt nanoparticles, so the alloying effect is an unavoidable problem. Accordingly, the performance improvement of the catalyst cannot be explained simply by the N/S co-doped carbon support. To more clearly understand the role of N/S co-doped carbon support in their supported catalysts, pure Pt nanoparticle catalysts loaded on N/S co-doped carbon supports are necessary. Ramaprabhu et al. [169] synthesized nitrogen-sulfur co-doped porous carbon (DPC) as the Pt support and they found that the as-prepared material had a high specific surface area and a porous carbon structure. When Pt/DPC was used as the cathode material of PEMFCs, the peak power density of the fuel cell reached $528 \mathrm{~mW} \mathrm{~cm}^{-2}$ at $60{ }^{\circ} \mathrm{C}$ and the current density was stabilized for more than $36 \mathrm{~h}$ at $60{ }^{\circ} \mathrm{C}$ and $0.6 \mathrm{~V}$, which was better than that of the commercial Pt/C. This performance improvement was attributed to the high porosity of DPC, which accelerated the mass transfer process and increased the number of active centers through the synergistic effect of N/S. Few studies on the catalytic performance of electrocatalysts with nitrogen and sulfur co-doped carbon as the support exist and it is not very clear how well nitrogen and sulfur work together. In a bold analysis, the $\mathrm{N}$ and $\mathrm{S}$ co-doping may result in a change in the electron spin state and asymmetric distribution of the charge density, resulting in more carbon active sites [169]. In N and $\mathrm{S}$ co-doped carbon-supported metal catalysts, $\mathrm{N}$ and $\mathrm{S}$, respectively, exhibits their respective ability to improve catalytic activity, which is mainly due to the difference in electronegativity between nitrogen and carbon and their mismatched outer orbital.

Additionally, apart from N/S co-doped carbon supports, other dual-element co-doped carbon supports, such as N/P, N/B, and S/P co-doped carbon supports, have also been designed based on $\mathrm{N}$ - and S-doped carbon supports. Wang et al. [170] prepared, by a hydrothermal method, nitrogen-phosphorus double-doped GP (N-P-G) as the support for a Pd catalyst in DMFCs (Fig. 15(a)), with nitrogen-doped GP (NG) and phosphorus-doped GP (P-G) serving as the control groups to explore the effect of N/P co-doping of the carbon support on the performance of $\mathrm{Pd}$ catalysts. The electrochemical results showed that the MOR peak current density of Pd/N-P-G (108.6 $\mathrm{mA} \mathrm{cm}-2$ ) was higher than that of $\mathrm{Pd} / \mathrm{PG}, \mathrm{Pd} / \mathrm{NG}$, and $\mathrm{Pd} / \mathrm{G}$ $\left(51.2,35.0\right.$, and $12.7 \mathrm{~mA} \mathrm{~cm}^{-2}$, respectively) (Fig. 15(b)) and the 


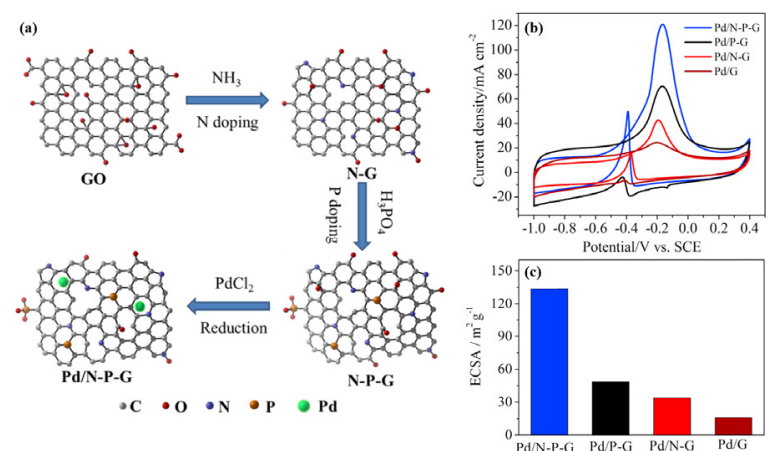

Fig. 15. (a) Schematic diagram for the preparation of the Pd/N-P-G catalyst; (b) Comparison of CV curves of different catalysts in $1 \mathrm{M} \mathrm{KOH}$; (c) Comparison chart of the ECSA values of different catalysts. Reproduced with permission from Ref. [170], Copyright 2019 Elsevier.

corresponding ECSA of Pd/N-P-G was also the highest amongst the four catalysts $\left(133.5,48.7,33.8\right.$, and $15.8 \mathrm{~m}^{2} \mathrm{~g}^{-1}$, respectively) (Fig. 15(c)). Evidently, N-P-G exhibited a significant influence on the $\mathrm{Pd}$ catalyst performance. The reason may be that after the co-doping of $\mathrm{N}$ and $\mathrm{P}$, the electronic structure of GP and the electron cloud density of Pd were changed and more $\mathrm{P}-\mathrm{C}$ bonds were generated, resulting in the enhanced binding ability of Pd nanoparticles and GP, producing more active centers. Additionally, Shi et al. [171] prepared nitrogen and boron dual-doped single-walled carbon nanohorns (NBCNHs) and loaded Pd nanoparticles on them to obtain Pd-NBCNHs catalysts. The electrochemical results showed that the Pd-NBCNHs exhibited better ORR catalytic performance than $\mathrm{Pt} / \mathrm{C}$, Pd-loaded pure single-walled carbon nanohorns (Pd/CNHs), and N/B single-walled carbon nanohorn catalysts (Pd/NCNHs and Pd/BCNHs). The ORR half-wave potentials of the Pd-NBCNHs were $-0.152 \mathrm{~V}$, which were $15,77,43$, and $51 \mathrm{mV}$ larger than that of Pt/C, Pd/CNHs, Pd/NCNHs, and Pd/BCNHs, respectively. The initial current loss after a $9000 \mathrm{~s}$ chronopotentiometric test was $4.7 \%$ and the current density attenuation under methanol conditions was not significant. Gao et al. [172] synthesized S and P co-doped GP (SPG) as the support for Pt nanoparticles and found that the ECSA value and MOR activity of the Pt/SPG catalyst were 1.4 and 3.6 times higher than those of $\mathrm{Pt} / \mathrm{C}$ catalyst, respectively. Further mechanism studies revealed that the SPG possessed a large number of uniformly dispersed defect sites, which enhanced the Pt-SPG metal-support interaction. Additionally, Pt/SPG generated a large number of oxygen-containing functional groups, which is helpful to oxidize $\mathrm{CO}$ and exhibits good CO resistance. Interestingly, not only has diatomic-doped carbon been reported but also tri-atom doped carbon supports. Min et al. [173] synthesized N, $\mathrm{S}$, and $\mathrm{P}$ tri-atom co-doping of polyphosphazene hollow carbon as Pd support, which exhibited more than twice the peak current density and ECSA of the Pd/C catalyst and an excellent stability without significant performance degradation after a 3600 s ADT. In short, dual-atom or tri-atom doped carbon could affect the performance of their supported metal catalysts more obviously than single-atom doped carbon supports. This is most likely caused by changing the electronic structure of the catalyst, constructing defect sites, generating two different heteroatom-C bonds, enhancing the interaction between catalyst and support, and promoting the adsorption of oxygen molecules, thereby significantly improving the activity and stability of the catalyst. However, it should be noted that although multi-atom co-doping can often exhibit a synergistic effect for the improved performance of catalysts, they do not show a linear relationship. This does not mean that doping more heteroatoms into carbon support will result in a better performance of the supported metal catalysts. Moreover, many heteroatoms have been proven to be doped into carbon supports, but the best combination of the doped heteroatoms also requires more research.

Summarizing the above-mentioned viewpoints, heteroatom doping can effectively improve the performance of Pt-based catalysts. Among them, nitrogen doping enhances the interaction between metal and support by changing the electronic structure of Pt catalysts. The oxygen-containing functional groups enable carbon support to better anchor Pt metal nanoparticles, control their particle size, prevent their agglomeration on the surface of the support, and enhance their dispersibility. Sulfur doping forms a C-S-C bond with carbon, produces strong metal-support interaction with $\mathrm{Pt}$, improves the dispersion of Pt nanoparticles, and controls Pt particle size to prevent the aggregation of Pt nanoparticles. Multi-atom co-doping is not completely consistent with single-atom doping. It mainly changes the electronic structure of carbon, constructs defect sites, enhances the interaction between metal and support, and promotes the adsorption of oxygen molecules, enabling the supported metal catalyst to show a significant improvement in activity and stability. However, it is worth noting that the mechanism for the activity and stability improvement of Pt-based catalysts by doping heteroatoms into carbon supports has not been confirmed by a more systematic study and further in-depth research, such as DFT calculations, is necessary.

\section{Functional carbide materials}

For PEMFCs, expensive and scarce Pt catalysts are a barrier to their widespread application. Moreover, $\mathrm{Pt}$ alone is more easily susceptible to $\mathrm{CO}$ in the $\mathrm{H}_{2}$-rich gas in the case of PEMFCs or CO-like species from alcohol electrooxidation in the case of DAFCs. The widely adopted materials for decreasing this poison effect are Pt-Ru bimetallic catalysts with a high activity for water activation to remove strongly adsorbed CO through a bifunctional mechanism. Unfortunately, $\mathrm{Ru}$ is also a precious metal. Since these Pt-based noble catalysts are scarce, incorporating other materials at low cost into the carbon walls of the nanocarbon supports to reduce Pt loading and usage is a critically important research topic. Functional materials, as the name suggests, are new materials with specific functions designed for the limitations of materials, and in response to the above-mentioned challenges, functional carbon materials with CO resistance or good durability after modification, including tungsten carbide (WC), molybdenum carbide $\left(\mathrm{Mo}_{2} \mathrm{C}\right)$, and other metal carbide materials, have been favored by many researchers (Fig. 16) [174-177]. 


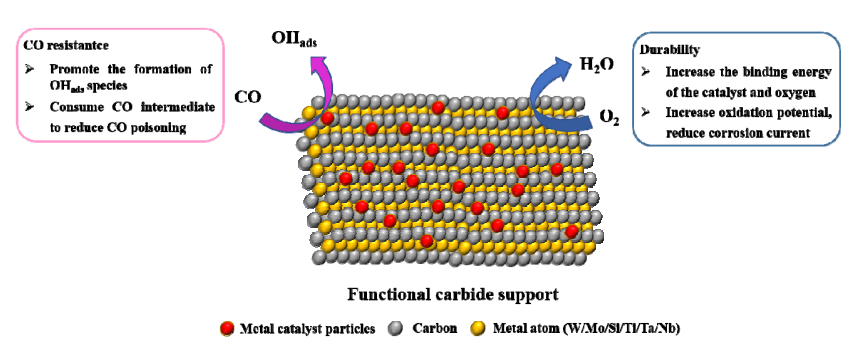

Fig. 16. The mechanism of CO resistance and the long-term durability of functional metal carbides as the electrocatalyst support.

\subsection{Tungsten carbide}

Among all the alternatives for noble metal Pt-based catalysts, WC, as one of the functional carbon materials, has attracted much attention because of its similarity to the catalytic activity of Pt group metals [178-180]. Moreover, WC has been found to have a beneficial effect on the activity of Pt catalysts to MOR and their tolerance to the CO poisoning of Pt catalysts $[108,181,182]$. Additionally, inserting WC into carbon support is also an effective method to improve the stability of PEMFCs [183]. Many WC-modified nanocarbons (WC-C and W2C) have been prepared by different methods and applied in electrocatalysis [174,184,185], as summarized in Table 7. The preparation methods of WC-C can be generally divided into in situ and post-treatment methods [177,186-189]. In the former case, ammonium metatungstate (AMT) or phosphotungstic acid (PTA) is adopted as the tungsten precursor and glucose or resorcinol-formaldehyde polymer as the carbon source. Before carbonization, a mixture of tungsten and carbon precursors will be conducted in a series of special treatments, such as hydrothermal reaction and gelation. These procedures are performed to achieve various unique nanostructures of WC-C. After this process, the precursor mixture is carbonized at high temperatures (for example, above $900{ }^{\circ} \mathrm{C}$ ) in an inert atmosphere $\left(\mathrm{N}_{2}\right.$ or $\left.\mathrm{Ar}\right)$ and reduction gas $\left(\mathrm{H}_{2}\right)$, and finally nanostructured WC modified carbons are formed [177]. In the case of the in situ method, one of the highlights is the introduction of WC into the templates, such as SBA-15 and PMMA (poly[methyl methacrylate]), where the tungsten precursor is impregnated into the template and then carbonized in $\mathrm{CH}_{4}$ gas, which is adopted as the carbon source. After removing the template by HF solution for SBA-15 or heat treatment for PMMA, WC /carbon composites are obtained with mesoporous or macroporous nanostructures.

As shown in Table 7, in the latter case, which is in the so called post-treatment process, WC is designed to be furnished onto the surface of available or pre-formed carbons, such as $\mathrm{CB}$ (Vulcan XC-72 R carbon), CNTs, and others. The tungsten precursor, AMT or PTA, is mixed with the pre-formed carbon and processed at above $900{ }^{\circ} \mathrm{C}$ in a carbonization atmosphere $\left(\mathrm{CH}_{4} / \mathrm{H}_{2} / \mathrm{Ar}\right)$ or treated using a microwave technique. The carbonization products not only contain WC species, but also retain the superior characteristics of pre-formed carbons [182,189-192].

Pure WC species without Pt nanoparticles have almost no activity toward MOR $[178,185,193-196]$. By comparison, the WC-C-supported Pt catalyst, even with a low Pt loading, exhibited a superior electrocatalytic activity toward the MOR as

Table 7

WC as electrocatalyst material supports.

\begin{tabular}{|c|c|c|c|c|c|c|c|}
\hline $\begin{array}{l}\text { Introduction } \\
\text { method }\end{array}$ & $\begin{array}{l}\text { Synthesis } \\
\text { product }\end{array}$ & Synthesis procedure & $\begin{array}{l}\text { Nanostructured } \\
\text { morphology }\end{array}$ & $\begin{array}{l}\text { Surface area } \\
\left(\mathrm{m}^{2} \mathrm{~g}^{-1}\right)\end{array}$ & $\begin{array}{l}\text { Particle } \\
\text { size }^{\mathrm{a}} \\
(\mathrm{nm})\end{array}$ & $\begin{array}{l}\text { Electrocatalyst ratio } \\
\text { for electrochemical } \\
\text { reaction }\end{array}$ & Ref. \\
\hline \multirow{8}{*}{ 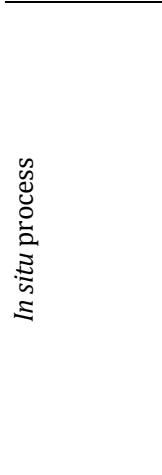 } & \multirow{5}{*}{ WC-C } & Hydrothermal carbonization & Microspheres & 256.0 & - & $\begin{array}{l}1.4 \text { for } \mathrm{ESA} \\
1.6 \text { for } \mathrm{ORR}^{\mathrm{b}, \mathrm{c}}\end{array}$ & [197] \\
\hline & & Hydrothermal carbonization & Mesoporous nanochain & 113.0 & - & $\begin{array}{c}1.3 \text { for ESA } \\
1.6 \text { for } \mathrm{MOR}^{\mathrm{b}}\end{array}$ & [181] \\
\hline & & Hydrothermal carbonization & Hollow morphology & 433 & 3.6 & 1.96 for $\mathrm{MOR}^{\mathrm{b}}$ & {$[182]$} \\
\hline & & & Spherical morphology & $\begin{array}{r}738 \\
89\end{array}$ & $\overline{5.0}$ & $\begin{array}{l}2.4 \text { for } \mathrm{MOR}^{\mathrm{b}} \\
1.5 \text { for } \mathrm{ORR}^{\mathrm{b}}\end{array}$ & {$[178]$} \\
\hline & & Soft templating carbonization & Ordered mesoporosity & 538.0 & 7.2 & 2.4 for $\mathrm{MOR}^{\mathrm{d}}$ & [198] \\
\hline & \multirow{3}{*}{ WC-OMC } & $\begin{array}{c}\text { Hydrothermal and } \\
\text { hard-templating carbonization }\end{array}$ & Ordered mesoporosity & 409.0 & 5.0 & 1.1 for $\mathrm{MOR}^{\mathrm{d}}$ & [199] \\
\hline & & $\begin{array}{l}\text { Pulse microwave-assisted polyol } \\
\text { carbonization }\end{array}$ & Ordered mesoporosity & 409.0 & 5.0 & 1.0 for $\mathrm{MOR}^{\mathrm{b}}$ & [200] \\
\hline & & Hydrothermal carbonization & Ordered mesoporosity & 344.0 & 3.86 & - & [201] \\
\hline \multirow{8}{*}{ 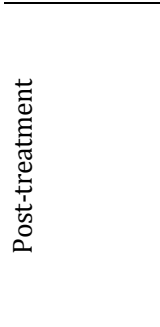 } & \multirow{3}{*}{ WC-C } & Carbothermal $\mathrm{H}_{2}$ reduction & Bamboo-like morphology & - & - & 1.56 for $\mathrm{MOR}^{\mathrm{b}}$ & [202] \\
\hline & & Carbothermal $\mathrm{N}_{2}$ calcination & Macroporosity & 82.1 & 3.4 & 2.9 for $\mathrm{ORR}^{\mathrm{b}}$ & [189] \\
\hline & & Carbothermal $\mathrm{H}_{2}$ reduction & Spherical morphology & 89.0 & $50.0-100.0$ & - & [178] \\
\hline & WC-Ge & Microwave assisted carburization & Hexagonal prism shape & - & 5 & 2.29 for $\mathrm{ESA}$ & [203] \\
\hline & WC-MWCNT $^{\mathrm{f}}$ & Microwave carburization & Nanotube structure & - & - & 1.1 for $\mathrm{MOR}^{\mathrm{b}}$ & [204] \\
\hline & WC-GCg & Indirect carbonization & 3D Spheris & - & $50.0-200.0$ & 3.7 for $\mathrm{ORR}^{\mathrm{a}}$ & [192] \\
\hline & WC-HMGh & Microwave irradiation & $\begin{array}{l}\text { Hemisphere-shaped } \\
\text { macroporosity }\end{array}$ & 58.7 & 3.0 & 2.4 for $\mathrm{ORR}^{\mathrm{b}}$ & [191] \\
\hline & WC-NCi & Indirect carbonization & Macroporosity & - & - & 2.5 for $\mathrm{ORR}^{\mathrm{b}}$ & [108] \\
\hline
\end{tabular}

a WC species, b compared to commercial Pt/C, c@0.8 V (vs. NHE), d compared with commercial PtRu/C @ 0.75 V (vs. Ag/AgCl), e graphene, ${ }^{\mathrm{f}} \mathrm{mul}$ ti-walled CNTs, g graphite-carbon, ${ }^{\mathrm{h}}$ hemisphere-shaped macroporous GP, ${ }^{\mathrm{i}} \mathrm{N}$-doped carbon. 
compared to Pt/C with a high Pt loading [177,184,187,200]. This is because the WC in the WC-C support possesses high activity to facilitate the facile removal of $\mathrm{CO}$ or CO-like intermediate species produced from methanol decomposition on the $\mathrm{Pt}$ surface [205]. Wang et al. [181] reported that Pt/WC-C had a more negative $\mathrm{CO}$ oxidation potential $(\sim 0.48 \mathrm{~V} v s$. SCE $)$ than $\mathrm{Pt} / \mathrm{C}(\sim 0.58 \mathrm{~V} v s$. SCE). Evidently, CO or CO-like poisoning intermediates could be easily oxidized on WC at a lower potential. This could be attributed to the similar function of WC to that of $\mathrm{Ru}$ in PtRu/C electrocatalysts toward the dissociation of water, which improves the formation of surface hydroxyls for the further oxidation of CO-like species and thus avoids, or at least decreases, CO poisoning to some extent [206]. The further reaction of $\mathrm{CO}$ adsorbed on Pt (Pt-CO) and surface hydroxyls formed on WC (WC-OH) can be given by Eq. (7) [187] and is schematically described in Fig. 17(a).

$$
\mathrm{Pt}-\mathrm{CO}+\mathrm{WC}-\mathrm{OH} \rightarrow \mathrm{Pt}+\mathrm{WC}+\mathrm{CO}_{2}+\mathrm{H}^{+}+\mathrm{e}^{-}
$$

All the above results demonstrate that $\mathrm{WC}$ acts as the active site for water dissociation at a lower potential to produce hydroxyls. In this way, WC-C-supported Pt catalysts exhibit interesting activity toward MOR and CO removal. This suggests that WC modified carbon can be adopted as a functional support instead of carbon alone for Pt nanoparticles to be potentially used as anode catalysts in DMFCs instead of PtRu catalysts. Consequently, this not only decreases Pt usage but also avoids the use of another noble metal, Ru.

With the significant contributing effect of WC on the electrochemical activity of $\mathrm{Pt}$, WC modified carbons with novel pore structures have also been intensively developed. Bosco et al. [207] reported that 3D ordered macroporous WC-C with 1-5 wt\% Pt modification demonstrated substantial activity for MOR, surpassing the commercial 20 wt \% Pt on CB (Alfa Aesar) in terms of the specific mass activity. Lee et al. [196] reported that mesoporous WC-C with $3.5 \mathrm{wt} \%$ Pt showed a higher mass activity by a factor of six than that of the commercial $20 \mathrm{wt} \%$ $\mathrm{PtRu} / \mathrm{C}$ (E-Tek Corp.). By comparing these cases, the difference
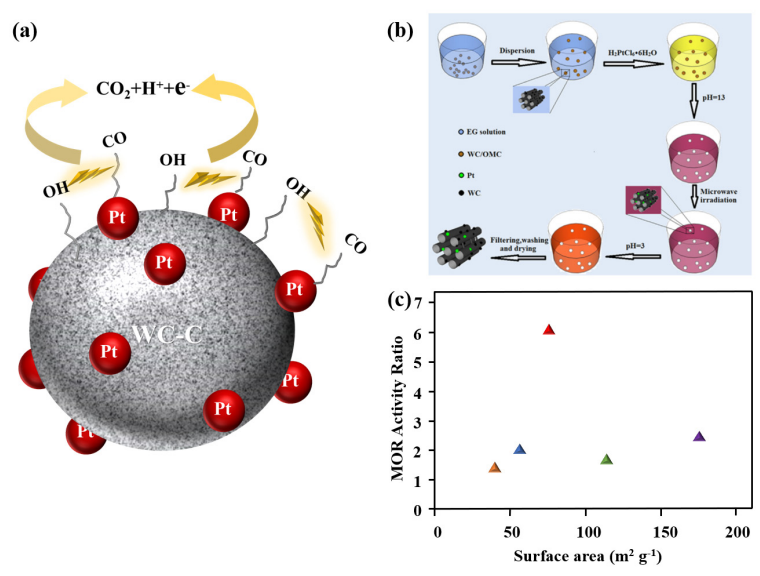

Fig. 17. (a) Schematic description for adsorbed CO on Pt and surface hydroxyls formed on WC with Pt/WC-C as the catalyst; (b) Schematic diagram of the preparation of the Pt@WC/OMC nanocomposite catalyst Reproduced with permission from Ref. [200], Copyright 2015 Elsevier. (c) The MOR activity ratio between Pt/WC-C electrocatalysts with different surface areas and the commercial Pt/C. only in the pore structure of WC modified carbon materials can has a significant effect on enhancing Pt activity toward MOR (approximately 1.4 to 1.9 times for macropores and 6 times for mesopores). This is because the pore structure directly determines the surface area of WC-C and affects the mass transfer process. The smaller surface area of macropores is unfavorable for the dispersion of Pt nanoparticles on the support surface and, consequently, lowers the Pt utilization coefficient. Additionally, our group [198-200] prepared WC/ordered mesoporous carbon (WC/OMC) nanocomposites (Fig. 17(b)) with a big specific surface area, large pore volume, and narrow pore size distribution. With Pt loaded, the Pt@WC/OMC catalyst showed better MOR performance than PtRu@C and exhibited superior stability and resistance to CO. Further research found that these excellent performances were not only because of the synergistic effect of WC and OMC, but also due to its highly ordered mesoporous structure and large specific surface area, which resulted in high Pt utilization and a good mass transfer performance.

The effect of the WC-C surface area on the activity of Pt towards MOR is further summarized in Fig. 17(c). For comparison, the MOR activity on the commercial Pt/C catalyst was used as the reference. Therefore, the activity ratio between MOR on Pt supported on WC-C with different surface areas and commercial $\mathrm{Pt} / \mathrm{C}$ versus the surface area of WC-C is presented in Fig. 17(c). It can be seen that the Pt supported on WC-C with a $75 \mathrm{~m}^{2} \mathrm{~g}^{-1}$ surface area shows the highest electrocatalytic activity ratio for MOR in all the Pt/WC-C electrocatalysts. In this case, WC-C a mesoporous structure. Combined with the results given in Table 7, not only is the big surface area necessary for nanostructured WC-C, but also a high amount of mesopores is important for a higher MOR activity. This is because the micropores are inaccessible to fuels and electrolytes (especially with Nafion ${ }^{\circledR}$ as the electrolyte) and thus do not contribute to electrocatalysis [208]. The large number of mesopores offers a facile mass transfer for reactants/products to/from the reaction sites. Therefore, WCs with novel ordered mesoporous nanostructures and tunable pore sizes have more potential applications as modifiers for carbon materials and their performance requires further investigation $[199,200]$.

In addition to $\mathrm{MOR}, \mathrm{WC}_{x}$ species introduced into the carbon support can also contribute to the ORR activity of Pt [192,209]. The Pt/WC $\mathrm{W}_{x}$-CNT electrocatalyst exhibited superior ORR specific activity to Pt/CNT owing to the synergistic effect between Pt and $\mathrm{WC}_{x}$. Li et al. [191] reported that the hollow hemispherical macroporous GP/WC/platinum (HMG/WC/Pt) nanocomposite catalyst exhibited a higher ORR half-wave potential $(0.9$ $\mathrm{V} v$ s. RHE), higher specific quality activity (206 mA mg-1 Pt), and better stability (the activity retention rate was $84.5 \%$ after 2000 cycles) than the Pt/C catalyst (Fig. 18). Lei et al. [192] synthesized a graphite carbon-WC (GC-WC) nanocomposite and its supported Pt catalyst exhibited excellent ORR performance with an onset potential of $0.75 \mathrm{~V}$ (vs. RHE) as well as good stability and methanol resistance. Its current loss after a 10000 s chronoamperometry test was $12 \%$, which was $8 \%$ lower than that of the Pt/C catalyst. The excellent ORR performance of Pt/GC-WC was mainly attributed to the synergy be- 

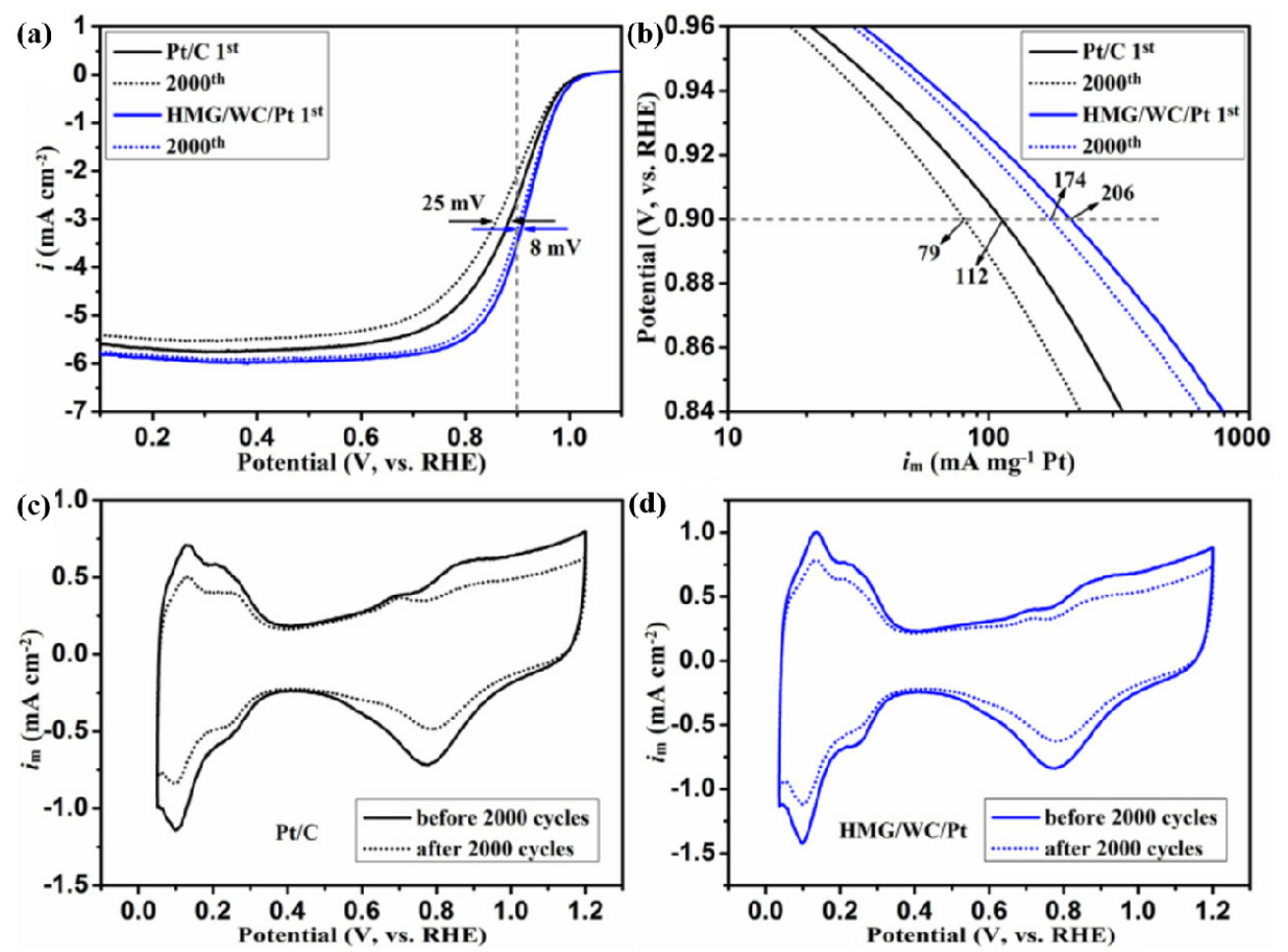

Fig. 18. (a) ORR test curves of HMG/WC/Pt and Pt/C (1 ${ }^{\text {st }}$ and $2000^{\text {th }}$ cycles); (b) Mass activity diagrams of HMG/WC/Pt and Pt/C; the CV curve of Pt/C (c) and HMG/WC/Pt (d) before and after 2000 cycles. Reproduced with permission from Ref. [191], Copyright 2016, Elsevier.

tween the inner carbide NPs and the outer active graphite carbon layer. The nano-WC particles activated the surface graphite carbon layer, and the surface graphite carbon layer protected the internal WC NPs, which were not damaged by the high oxidation environment. These reports indicate that the introduction of WC provides carbon materials with a synergistic function, which improves the ORR activity of Pt catalysts.

Additionally, the WC phase affects the ORR activity. Ticianelli et al. [185] synthesized hexagonal phase ( $\alpha-\mathrm{WC} / \mathrm{C})$ and cubic phase $\left(\beta-\mathrm{WC}_{1-x} / \mathrm{C}\right) \mathrm{WC}$ composites as catalyst supports. The Pt- $\alpha-W C / C$ catalyst exhibited an ORR activity similar to that of commercial $\mathrm{Pt} / \mathrm{C}$, and unexpectedly, at a carbide-to-carbon loading of $40 \mathrm{wt} \%$, the Pt- $\beta-\mathrm{WC}_{1-x} / \mathrm{C}$ catalyst exhibited an ORR activity 3.6 times higher than that of $\mathrm{Pt} / \mathrm{C}$. The difference in the performance of these two-phase WC-supported Pt catalysts could be attributed to the different bond energies of oxygen adsorbed by different WC supports. Owing to the high Pt $5 d$ band occupancy of Pt- $\beta-\mathrm{WC} / \mathrm{C}_{1-x}$, the Pt- $\mathrm{OH}_{x}$ interaction was weakened and, therefore, Pt- $\beta-\mathrm{WC} / \mathrm{C}_{1-x}$ exhibited high ORR kinetics.

WC-C as a catalyst support can cause a synergistic effect with metal Pt. The introduction of WC can promote the decomposition of water to produce $\mathrm{OH}_{\text {ads }}$ components, which can accelerate the CO-like intermediates to further oxidize with the surface hydroxyl groups and expose more active sites. Thus, this helps to greatly improve the activity of Pt towards both MOR and ORR even with a low Pt loading. Although it has been found that the pore structure and surface area of WC modified carbon significantly affect the electrochemical performance of Pt, further optimization of their pore structure needs to be in- vestigated. Moreover, as support materials for PEMFC electrocatalysts, the stability of WC modified carbon should be considered and investigated because of the acidic environment, and especially, the high operation potential and high oxygen conditions in the case of ORR.

\subsection{Molybdenum carbide}

The corrosion of metal catalysts for PEMFCs is one of the difficult challenges in their commercialization process [210]. This severely degrades the electrochemical surface area, leading to the degradation of catalytic activity and the destruction of stability [22]. The traditional carbon support used for metal catalysts can be oxidized to carbon dioxide during the corrosion process. Consequently, functional carbon material that can improve the corrosion resistance of the catalyst is necessary to support precious metal catalysts. Transition metal carbides (TMCs) have been proven to be potential support materials $[184,211]$. In addition to WC discussed above, $\mathrm{Mo}_{2} \mathrm{C}$ also shows a particular positive effect on improving the corrosion resistance of electrocatalysts (Table 8) [212-214].

In the research on $\mathrm{Mo}_{2} \mathrm{C}$ support, Lust et al. $[73,119,194,215]$ conducted much research work from different angles, including the hierarchical pore structure of $\mathrm{Mo}_{2} \mathrm{C}$ support and the durability, size, and quantity of Pt catalyst supported on $\mathrm{Mo}_{2} \mathrm{C}$. Regarding the hierarchical pore structure of the $\mathrm{Mo}_{2} \mathrm{C}$ support, they used the high-temperature chlorination method to prepare microporous-mesoporous $\mathrm{Mo}_{2} \mathrm{C}$ supports with different pore structures by changing the synthesis temperature $\left(600-1000{ }^{\circ} \mathrm{C}\right)$ and then used the sodium boro- 
Table 8

$\mathrm{Mo}_{2} \mathrm{C}$ as the PEMFC electrocatalyst support.

\begin{tabular}{|c|c|c|c|c|c|c|}
\hline Catalyst type & Structure & Method & Particle size (nm) & $\mathrm{pH}$ & Catalytic performance & Ref. \\
\hline Pt-C $\left(\mathrm{Mo}_{2} \mathrm{C}\right)$ & Microporous-mesoporous carbon & $\begin{array}{c}\text { Powder chlorination }+ \\
600-1000^{\circ} \mathrm{C}\end{array}$ & $4.5 \pm 0.5$ & 2.0 & $3.0-27.4^{\mathrm{a}}$ & [215] \\
\hline Pt-C $\left(\mathrm{Mo}_{2} \mathrm{C}\right)$ & $\begin{array}{l}\text { Hierarchical microporous- } \\
\text { mesoporous carbon }\end{array}$ & $\begin{array}{l}\text { Powder chlorination }+ \\
850^{\circ} \mathrm{C}\end{array}$ & $4.1 \pm 0.6$ & 1.0 & $\begin{array}{c}7 \% \text { after } 10000 \text { cycles }^{b} \\
22.2 \pm 0.8^{a}\end{array}$ & [119] \\
\hline $\mathrm{Pt} / \mathrm{HMoCS}$ & Hollow $\mathrm{Mo}_{2} \mathrm{C}$ spheres & - & 3.3 & 2.0 & $\begin{array}{c}234 \text { (for ORR) }^{\mathrm{c}} \\
1581 \text { (for MOR) }^{\mathrm{c}}\end{array}$ & [216] \\
\hline
\end{tabular}

a electrochemical surface area $\left(\mathrm{m}^{2} \mathrm{~g}^{-1}\right),{ }^{\mathrm{b}}$ limiting diffusion current $(\%),{ }^{\mathrm{c}}$ mass activity $\left(\mathrm{mA} \mathrm{mg}_{\mathrm{Pt}}{ }^{-1}\right)$.

hydride method to load Pt on the supports to prepare Pt-C $(\mathrm{Mo} 2 \mathrm{C})$ catalysts $[73,215]$. They found that the pore structure of the $\mathrm{Mo}_{2} \mathrm{C}$ support could change the mass transfer efficiency of $\mathrm{O}_{2}$ and $\mathrm{H}_{2} \mathrm{O}$ and significantly affect the performance of single PEMFCs. It was further found that the $\mathrm{Mo}_{2} \mathrm{C} /$ carbon support with a synthesis temperature of approximately $800{ }^{\circ} \mathrm{C}$ had a bigger specific surface area and a narrower pore size distribution. As the electrocatalyst support, the power density of the corresponding single PEFMC was as high as $500 \mathrm{~mW} \mathrm{~cm}^{-2}$ and the degradation rate after a $600 \mathrm{~h}$ time stability test was $33 \%$ (the single cell potential dropped from 240 to $160 \mu \mathrm{V} \mathrm{h}^{-1}$ ). Additionally, they also conducted a detailed exploration for the durability of the Pt catalyst supported on $\mathrm{Mo}_{2} \mathrm{C}$. They also prepared a Pt-C $\left(\mathrm{Mo}_{2} \mathrm{C}\right)$ catalyst, using the method described above, when studying the pore structure effect and then performed an ADT investigation [119]. It was found that after 30000 ADT cycles, the Pt in Pt-C (Mo2 $\mathrm{C})$ lost $18 \mathrm{wt} \%$ (the mass percentage decreased from $70.5 \mathrm{wt} \%$ to $52.6 \mathrm{wt} \%$ ), indicating the separation and dissolution of Pt particles during the ADT test. Additionally, Pt-C $\left(\mathrm{Mo}_{2} \mathrm{C}\right)$ stabilized after a $10 \%$ drop in the first 1000 cycles, while the capacitance dropped by $20 \%$ after 30000 cycles, and the series resistance dropped by $15 \%$. It is evident that the values of capacitance, series resistance, and charge transfer resistance slowly decrease with an increasing number of potential cycles. Relatively speaking, the durability test of Pt-C $\left(\mathrm{Mo}_{2} \mathrm{C}\right)$ outperforms most catalysts. Furthermore, they also studied the Pt loading effect on the Pt catalyst supported on $\mathrm{Mo}_{2} \mathrm{C}$ and explained them from the perspective of kinetics [194]. They prepared $\mathrm{Mo}_{2} \mathrm{C}$-derived carbon-supported Pt catalysts with Pt loadings of 3.5 wt\%, 8.3 $w \mathrm{t} \%$, and $12.4 \mathrm{wt} \%$ and the average particle size of the Pt nanoparticles was $3.3 \mathrm{~nm}$. To eliminate the influence of pores on the Pt catalysts performance, BET tests showed that the specific surface area of carbon support decreased slightly before and after $\mathrm{Mo}_{2} \mathrm{C}$ modification, but its pore volume did not change significantly. Electrochemical tests revealed that the catalyst with a Pt loading of $8.3 \mathrm{wt} \%$ showed the best electrochemical activity and stability, meaning that it was most suitable for ORR of PEMFCs. Briefly, for the $\mathrm{Mo}_{2} \mathrm{C}$ support, a higher Pt loading is not better as it is necessary to be within a suitable range. Too little Pt loading cannot achieve the required catalytic performance but too much Pt loading not only significantly increases the manufacturing cost of the catalysts, but also reduces the Pt catalyst performance. This behavior may be due to that the excessive Pt loading causes the accumulation of Pt nanoparticles and the increase in the Pt particle size blocks the pores on the carbon support. This is similar to the effect of the pore structure of support on the catalyst performance discussed above. For functional $\mathrm{Mo}_{2} \mathrm{C}$-supported Pt catalysts, based on the series studies by Lust et al. [215], the pore structure of the support, including pore size and porosity, and the amount of $\mathrm{Pt}$ loading have a significant effect on the performance of Pt catalysts, including both activity and stability.

Physical parameters, such as the crystal structure, specific surface area, and pore size distribution of carbon support, have a great influence on the performance of PEMFC electrocatalysts, as mentioned and discussed in the previous section. Many researchers have conducted targeted research on $\mathrm{Mo}_{2} \mathrm{C}$ support. Shen et al. [216] dispersed $\mathrm{Mo}_{2} \mathrm{C}$ particles in the shell of hollow carbon spheres to synthesize hollow $\mathrm{Mo}_{2} \mathrm{C}$ spheres and used them as the $\mathrm{Pt}$ nanoparticles support to prepare Pt/HMoCS electrocatalysts. The electrochemical tests revealed that the ORR and MOR mass activities of the Pt/HMoCS electrocatalyst were twice as high as those of the commercial $\mathrm{Pt} / \mathrm{C}$-TKK catalyst, which were 234 and $1581 \mathrm{~mA} \mathrm{mgPt}^{-1}$, respectively. The physicochemical characterization showed that the specific surface area of the HMoCS support was as high as $542 \mathrm{~m}^{2} \mathrm{~g}^{-1}$, which may improve the mass transfer process of the reactants so that the catalyst exhibited excellent catalytic activity. Moreover, a strong electronic interaction was formed between MoC and Pt, reducing the Pt particle size and increasing its stability. Additionally, similar to $\mathrm{WC}$, the $\mathrm{Mo}_{2} \mathrm{C}$ phase also has a significant effect on the electrocatalyst performance. Although both cubic and hexagonal $\mathrm{Mo}_{2} \mathrm{C}$ improve the catalytic activity of their supported metal catalysts, the degree of improvement between them is different. Ticianelli et al. [217] synthesized carbon-supported hexagonal $\mathrm{Mo}_{2} \mathrm{C}\left(\alpha-\mathrm{Mo}_{2} \mathrm{C}\right)$ and cubic $\mathrm{Mo}_{2} \mathrm{C}(\delta-\mathrm{MoC})$ as the support for Pt catalysts. The electrochemical characterization results showed that the ORR limiting diffusion current $\left(j_{\mathrm{k}}\right)$ and mass activity of $\mathrm{Pt}-\delta$-MoC/C were higher than those of Pt- $\alpha-\mathrm{Mo}_{2} \mathrm{C} / \mathrm{C}$ and $\mathrm{Pt} / \mathrm{C}$, but its corresponding ECSA was lower. This performance difference could be due to the different adsorption affinities for surface oxygen-containing substances caused by the different phases of the $\mathrm{Mo}_{2} \mathrm{C}$ supports.

Most of the research on functional carbon supports focused on carbides, such as WC and $\mathrm{Mo}_{2} \mathrm{C}$. Although they have indeed demonstrated some capability to improve their supported catalyst performance, clarity will be needed that they will still be converted into oxides or dissolved under the influence of corrosion in the real working conditions of PEMFCs, which is still an inevitable challenge for their commercialization [218]. 
Table 9

Other functional carbides as the support for PEMFC electrocatalysts.

\begin{tabular}{|c|c|c|c|c|c|c|}
\hline \multirow{2}{*}{$\begin{array}{l}\text { Functional carbide } \\
\text { support }\end{array}$} & \multirow{2}{*}{ Catalyst synthesis method } & \multirow{2}{*}{$T /{ }^{\circ} \mathrm{C}$} & \multirow{2}{*}{ Pt particle size $(\mathrm{nm})$} & \multicolumn{2}{|r|}{ ORR } & \multirow[t]{2}{*}{ Ref. } \\
\hline & & & & $\mathrm{pH}$ & $\mathrm{ECSA}^{\mathrm{c}} / \mathrm{m}^{2} \mathrm{~g}_{\mathrm{Pt}^{-1}}$ & \\
\hline $\mathrm{SiC}$ & $\begin{array}{l}\text { 1. Wood pyrolysis } \\
\text { 2. } \mathrm{Si} \text { and } \mathrm{SiO}_{2} \text { calcination } \\
\text { 3. Unreacted carbon separation } \\
\text { 4. Acid washing }\end{array}$ & 1450 & - & 2.0 & $34^{\mathrm{d}} ;>80 \% \mathrm{e}^{\mathrm{e}}$ & [223] \\
\hline $\mathrm{TiC}$ & - & - & 3.8 & 2.0 & $75^{\mathrm{d}} ;-$ & {$[224]$} \\
\hline $\mathrm{NbC}$ & $\begin{array}{l}\text { 1. } \mathrm{ANO}^{\mathrm{a}}+\mathrm{PVPb}^{\mathrm{b}} \text { electrospinning } \\
\text { 2. Calcination }\end{array}$ & 1100 & 3.1 & 13.0 & $43^{\mathrm{d}} ; 31 \%^{\mathrm{f}}$ & [226] \\
\hline
\end{tabular}

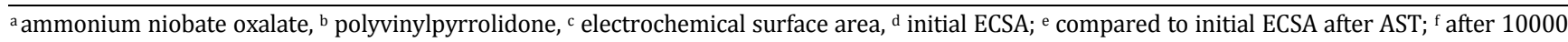
CV tests (1.4 $\left.\mathrm{V}_{\mathrm{RHE}}\right)$.

Moreover, because metal is introduced on the carbon support, the oxidation potential of the catalysts and the binding energy with oxygen will change [219], resulting in an unstable ORR catalytic performance. The ultimate goal is for the catalyst to concurrently have an excellent catalytic activity and stability [220] and the introduction of multiple components (both activity-promoting components and stability-promoting components) may be a feasible idea for preparing functional carbon supports, however, more research and exploration is needed.

\subsection{Other carbides}

Carbides are currently the most frequently studied functional materials for support of PEMFCs because their preparation method is simple and they also significantly improve the performance of metal catalysts [193,221,222]. WC and Mo2 C were previously discussed as two typical and commonly used functional carbon materials as catalyst supports for PEMFCs. However, other transition metal-based carbides, including silicon carbide [223] (SiC), titanium carbide [224,225] (TiC), niobium carbide ( $\mathrm{NbC}$ ) [226], and tantalum carbide (TaC) [176], have also been studied by some researchers. The following discussion will further consider their influence on the electrocatalytic performance of PEMFCs (Table 9).

$\mathrm{SiC}$ has been widely reported in the electrocatalysis and semiconductor industries owing to its high thermal conductivity, good mechanical resistance, acid resistance, and oxidation resistance, and it has also been found to be a good functional carbon support. Larsen et al. [223] prepared Pt electrocatalysts with $\mathrm{SiC}$ as support for PEMFCs, which were assembled into membrane electrode assemblies and single cells to test their performance. The electrochemical test and accelerated stress test (AST) revealed that during a 30000 cycle AST, the current density and ECSA of the single cell with $\mathrm{Pt} / \mathrm{SiC}$ were always higher than those of the single cell with $\mathrm{Pt} / \mathrm{C}$ electrocatalyst (Fig. 19(a)). Additionally, during this period, the Pt/C electrode experienced severe carbon corrosion and polymer degradation while the $\mathrm{Pt} / \mathrm{SiC}$ electrode maintained a relatively stable chemical composition, signifying that $\mathrm{Pt} / \mathrm{SiC}$ was much more stable than Pt/C (Fig. 19(b)). Additionally, TiC is also a functional carbon material with good stability and corrosion resistance and it has also been used by researchers as the support for PEMFC electrocatalysts. Uchida et al. [224] prepared a TiC-supported Pt nanoparticle catalyst (Pt/TiC), which exhibited an electrochemically comparable performance and better durability than commercial Pt/ CB (C-Pt/CB) in PEMFCs. At the beginning of the catalytic ORR, Pt/TiC and C-Pt/CB exhibited comparable electrochemical activities, with mass activities of 507 and $527 \mathrm{~A} \mathrm{~g}^{-1}$, respectively, and ECSA of 74 and $80 \mathrm{~m}^{2} \mathrm{gPt}^{-1}$, respectively. In contrast, after 100 cycles, the mass activity and ECSA of both decreased rapidly, but the decline rate of Pt/TiC was lower than that of $\mathrm{C}-\mathrm{Pt} / \mathrm{CB}$, signifying that the former was more stable than the latter. Interestingly, novel functional carbides, such as $\mathrm{NbC}$ and $\mathrm{TaC}$, were also used as electrocatalysts for PEMFCs. However, there is no case in the existing literature where they are used alone, but they are often used in combina-
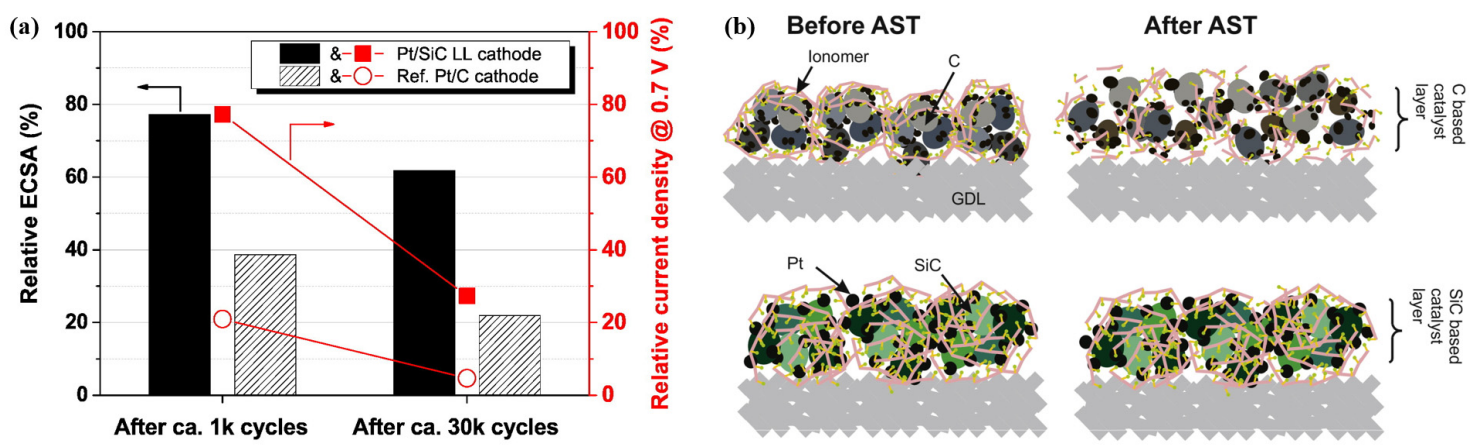

Fig. 19. (a) Comparison chart of the ECSA and current density of Pt/SiC and Pt/C single cells and (b) interface structure diagram of Pt/SiC and Pt/C electrodes before and after the AST test. Reproduced with permission from Ref. [223], Copyright 2017 Elsevier. 
tion with other nanocarbons or carbides. Nabil et al. [226] used the electrospinning method to prepare a $\mathrm{NbC} /$ carbon nanotube porous structure $(\mathrm{NbC} / \mathrm{C})$ and used it as the support for Pt-based electrocatalyst to prepare $\mathrm{Pt} / \mathrm{NbC} / \mathrm{C}$ catalyst. Under high potential cycling, $\mathrm{Pt} / \mathrm{NbC} / \mathrm{C}$ exhibited a larger ECSA and better stability than commercial Pt/C. In a single fuel cell, the maximum power density of the MEA with $\mathrm{Pt} / \mathrm{NbC} / \mathrm{C}$ as the cathode catalyst was $0.43 \mathrm{~W} \mathrm{~cm}^{-2}$ and the Tafel slope in the electron transfer control region was $53 \mathrm{mV} \mathrm{dec}^{-1}$, which was close to the theoretical Tafel slope of the $4 \mathrm{e}^{-}$ORR reaction (60 $\mathrm{mV} \mathrm{dec}^{-1}$ ). To solve the carbon corrosion problem in PEMFCs, Rosen et al. [176] designed $\mathrm{TaC}$ and $\mathrm{Mo}_{2} \mathrm{C}$ alloy carbides as the support for PEMFC electrocatalysts. It was found that the ORR activity of Ta/Mo alloy carbide-supported Pt catalyst was not as good as that of the $\mathrm{Mo}_{2} \mathrm{C}$-supported Pt catalyst. In contrast, the oxidation potential was increased by $150 \mathrm{mV}$ and the corrosion current was reduced to $1 / 6$ (437 to $87 \mu \mathrm{A} \mathrm{cm} \mathrm{Pt}^{-2}$ ), signifying that the corrosion resistance of the $\mathrm{Pt} / \mathrm{TaC} / \mathrm{Mo}_{2} \mathrm{C}$ catalyst was significantly better than that of $\mathrm{Pt} / \mathrm{Mo}_{2} \mathrm{C}$.

In summary, to solve the problems of carbon corrosion, $\mathrm{CO}$ poisoning, and poor durability of the metal catalysts supported on Vulcan XC-72 R CB supports that are currently commonly used in PEMFCs as well as the high cost of PEMFC commercialization, functional carbide materials that can achieve specific functions, including $\mathrm{Mo}_{2} \mathrm{C}, \mathrm{TiC}, \mathrm{SiC}, \mathrm{NbC}$, and $\mathrm{TaC}$, have been reported by many researchers. Existing reports have demonstrated that they have a significant effect on the PEMFC performance, but for different functional requirements, the action mechanism of functional carbon supports is not completely identical. To improve CO resistance, WC mainly promotes the decomposition of water to generate $\mathrm{OH}_{\text {ads }}$ components, accelerating the further oxidation of $\mathrm{CO}$ intermediates to surface hydroxyl groups, thereby consuming excess $\mathrm{CO}$ and exposing more active centers. To improve the durability, $\mathrm{Mo}_{2} \mathrm{C}$ mainly increases the oxygen binding energy and oxidation potential of the catalyst, and reduces the corrosion current of fuel cells, thus improving the corrosion resistance and durability. However, most of the existing explanations for the performance improvement of PEMFC catalysts with functional carbon supports are not supported by a clear theory and there is still no accepted view. Perhaps, supported by large amounts of experimental data, requiring the selfless contribution of more researchers, further theoretical calculations will provide a clear answer.

\section{Conclusion and outlook}

PEMFCs are widely favored owing to their advantages of fast start-up, low operating temperature, and good flexibility, but the high cost of Pt electrocatalysts hinders the commercial application of PEMFCs. As a part of PEMFC electrocatalysts, the support has a strong correlation with the catalyst performance, affecting various physical characteristics (particle size, dispersion, and specific surface area) and electrochemical properties (activity and stability) of the catalysts. The PEMFC electrocatalyst supports should have a large number of pores with suitable pore structures, abundant active sites, high conductivity, and high stability. Currently, CB supports, which are widely used in
PEMFCs, have a low specific surface area, a small pore structure, and a shortage of functional groups, causing Pt nanoparticles to easily aggregate on the CB surface, thereby reducing the activity and stability of electrocatalysts and increasing the cost. Nanocarbon supports have a variety of shapes (tubular, spherical, fibrous, and others) and a large number of adjustable pores, which can increase the specific surface area of the catalysts and enhance their catalytic activity. Additionally, the modified nanocarbon support can better anchor Pt nanoparticles to prevent the aggregation of Pt nanoparticles and expose more active sites, reducing the cost of PEMFCs and accelerating their commercial application. This review presents the recent development of nanocarbons as the electrocatalysts support in PEMFCs with an emphasis on the effect of pore structure, heteroatom doping, and functional carbon-based supports on the electrochemical performance of supported Pt-based electrocatalysts. Although it is true that nanocarbons have been commonly and widely used in PEMFCs because of their big surface area, tailored pore architecture, high electrical conductivity, and desirable stability under fuel cell working conditions, issues regarding the suitable nanoarchitecture and surface physicochemistry of nanocarbon supports for specific reaction systems have not been clearly addressed.

It has been demonstrated that both the nanostructures and surface physicochemical properties of nanocarbon supports play a significant, and even determining, role in the electrochemical performance of Pt-based electrocatalysts in PEMFCs. A desirable electrocatalyst support should maximize the surface accessibility to both reactants and electrolyte through mesopores and macropores. Simultaneously, the highly ordered and 3D interconnected structure of carbon materials is beneficial for easier mass transfer of reactants and products, and thus provides Pt-based catalysts with a high Pt utilization coefficient and a large electrochemical surface area, and consequently, superior electrocatalytic activity. As far as the surface chemistry of carbon is concerned, the introduced chemical groups act as surface modifiers to enhance the hydrophilicity of the carbon surface to obtain catalysts with high dispersion and provide anchoring sites for high stability catalysts. Doping heteroatoms, such as nitrogen, oxygen, sulfur, phosphorus, and others, into carbon support can change the $s p^{2}$ spin charge distribution of carbon atoms adjacent to the doped heteroatoms, significantly impacting the adsorption state of the oxygen reduction intermediates. Furthermore, the heteroatom-doped carbon support accelerates ORR by promoting adsorption of the reaction intermediates. In the presence of oxygen-containing functional groups, Pt-CO enhances Pt activity and the tolerance to $\mathrm{CO}$ poisoning through the bi-functional mechanism. For NCs as the support for Pt catalysts, Pt/NCs exhibits a comparable activity and much longer stability towards ORR, as compared with Pt/C catalysts. Even more interesting is that superior inertness to methanol and $\mathrm{CO}$ oxidation is also shown, which is attractive for DMFC cathode catalysts because of the unavoidable problem of methanol crossover. Moreover, sulfur-doped carbon improves the dispersibility of supported metal nanoparticles and controls the nanoparticle size under strong metal-support interactions. Since sulfur has 
greater electronegativity, controlling the amount of sulfur doping has a significant impact on carbon support and is necessary to prevent the main structure of carbon support from being damaged. Multi-atom co-doped carbons can improve the catalyst performance more obviously than single-element doped carbon. In contrast, it is necessary to realize that this form of multi-atom co-doping does not have an infinite additive effect on the performance improvement because the interaction between the multiple atoms will limit the catalyst performance, which will not show a linear improvement effect. Additionally, regarding the functional carbon-based support, WC has a significant positive effect on improving the CO resistance of PEMFCs because it can produce a synergistic effect to generate $\mathrm{OH}_{\text {ads }}$ components so that $\mathrm{CO}$ is quickly oxidized to the surface hydroxyl groups, which is the key to improving the MOR performance of Pt catalysts. Additionally, $\mathrm{Mo}_{2} \mathrm{C}$ has a significant effect on improving the catalyst durability, mainly increasing the catalyst oxidation potential by increasing the binding energy of metal catalyst and oxygen and reducing the corrosion current of the fuel cell to improve the corrosion resistance, thereby enhancing the durability.

From the perspective of nanocarbons as the electrocatalyst supports, the nanoarchitecture should combine both physical and chemical properties, especially the specific pore characteristics and surface functional groups. For a comprehensive assessment of end-use applications, novel nanocarbons themselves-supported catalysts should be evaluated in real fuel cell working conditions for their electrochemical activity and longevity. Nanocarbon materials used as catalyst supports often need to be optimized, such as by adjusting the pore size, doping heteroatoms, constructing defect sites, and others [227]. Additionally, different nanocarbon materials have different characteristics, so a composite carbon material combining two or more nanocarbon materials as a catalyst support [11,228-230] may complement each other with advantages, thereby exhibiting better performance. Compared with the classical metal-supported catalyst model, the metal-organic framework (MOF)-based catalysts have better structure and chemical property controllability and their huge potential cannot be ignored [231]. With continuous development, PEMFCs with more efficient, more environmentally friendly, cheaper, and sustainable properties will always be the goal pursued by researchers around the world. In the future carbon support research, excluding nanocarbon materials, biomass carbon materials may be a potential new type of fuel cell carbon supports $[227,232,233]$. Because of their wide source, simple production, and the realization of secondary utilization of resources, it may become the next research hotspot, and it is worth exploring by researchers. The corrosion problem of carbon supports under harsh electrochemical conditions, which hinders the commercialization of PEMFCs, is still an urgent problem that needs to be solved, while non-carbon materials with high oxidation resistance (such as nanoceramics) as catalyst supports may be able to improve the CO resistance of catalysts [234], implying feasible application prospects. Although this review summarizes a large number of novel nanocarbon-based supports, the current technology for preparing nanomaterials is still not particularly mature, especially for large-scale production. Although, in theory, the nanomaterial morphology can be adjusted, in reality the conditions that need to be met to adjust the morphology are very complicated. Therefore, at present, as the most mature and widely used XC 72R CB is still mainly and commonly applied as a support for PEMFC electrocatalysts. The improvement of nano-production technology is the "engine" that promotes PEMFCs development whether it is the catalyst itself or the catalyst support. In the future, catalyst development will gradually shift from noble metal catalysts to non-precious metal catalysts, from nanocatalysts to SACs or nano-cluster catalysts, and the development of catalyst supports will move from carbon supports to non-carbon supports or even free-supports. With the improvement of various theoretical calculation models and the development of more advanced in situ technologies, revealing the catalytic mechanism and structural changes of the catalyst during the real reaction process will become easier.

\section{Electronic supporting information}

Supporting information is available in the online version of this article.

\section{References}

[1] T. Ioroi, Z. Siroma, S. i. Yamazaki, K. Yasuda, Adv. Energy Mater, 2019, 9, 1801284.

[2] X. Tang, D. Fang, L. Qu, D. Xu, X. Qin, B. Qin, W. Song, Z. Shao, B. Yi, Chin. J. Catal., 2019, 40, 504-514.

[3] F. Xie, Z. Shao, M. Hou, H. Yu, W. Song, S. Sun, L. Zhou, B. Yi, J. Energy Chem., 2019, 36, 129-140.

[4] R. L. Borup, A. Kusoglu, K. C. Neyerlin, R. Mukundan, R. K. Ahluwalia, D. A. Cullen, K. L. More, A. Z. Weber, D. J. Myers, Curr. Opin. Electrochem., 2020, 21, 192-200.

[5] Y. Zhao, Y. Mao, W. Zhang, Y. Tang, P. Wang, Int. J. Hydrogen Ener$g y$, 2020, 45, 23174-23200.

[6] B. Randrianarizafy, P. Schott, M. Gerard, Y. Bultel, Energies, 2020, 13, 2338.

[7] Z. Ma, Z. P. Cano, A. Yu, Z. Chen, G. Jiang, X. Fu, L. Yang, T. Wu, Z. Bai, J. Lu, Angew. Chem.-Int. Ed., 2020, 59, 18334-18348.

[8] A. Yuda, A. Ashok, A. Kumar, Catal. Rev., 2020, DOI: 10.1080/01614940.2020.1802811.

[9] F. Lyu, M. Cao, A. Mahsud, Q. Zhang, J. Mater. Chem. A, 2020, 8, 15445-15457.

[10] M. Shao, Q. Chang, J. P. Dodelet, R. Chenitz, Chem. Rev., 2016, 116, 3594-3657.

[11] M. S. Garapati, R. Sundara, Int. J. Hydrogen Energy, 2019, 44, 10951-10963.

[12] P. Li, W. Chen, Chin. J. Catal., 2019, 40, 4-22.

[13] X. He, F. Yin, H. Wang, B. Chen, G. Li, Chin. J. Catal., 2018, 39, 207-227.

[14] J. Kong, W. Cheng, Chin. J. Catal., 2017, 38, 951-969.

[15] J. Zhang, S. Lu, Y. Xiang, S. P. Jiang, ChemSusChem, 2020, 13, 2484-2502.

[16] B. Hasa, E. Martino, J. Vakros, G. Trakakis, C. Galiotis, A. Katsaounis, ChemElectroChem, 2019, 6, 4970-4979.

[17] T. W. van Deelen, C. Hernández Mejía, K. P. de Jong, Nat. Catal., 2019, 2, 955-970.

[18] Y. C. Park, H. Tokiwa, K. Kakinuma, M. Watanabe, M. Uchida, J. 


\section{Graphical Abstract}

Chin. J. Catal., 2021, 42: 1297-1326 doi: 10.1016/S1872-2067(20)63736-6

\section{Recent developments of nanocarbon based supports for PEMFCs electrocatalysts}

Junwei Chen, Zuqiao Ou, Haixin Chen, Shuqin Song, Kun Wang, Yi Wang *

Sun Yat-sen University

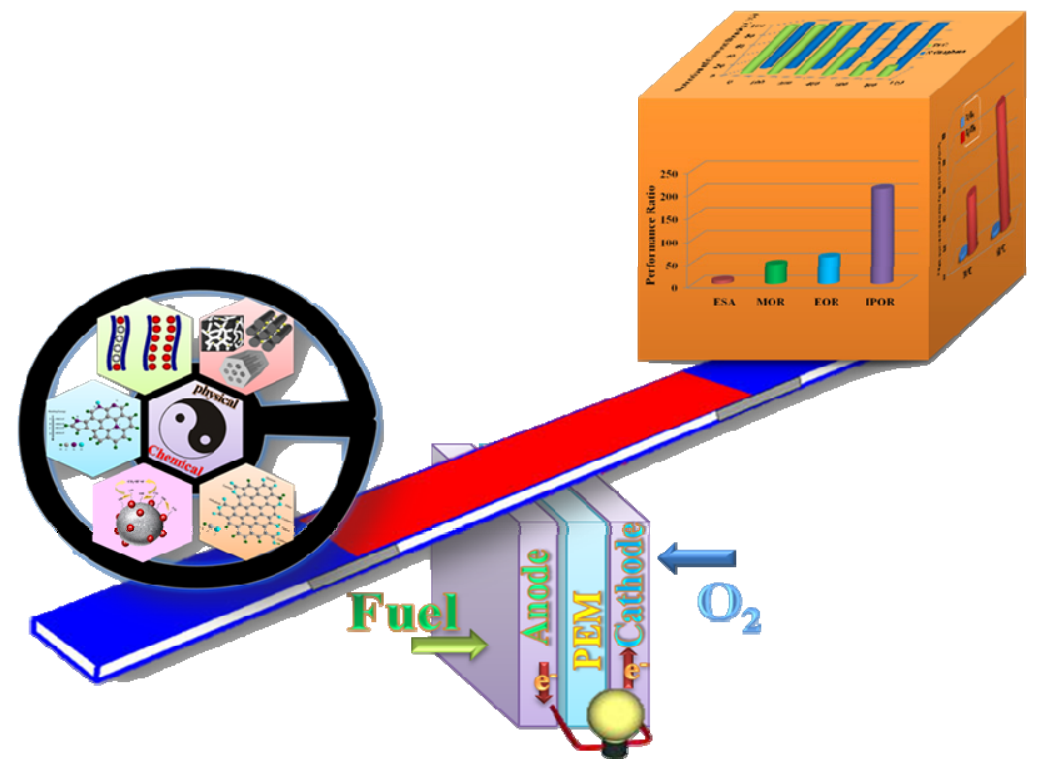

This work reviews the recent development of nanocarbon-based supports for PEMFC electrocatalysts, with an emphasis on the effect of their physical characteristics and chemical properties on the electrocatalytic performance of supported Pt-based catalysts at the microand even, nano- and molecular-level.

Power Sources, 2016, 315, 179-191.

[19] X. Chen, F. He, Y. Shen, Y. Yang, H. Mei, S. Liu, T. Mori, Y. Zhang, Chem. Eur. J., 2017, 23, 14597-14603.

[20] F. Zhu, L. Luo, A. Wu, C. Wang, X. Cheng, S. Shen, C. Ke, H. Yang, J. Zhang, ACS Appl. Mater. Interfaces, 2020, 12, 26076-26083.

[21] A. Brouzgou, S. Song, Z. X. Liang, P. Tsiakaras, Catalysts, 2016, 6, 159.

[22] J. Gacia-Cardona, I. Sirés, F. Alcaide, E. Brillas, F. Centellas, P. L. Cabot, Int. J. Hydrogen Energy, 2020, 45, 20582-20593.

[23] Z. Qiao, S. Hwang, X. Li, C. Wang, W. Samarakoon, S. Karakalos, D. Li, M. Chen, Y. He, M. Wang, Z. Liu, G. Wang, H. Zhou, Z. Feng, D. Su, J. S. Spendelow, G. Wu, Energy Environ. Sci., 2019, 12, 2830-2841.

[24] E. Arici, B. Y. Kaplan, A. M. Mert, S. Alkan Gursel, S. Kinayyigit, Int. J. Hydrogen Energy, 2019, 44, 14175-14183.

[25] M. V. Martínez-Huerta, M. J. Lázaro, Catal. Today, 2017, 285, 3-12.

[26] I. Udin, M. S. Shaharun, A. Naeem, M. A. Alotaibi, A. I. Alharthi, M. A. Bakht, Q. Nasir, Ceram. Int., 2020, 46, 18446-18452.

[27] K. Cheng, K. Zhu, S. Liu, M. Li, J. Huang, L. Yu, Z. Xia, C. Zhu, X. Liu, W. Li, W. Lu, F. Wei, Y. Zhou, W. Zheng, S. Mu, ACS Appl. Mater. Interfaces, 2018, 10, 21306-21312.

[28] H. Li, N. Cheng, Y. Zheng, X. Zhang, H. Lv, D. He, M. Pan, F. Kleitz, S. Z. Qiao, S. Mu, Adv. Energy Mater, 2013, 3, 1176-1179.

[29] K. D. Yang, C. W. Lee, J. H. Jang, T. R. Ha, K. T. Nam, Nanotechnology, 2017, 28, 352001.

[30] F. Yang, D. Deng, X. Pan, Q. Fu, X. Bao, Natl. Sci. Rev., 2015, 2, 183-201.
[31] G. Zhang, Y. S. Feng, W. T. Lu, D. He, C. Y. Wang, Y. K. Li, X. Y. Wang, F. F. Cao, ACS Catal., 2018, 8, 5431-5441.

[32] H. Li, J. Xiao, Q. Fu, X. Bao, Proc. Natl. Acad. Sci. USA, 2017, 114 5930-5934.

[33] K. Huang, Z. Zhao, H. Du, P. Du, H. Wang, R. Wang, S. Lin, H. Wei, Y. Long, M. Lei, W. Guo, H. Wu, ACS Sustain. Chem. Eng., 2020, 8, 6905-6913.

[34] Z. Bai, W. Tu, J. Zhu, J. Li, Z. Deng, D. Li, H. Tang, Polymers, 2019, 11, 576.

[35] S. Song, C. He, J. Liu, Y. Wang, A. Brouzgou, P. Tsiakaras, Appl. Catal. $B, 2012,119-120,227-233$.

[36] J. Liu, G. Lan, Y. Qiu, X. Wang, Y. Li, Chin. J. Catal., 2018, 39, 1664-1671.

[37] N. Hu, X. Y. Li, S. M. Liu, Z. Wang, X. K. He, Y. X. Hou, Y. X. Wang, Z. Deng, L. H. Chen, B. L. Su, Chin. J. Catal., 2020, 41, 1081-1090.

[38] A. Ali, C. Zhao, Chin. J. Catal., 2020, 41, 1174-1185.

[39] Z. P. Hu, J. T. Ren, D. Yang, Z. Wang, Z. Y. Yuan, Chin. J. Catal., 2019, 40, 1385-1394.

[40] J. Xing, F. Lin, L. Huang, Y. Si, Y. Wang, L. Jiao, Chin. J. Catal., 2019, 40, 1352-1359.

[41] K. Cheng, Z. Kou, J. Zhang, M. Jiang, H. Wu, L. Hu, X. Yang, M. Pan, S. $\mathrm{Mu}, J$. Mater. Chem. A, 2015, 3, 14007-14014.

[42] T. Asset, N. Job, Y. Busby, A. Crisci, V. Martin, V. Stergiopoulos, C. Bonnaud, A. Serov, P. Atanassov, R. Chattot, L. Dubau, F. Maillard, ACS Catal., 2018, 8, 893-903.

[43] E. Antolini, Appl. Catal. B, 2012, 123-124, 52-68. 
[44] M. Yaldagard, M. Jahanshahi, N. Seghatoleslami, World J. Nano Sci. Eng., 2013, 3, 121-153.

[45] N. M. Julkapli, S. Bagheri, Int. J. Hydrogen Energy, 2015, 40, 948-979.

[46] X. Mao, G. C. Rutledge, T. A. Hatton, Nano Today, 2014, 9, 405-432.

[47] S. Jayabal, G. Saranya, D. Geng, L. Y. Lin, X. Meng, J. Mater. Chem. A, 2020, 8, 9420-9446.

[48] J. Lai, A. Nsabimana, R. Luque, G. Xu, Joule, 2018, 2, 76-93.

[49] S. Cai, R. Wang, W. M. Yourey, J. Li, H. Zhang, H. Tang, Sci. Bull., 2019, 64, 968-975.

[50] K. Huang, R. Wang, S. Zhao, P. Du, H. Wang, H. Wei, Y. Long, B. Deng, M. Lei, B. Ge, H. Gou, R. Zhang, H. Wu, Energy Storage Mater., 2020, 29, 156-162.

[51] H. Wu, T. Peng, Z. Kou, J. Zhang, K. Cheng, D. He, M. Pan, S. Mu, Chin. J. Catal., 2015, 36, 490-495.

[52] D. He, H. Tang, Z. Kou, M. Pan, X. Sun, J. Zhang, S. Mu, Adv. Mater., 2017, 29, 1601741.

[53] Y. Wang, L. Zou, Q. Huang, Z. Zou, H. Yang, Int. J. Hydrogen Energy, 2017, 42, 26695-26703.

[54] H. Jin, J. Li, L. Gao, F. Chen, H. Zhang, Q. Liu, Int. J. Hydrogen Energy, 2016, 41, 9204-9210.

[55] Z. Liang, H. Zheng, R. Cao, ChemElectroChem, 2019, 6, 2600-2614.

[56] S. Q. Song, Y. R. Liang, Z. H. Li, Y. Wang, R. W. Fu, D. C. Wu, P. Tsiakaras, Appl. Catal. B, 2010, 98, 132-137.

[57] S. Ott, A. Orfanidi, H. Schmies, B. Anke, H. N. Nong, J. Hubner, U. Gernert, M. Gliech, M. Lerch, P. Strasser, Nat. Mater., 2020, 19, 77-85.

[58] A. Seifi, A. R. Bahramian, A. Sharif, J. Energy Storage, 2016, 7, 195-203.

[59] C. He, Y. Liang, R. Fu, D. Wu, S. Song, R. Cai, J. Mater. Chem., 2011, 21, 16357.

[60] K. Wang, H. Chen, X. Zhang, Y. Tong, S. Song, P. Tsiakaras, Y. Wang, Appl. Catal. B, 2020, 264, 118468.

[61] Z. Wang, X. Yao, Y. Kang, L. Miao, D. Xia, L. Gan, Adv. Func. Mater., 2019, 29, 1902987.

[62] H. Kuang, Y. Cheng, C. Q. Cui, S. P. Jiang, J. Nanosci. Nanotechnol., 2020, 20, 2736-2745.

[63] S. Bong, D. Han, Electroanalysis, 2019, 32, 104-111.

[64] M. Tavakkoli, E. Flahaut, P. Peljo, J. Sainio, F. Davodi, E. V. Lobiak, K. Mustonen, E. I. Kauppinen, ACS Catal., 2020, 10, 4647-4658.

[65] L. Tian, D. Ji, S. Zhang, X. He, S. Ramakrishna, Q. Zhang, Small, 2020, 16, 2001743.

[66] L. M. Zhang, X. L. Sui, L. Zhao, G. S. Huang, D. M. Gu, Z. B. Wang, Carbon, 2017, 121, 518-526.

[67] M. S. Çögenli, A. Bayrakçeken Yurtcan, Int. J. Hydrogen Energy, 2020, 45, 650-666.

[68] F. Meng, L. Li, Z. Wu, H. Zhong, J. Li, J. Yan, Chin. J. Catal., 2014, 35, 877-883.

[69] Y. Zhou, X. Hu, S. Guo, C. Yu, S. Zhong, X. Liu, Electrochim. Acta, 2018, 264, 12-19.

[70] M. Zeng, C. Y. Wang, L. Su, Z. H. Luo, J. K. Wu, Y. Yi, ChemistrySelect, 2020, 5, 9296-9300.

[71] M. Ouattara-Brigaudet, S. Berthon-Fabry, C. Beauger, M. Chatenet, N. Job, M. Sennour, P. Achard, Int. J. Hydrogen Energy, 2012, 37, 9742-9757.

[72] X. Tang, Y. Zeng, L. Cao, L. Yang, Z. Wang, D. Fang, Y. Gao, Z. Shao, B. Yi, J. Mater. Chem. A, 2018, 6, 15074-15082.

[73] S. Sepp, K. Vaarmets, J. Nerut, I. Tallo, E. Tee, H. Kurig, J. Aruväli, R. Kanarbik, E. Lust, J. Solid State Electrochem., 2016, 21, 1035-1043.

[74] Q. L. Zhu, W. Xia, L. R. Zheng, R. Zou, Z. Liu, Q. Xu, ACS Energy Lett., 2017, 2, 504-511.

[75] Y. Li, D. Wang, H. Xie, C. Zhang, ChemistrySelect, 2019, 4,
12601-12607.

[76] L. Nan, W. Yue, ACS Appl. Mater. Interfaces, 2018, 10, 26213-26221.

[77] W. Zhao, Y. Ye, W. Jiang, J. Li, H. Tang, J. Hu, L. Du, Z. Cui, S. Liao, J. Mater. Chem. A, 2020, 8, 15822-15828.

[78] S. Song, S. Yin, Z. Li, P. K. Shen, R. Fu, D. Wu, J. Power Sources, 2010, 195, 1946-1949.

[79] J. J. Arroyo-Gómez, D. Barrera, R. M. Castagna, J. M. Sieben, A. E. Alvarez, M. M. E. Duarte, K. Sapag, ChemCatChem, 2019, 11, 3451-3464.

[80] A. Elsheikh, V. L. Martins, J. McGregor, Energy Procedia, 2018, 151, 79-83.

[81] R. Zhang, T. Min, L. Chen, Q. Kang, Y. L. He, W. Q. Tao, Appl. Energy, 2019, 253, 113590.

[82] M. Wei, M. Jiang, X. Liu, M. Wang, S. Mu, J. Power Sources, 2016, 327, 384-393.

[83] C. Zhu, H. Li, S. Fu, D. Du, Y. Lin, Chem. Soc. Rev., 2016, 45, 517-531.

[84] I. C. Gerber, P. Serp, Chem. Rev., 2019, 120, 1250-1349.

[85] A. Mishra, V. K. Singh, T. Mohanty, J. Mater. Sci., 2017, 52, 7677-7687.

[86] M. Kiani, J. Zhang, Y. Luo, C. Jiang, J. Fan, G. Wang, J. Chen, R. Wang, J. Energy Chem., 2018, 27, 1124-1139.

[87] H. Tang, Y. Zeng, Y. Zeng, R. Wang, S. Cai, C. Liao, H. Cai, X. Lu, P. Tsiakaras, Appl. Catal. B, 2017, 202, 550-556.

[88] Y. Cao, S. Mao, M. Li, Y. Chen, Y. Wang, ACS Catal., 2017, 7, 8090-8112.

[89] J. Liang, X. Zhang, L. Jing, H. Yang, Chin. J. Catal., 2017, 38, 1252-1260.

[90] K. Huang, L. Zhang, T. Xu, H. Wei, R. Zhang, X. Zhang, B. Ge, M. Lei, J. Y. Ma, L. M. Liu, H. Wu, Nat. Commun., 2019, 10, 606.

[91] H. Zhao, C. C. Weng, J. T. Ren, L. Ge, Y. P. Liu, Z. Y. Yuan, Chin. J. Catal., 2020, 41, 259-267.

[92] H. Li, D. Liu, X. Zhu, D. Qu, Z. Xie, J. Li, H. Tang, D. Zheng, D. Qu, Nano Energy, 2020, 73, 104763.

[93] J. A. Prithi, N. Rajalakshmi, G. Ranga Rao, Int. J. Hydrogen Energy, 2018, 43, 4716-4725.

[94] C. Zhang, L. Fu, N. Liu, M. Liu, Y. Wang, Z. Liu, Adv. Mater., 2011, 23, 1020-1024.

[95] H. Jiang, L. Liu, K. Zhao, Z. Liu, X. Zhang, S. Hu, Electrochim. Acta, 2020, 337, 135758.

[96] J. Xu, B. Liu, Appl. Surf. Sci., 2020, 500, 144020.

[97] X. Jiang, J. Wang, T. Huang, G. Fu, Y. Tang, X. Qiu, J. Zhou, J. M. Lee, J. Mater. Chem. A, 2019, 7, 26243-26249.

[98] Q. Wang, Z. Zhang, M. Wang, J. Li, J. Fang, Y. Lai, Chin. J. Catal., 2018, 39, 1210-1218.

[99] K. K. Karuppanan, Appu V. Raghu, M. K. Panthalingal, V. Thiruvenkatam, K. P. B. Pullithadathil, Sustain. Energy Fuels, 2019, 3, 996-1011.

[100] J. Liu, W. Li, R. Cheng, Q. Wu, J. Zhao, D. He, S. Mu, Langmuir, 2019, 35, 2580-2586.

[101] L. Zhao, Q. Wang, X. Zhang, C. Deng, Z. Li, Y. Lei, M. Zhu, ACS Appl. Mater. Interfaces, 2018, 10, 35888-35895.

[102] L. Warczinski, B. Hu, T. Eckhard, B. Peng, M. Muhler, C. Hättig, Phys. Chem. Chem. Phys., 2020, 22, 21317-21325.

[103] F. Han, Z. Liu, J. Jia, J. Ai, L. Liu, J. Liu, Q. D. Wang, Mater. Chem. Phys., 2019, 237, 121881.

[104] E. Haque, A. Zavabeti, N. Uddin, Y. Wang, M. A. Rahim, N. Syed, K. Xu, A. Jannat, F. Haque, B. Y. Zhang, M. A. Shoaib, S. Shamsuddin, M. Nurunnabi, A. I. Minett, J. Z. Ou, A. T. Harris, Chem. Mater., 2020, 32, 1384-1392.

[105] S. Shanmugam, T. Osaka, Chem. Commun., 2011, 47, 4463-4465. 
[106] K. Wan, Z. P. Yu, Z. X. Liang, Catalysts, 2015, 5, 1034-1045.

[107] G. Chen, T. Wang, P. Liu, Z. Liao, H. Zhong, G. Wang, P. Zhang, M. Yu, E. Zschech, M. Chen, J. Zhang, X. Feng, Energy Environ. Sci., 2020, 13, 2849-2855.

[108] J. Li, S. You, M. Liu, P. Zhang, Y. Dai, Y. Yu, N. Ren, J. Zou, Appl. Catal. B, 2020, 265, 118574

[109] D. S. Geng, Y. Chen, Y. G. Chen, Y. L. Li, R. Y. Li, X. L. Sun, S. Y. Ye, S. Knights, Energy Environ. Sci., 2011, 4, 760-764.

[110] X. Q. Wang, J. S. Lee, Q. Zhu, J. Liu, Y. Wang, S. Dai, Chem. Mater., 2010, 22, 2178-2180.

[111] N. Karthikeyan, B. P. Vinayan, M. Rajesh, K. Balaji, A. K. Subramani, S. Ramaprabhu, Fuel Cells, 2015, 15, 278-287.

[112] E. N. Gribov, A. N. Kuznetsov, V. A. Golovin, D. V. Krasnikov, V. L. Kuznetsov, Mater. Renew. Sustain. Energy, 2019, 8, 7.

[113] E. Antolini, Renew. Sust. Energ. Rev., 2016, 58, 34-51.

[114] Y. Wei, X. Zhang, Z. Luo, D. Tang, C. Chen, T. Zhang, Z. Xie, Nano-Micro Lett., 2017, 9, 28.

[115] H. Jin, T. Xiong, Y. Li, X. Xu, M. Li, Y. Wang, Chem. Commun., 2014 $50,12637-12640$.

[116] C. E. Thaw, A. Villa, G. M. Veith, L. Prati, ChemCatChem, 2015, 7, 1338-1346.

[117] K. Jukk, N. Kongi, P. Rauwel, L. Matisen, K. Tammeveski, Electrocatalysis, 2016, 7, 428-440.

[118] X. Sun, P. Han, B. Li, S. Mao, T. Liu, S. Ali, Z. Lian, D. Su, Chem. Commun., 2018, 54, 864-875.

[119] K. Vaarmets, J. Nerut, S. Sepp, R. Kanarbik, E. Lust, J. Electrochem. Soc., 2017, 164, F338-F346.

[120] C. Park, E. Lee, G. Lee, Y. Tak, Appl. Catal. B, 2020, 268, 118414.

[121] L. Guo, W. J. Jiang, Y. Zhang, J. S. Hu, Z. D. Wei, L. J. Wan, ACS Catal., 2015, 5, 2903-2909.

[122] M. Qiao, Y. Wang, X. Mamat, A. Chen, G. Zou, L. Li, G. Hu, S. Zhang, X. Hu, D. Voiry, ChemSusChem, 2020, 13, 741-748.

[123] L. Zhang, K. D. Davis, X. Sun, Energy Environ. Sci., 2019, 12, 492-517.

[124] M. Yoo, Y. S. Yu, H. Ha, S. Lee, J. S. Choi, S. Oh, E. Kang, H. Choi, H. An, K. S. Lee, J. Y. Park, R. Celestre, M. A. Marcus, K. Nowrouzi, D. Taube, D. A. Shapiro, W. Jung, C. Kim, H. Y. Kim, Energy Environ. Sci., 2020, 13, 1231-1239.

[125] J. Wu, L. Xiong, B. Zhao, M. Liu, L. Huang, Small Methods, 2020, 4, 1900540.

[126] B. Han, Y. Guo, Y. Huang, W. Xi, J. Xu, J. Luo, H. Qi, Y. Ren, X. Liu, B. Qiao, T. Zhang, Angew. Chem.-Int. Ed., 2020, 59, 11824-11829.

[127] K. Huang, R. Wang, H. Wu, H. Wang, X. He, H. Wei, S. Wang, R. Zhang, M. Lei, W. Guo, B. Ge, H. Wu, J. Mater. Chem. A, 2019, 7, 25779-25784.

[128] S. Sun, G. Zhang, N. Gauquelin, N. Chen, J. Zhou, S. Yang, W. Chen, X. Meng, D. Geng, M. N. Banis, R. Li, S. Ye, S. Knights, G. A. Botton, T. K. Sham, X. Sun, Sci. Rep., 2013, 3, 1775.

[129] J. Xu, R. Li, R. Zeng, X. Yan, Q. Zhao, J. Ba, W. Luo, D. Meng, ACS Appl. Mater. Interfaces, 2020, 12, 38106-38112.

[130] P. Zhou, F. Lv, N. Li, Y. Zhang, Z. Mu, Y. Tang, J. Lai, Y. Chao, M. Luo, F. Lin, J. Zhou, D. Su, S. Guo, Nano Energy, 2019, 56, 127-137.

[131] Y. Q. Su, Y. Wang, J. X. Liu, I. A. W. Filot, K. Alexopoulos, L. Zhang, V. Muravev, B. Zijlstra, D. G. Vlachos, E. J. M. Hensen, ACS Catal., 2019, 9, 3289-3297.

[132] D. Kunwar, S. Zhou, A. DeLaRiva, E. J. Peterson, H. Xiong, X. I. Pereira-Hernández, S. C. Purdy, R. ter Veen, H. H. Brongersma, J. T. Miller, H. Hashiguchi, L. Kovarik, S. Lin, H. Guo, Y. Wang, A. K. Datye, ACS Catal., 2019, 9, 3978-3990.

[133] X. Li, X. Yang, J. Zhang, Y. Huang, B. Liu, ACS Catal., 2019, 9, 2521-2531.
[134] M. J. Hulsey, B. Zhang, Z. Ma, H. Asakura, D. A. Do, W. Chen, T Tanaka, P. Zhang, Z. Wu, N. Yan, Nat. Commun., 2019, 10, 1330.

[135] E. D. Boyes, A. P. LaGrow, M. R. Ward, R. W. Mitchell, P. L. Gai, Acc. Chem. Res., 2020, 53, 390-399.

[136] M. González-Hernández, E. Antolini, J. Perez, Int. J. Hydrogen Energy, 2020, 45, 5276-5284.

[137] J. Ding, L. Ma, M. Gan, W. Zhan, C. Zhou, D. Wei, S. Han, J. Shen, F. Xie, X. Zhong, Int. J. Hydrogen Energy, 2019, 44, 30388-30400.

[138] A. C. Johansson, J. V. Larsen, M. A. Verheijen, K. B. Haugshøj, H. F. Clausen, W. M. M. Kessels, L. H. Christensen, E. V. Thomsen, J. Catal., 2014, 311, 481-486

[139] H. Jin, C. Guo, X. Liu, J. Liu, A. Vasileff, Y. Jiao, Y. Zheng, S. Z. Qiao, Chem. Rev., 2018, 118, 6337-6408.

[140] B. Zhang, D. S. Su, ChemCatChem, 2015, 7, 3639-3645.

[141] Y. N. Chen, X. Zhang, Z. Zhou, Small Methods, 2019, 3, 1900050.

[142] Z. Tong, M. Wen, C. Lv, Q. Zhang, Y. Yin, X. Liu, Y. Li, C. Liao, Z. Wu, D. D. Dionysiou, Appl. Catal. B, 2020, 269, 118764.

[143] Y. Miao, J. Zheng, Y. Liu, N. Xiang, Y. Li, X. Han, Z. Huang, Catal. Lett., 2020, 150, 3243-3255.

[144] D. Xiao, J. Ma, C. Chen, Q. Luo, J. Ma, L. Zheng, X. Zuo, Mater. Res. Bull., 2018, 105, 184-191.

[145] C. A. Trujillo, N. T. Ramírez-Marquez, J. S. Valencia-Rios, Thermochim. Acta, 2020, 689, 178651

[146] S. Andreoli, S. Eser, Carbon, 2020, 168, 362-371.

[147] H. Ogihara, T. Maezuru, Y. Ogishima, Y. Inami, M. Saito, S. Iguchi, I. Yamanaka, ACS Omega, 2020, 5, 19453-19463.

[148] J. R. C. Salgado, R. G. Duarte, L. M. Ilharco, A. M. B. do Rego, A. M. Ferraria, M. G. S. Ferreira, Appl. Catal. B, 2011, 102, 496-504.

[149] S. Liu, F. Dong, Z. Tang, Q. Wang, Int. J. Hydrogen Energy, 2020 45, 30547-30558.

[150] S. H. Liu, J. R. Wu, Int. J. Hydrogen Energy, 2012, 37, 16994-17001.

[151] B. T. Sneed, D. A. Cullen, K. S. Reeves, O. E. Dyck, D. A. Langlois, R. Mukundan, R. L. Borup, K. L. More, ACS Appl. Mater. Interfaces, 2017, 9, 29839-29848.

[152] L. Castanheira, W. O. Silva, F. H. B. Lima, A. Crisci, L. Dubau, F. Maillard, ACS Catal., 2015, 5, 2184-2194.

[153] W. Chen, D. Jiang, M. Zhu, T. Shi, H. Li, K. Wang, J. Alloys Compd., 2018, 741, 1203-1211.

[154] B. H. Suryanto, S. Chen, J. Duan, C. Zhao, ACS Appl. Mater. Interfaces, 2016, 8, 35513-35522.

[155] J. H. Kim, J. Y. Cheon, T. J. Shin, J. Y. Park, S. H. Joo, Carbon, 2016, 101, 449-457.

[156] L. Calvillo, V. Celorrio, R. Moliner, M. J. Lazaro, Mater. Chem. Phys., 2011, 127, 335-341.

[157] C. X. He, S. Q. Song, J. C. Liu, V. Maragou, P. Tsiakaras, J. Power Sources, 2010, 195, 7409-7414

[158] W. Xiong, B. A. T. Mehrabadi, S. G. Karakolos, R. D. White, A. Shakouri, P. Kasak, S. J. Zaidi, J. W. Weidner, J. R. Regalbuto, H. Colon-Mercado, J. R. Monnier, ACS Appl. Energy Mater., 2020, 3 , 5487-5496.

[159] S. A. Grigoriev, V. N. Fateev, A. S. Pushkarev, I. V. Pushkareva, N. A. Ivanova, V. N. Kalinichenko, M. Yu Presnyakov, X. Wei, Materials, 2018, 11, 1405.

[160] X. Ning, X. Zhou, J. Luo, L. Ma, X. Xu, L. Zhan, Electrochim. Acta, 2019, 319, 129-137.

[161] E. Montiel Macias, A. M. Valenzuela-Muñiz, G. Alonso-Núñez, M. H. Farías Sánchez, R. Gauvin, Y. Verde Gómez, Diam. Relat. Mater. 2020, 103, 107671.

[162] K. Ham, S. Chung, J. Lee, J. Power Sources, 2020, 450, 227650.

[163] D. K. Perivoliotis, Y. Sato, K. Suenaga, N. Tagmatarchis, ACS Appl. Energy Mater., 2018, 1, 3869-3880. 
[164] M. A. Hoque, F. M. Hassan, M. H. Seo, J. Y. Choi, M. Pritzker, S. Knights, S. Ye, Z. Chen, Nano Energy, 2016, 19, 27-38.

[165] M. A. Hoque, F. M. Hassan, A. M. Jauhar, G. Jiang, M. Pritzker, J. Y. Choi, S. Knights, S. Ye, Z. Chen, ACS Sustain. Chem. Eng., 2017, 6, 93-98.

[166] J. J. Fan, Y. J. Fan, R. X. Wang, S. Xiang, H. G. Tang, S. G. Sun, J. Mater. Chem. A, 2017, 5, 19467-19475.

[167] O. L. Li, Z. Shi, H. Lee, T. Ishizaki, Sci. Rep., 2019, 9, 12704.

[168] Y. Li, S. Lin, X. Ren, H. Mi, P. Zhang, L. Sun, L. Deng, Y. Gao, Electrochim. Acta, 2017, 253, 445-454.

[169] M. Sahoo, S. Ramaprabhu, Energy, 2017, 119, 1075-1083.

[170] D. Chen, Z. He, S. E. Pei, L. A. Huang, H. Shao, Y. Jin, J. Wang, J. Alloys Compd., 2019, 785, 781-788.

[171] X. Tan, J. Zhang, X. Wu, Y. Wang, M. Li, Z. Shi, RSC Adv., 2018, 8, 33688-33694.

[172] M. An, L. Du, C. Du, Y. Sun, Y. Wang, G. Yin, Y. Gao, Electrochim. Acta, 2018, 285, 202-213.

[173] K. Yu, Y. Lin, j. Fan, Q. Li, P. Shi, Q. Xu, Y. Min, Catalysts, 2019, 9, 114.

[174] X. Zhang, Int. J. Electrochem. Sci., 2019, 14, 10931-10942.

[175] M. K. Sahoo, R. Shanmugam, E. Umeshbabu, G. Ranga Rao, ChemistrySelect, 2020, 5, 7205-7216.

[176] E. R. Hamo, P. Tereshchuk, M. Zysler, D. Zitoun, A. Natan, B. A. Rosen, J. Electrochem. Soc., 2019, 166, F1292-F1300.

[177] H. Na, H. Choi, J. W. Oh, D. B. Kim, Y. S. Cho, Green Chem., 2020, 22, 2028-2035.

[178] W. Zhu, A. Ignaszak, C. Song, R. Baker, R. Hui, J. Zhang, F. Nan, G. Botton, S. Ye, S. Campbell, Electrochim. Acta, 2012, 61, 198-206.

[179] Z. Li, B. Li, Z. Liu, Z. Liu, D. Li, RSC Adv., 2015, 5, 106245-106251.

[180] N. R. Elezović, B. M. Babić, L. Gajić-Krstajić, P. Ercius, V. R. Radmilović, N. V. Krstajić, L. M. Vračar, Electrochim. Acta, 2012, 69, 239-246.

[181] Y. Wang, S. Q. Song, P. K. Shen, C. X. Guo, C. M. Li, J. Mater. Chem., 2009, 19, 6149-6153.

[182] Z. Yan, F. Li, J. Xie, X. Miu, RSC Adv., 2015, 5, 6790-6796.

[183] N. E. Souza, J. L. Bott-Neto, T. A. Rocha, G. C. da Silva, E. Teixeira-Neto, E. R. Gonzalez, E. A. Ticianelli, Electrochim. Acta, 2018, 265, 523-531.

[184] Y. Zhou, X. Li, C. Yu, X. Hu, Y. Yin, S. Guo, S. Zhong, ACS Appl. Energy Mater., 2019, 2, 8459-8463.

[185] J. L. Bott-Neto, W. Beck, L. C. Varanda, E. A. Ticianelli, Int. J. Hydrogen Energy, 2017, 42, 20677-20688.

[186] S. M. Brkovic, M. P. Marceta Kaninski, P. Z. Lausevic, A. B. Saponjic, A. M. Radulovic, A. A. Rakic, I. A. Pasti, V. M. Nikolic, Int. J. Hydrogen Energy, 2020, 45, 13929-13938.

[187] D. Göhl, A. M. Mingers, S. Geiger, M. Schalenbach, S. Cherevko, J. Knossalla, D. Jalalpoor, F. Schüth, K. J. J. Mayrhofer, M. Ledendecker, Electrochim. Acta, 2018, 270, 70-76.

[188] Y. Wang, J. Su, L. Dong, P. Zhao, Y. Zhang, W. Wang, S. Jia, J. Zang, ChemCatChem, 2017, 9, 3982-3988.

[189] Y. Sohn, J. Y. Jung, P. Kim, Korean J. Chem. Eng., 2017, 34, 2162-2168.

[190] X. Lang, M. Shi, Y. Jiang, H. Chen, C. Ma, RSC Adv., 2016, 6, 13873-13880.

[191] Z. Li, Z. Liu, B. Li, Z. Liu, D. Li, H. Wang, Q. Li, Electrochim. Acta, 2016, 221, 31-40.

[192] K. Huang, K. Bi, J. C. Xu, C. Liang, S. Lin, W. J. Wang, T. Z. Yang, Y. X. Du, R. Zhang, H. J. Yang, D. Y. Fan, Y. G. Wang, M. Lei, Electrochim. Acta, 2015, 174, 172-177.

[193] G. García, O. Guillén-Villafuerte, J. L. Rodríguez, M. C. Arévalo, E. Pastor, Int. J. Hydrogen Energy, 2016, 41, 19664-19673.

[194] R. J“ager, E. H“ark, P. E. Kasatkin, P. Pikma, U. Joost, P. Paiste, J.
Aruv“ali, T. Kallio, H. Jiang, E. Lust, J. Electrochem. Soc., 2017, 164, F448-F453.

[195] G. Singla, K. Singh, O. P. Pandey, Mater. Chem. Phys., 2017, 186, 19-28.

[196] R. Ganesan, D. J. Ham, J. S. Lee, Electrochem. Commun., 2007, 9, 2576-2579.

[197] Y. Wang, S. Q. Song, V. Maragou, P. K. Shen, P. Tsiakaras, Appl. Catal. B, 2009, 89, 223-228.

[198] Y. Wang, C. He, A. Brouzgou, Y. Liang, R. Fu, D. Wu, P. Tsiakaras, S. Song, J. Power Sources, 2012, 200, 8-13.

[199] K. Wang, Y. Wang, Z. Liang, Y. Liang, D. Wu, S. Song, P. Tsiakaras, Appl. Catal. B, 2014, 147, 518-525.

[200] K. Wang, Z. Pan, F. Tzorbatzoglou, Y. Zhang, Y. Wang, T. Panagiotis, S. Song, Appl. Catal. B, 2015, 166, 224-230.

[201] H. Zheng, Z. Chen, Y. Li, C. A. Ma, Electrochim. Acta, 2013, 108, 486-490.

[202] M. Rahsepar, M. Pakshir, P. Nikolaev, A. Safavi, K. Palanisamy, H. Kim, Appl. Catal. B, 2012, 127, 265-272.

[203] C. He, J. Tao, Y. Ke, Y. Qiu, RSC Adv., 2015, 5, 66695-66703.

[204] M. Rahsepar, M. Pakshir, P. Nikolaev, Y. Piao, H. Kim, Int. J. Hydrogen Energy, 2014, 39, 15706-15717.

[205] S. Xue, W. Wang, J. Song, P. Tao, P. Wang, Z. Lei, J. Taiwan Inst. Chem. Eng., 2018, 84, 93-100.

[206] Z. Yang, M. Chen, M. Xia, M. Wang, X. Wang, Appl. Surf. Sci., 2019, 487, 655-663.

[207] J. P. Bosco, K. Sasaki, M. Sadakane, W. Ueda, J. G. G. Chen, Chem. Mater., 2010, 22, 966-973.

[208] Z. Jiang, J. Yu, T. Huang, M. Sun, Polymers, 2018, 10, 1397.

[209] J. Diao, Y. Qiu, S. Liu, W. Wang, K. Chen, H. Li, W. Yuan, Y. Qu, X. Guo, Adv. Mater., 2020, 32, 1905679.

[210] L. M. Rivera-Gavidia, M. Luis-Sunga, J. L. Rodríguez, E. Pastor, G. García, Int. J. Hydrogen Energy, 2020, 45, 20673-20678.

[211] J. Zhang, Y. She, Front. Chem. Sci. Eng., 2020, 14, 1052-1064.

[212] S. Han, L. Ma, M. Gan, J. Shen, D. Wei, W. Zhan, J. Ding, C. Zhou, X. Zhong, Appl. Surf. Sci., 2020, 505, 144652.

[213] O. Lori, S. Gonen, L. Elbaz, J. Electrochem. Soc., 2017, 164, F825-F830.

[214] S. Saha, J. A. Cabrera Rodas, S. Tan, D. Li, J. Power Sources, 2018, 378, 742-749.

[215] S. Sepp, K. Vaarmets, J. Nerut, I. Tallo, E. Tee, H. Kurig, J. Aruväli, R. Kanarbik, E. Lust, Electrochim. Acta, 2016, 203, 221-229.

[216] Z. Yan, J. Xie, P.K. Shen, J. Power Sources, 2015, 286, 239-246.

[217] A. M. Gómez-Marín, J. L. Bott-Neto, J. B. Souza, T. L. Silva, W. Beck, L. C. Varanda, E. A. Ticianelli, ChemElectroChem, 2016, 3, 1570-1579.

[218] S. Saha, B. Martin, B. Leonard, D. Li, J. Mater. Chem. A, 2016, 4, 9253-9265.

[219] D. Göhl, H. Rueß, M. Pander, A. R. Zeradjanin, K. J. J. Mayrhofer, J. M. Schneider, A. Erbe, M. Ledendecker, J. Electrochem. Soc., 2020, $167,021501$.

[220] C. He, J. Tao, G. He, P. K. Shen, Electrochim. Acta, 2016, 216, 295-303.

[221] C. B. Krishnamurthy, O. Lori, L. Elbaz, I. Grinberg, J. Phys. Chem. Lett., 2018, 9, 2229-2234.

[222] J. Lobato, H. Zamora, J. Plaza, M. A. Rodrigo, ChemCatChem, 2016, 8, 848-854.

[223] S. M. Andersen, M. J. Larsen, J. Electroanal. Chem., 2017, 791, 175-184.

[224] M. Chiwata, K. Kakinuma, M. Wakisaka, M. Uchida, S. Deki, M. Watanabe, H. Uchida, Catalysts, 2015, 5, 966-980.

[225] G. Zhao, T. Zhao, X. Yan, L. Zeng, J. Xu, Energy Tech., 2016, 4, 1064-1070. 
[226] Y. Nabil, S. Cavaliere, I. A. Harkness, J. D. B. Sharman, D. J. Jones, J. Rozière, J. Power Sources, 2017, 363, 20-26.

[227] G. Liu, B. Wang, L. Xu, P. Ding, P. Zhang, J. Xia, H. Li, J. Qian, Chin. J. Catal., 2018, 39, 790-799.

[228] S. Y. Lin, M. H. Chang, Int. J. Hydrogen Energy, 2015, 40, 7879-7885.

[229] P. Chandran, D. Puthusseri, S. Ramaprabhu, Int. J. Hydrogen Energy, 2019, 44, 4951-4961.

[230] M. Müllner, M. Riva, F. Kraushofer, M. Schmid, G. S. Parkinson, S.
F. L. Mertens, U. Diebold, J. Phys. Chem. C, 2018, 123, 8304-8311. [231] K. Huang, S. Guo, R. Wang, S. Lin, N. Hussain, H. Wei, B. Deng, Y. Long, M. Lei, H. Tang, H. Wu, Chin. J. Catal., 2020, 41, 1754-1760.

[232] T. M. Huggins, J. J. Pietron, H. Wang, Z. J. Ren, J. C. Biffinger, Bioresour. Technol., 2015, 195, 147-153.

[233] P. R. Kasturi, A. Arunchander, D. Kalpana, R. K. Selvan, J. Phys. Chem. Solids, 2019, 124, 305-311.

[234] H. Lv, S. Mu, Nanoscale, 2014, 6, 5063-5074.

\title{
电催化剂纳米碳基载体的研究进展
}

\author{
陈军伟，欧祖矢，陈海金金，宋树芹，王 昆，王 毅* \\ 中山大学化学工程与技术学院, 材料科学与工程学院, 广东省低碳化学与过程节能重点实验室, 广东广州510275
}

摘要: 质子交换膜燃料电池(PEMFCs)因具有工作温度低、结构紧凑、无腐蚀、启动快和灵活性好等优点, 受到人们广泛关 注. 但其工作时动力学迟缓且易受 $\mathrm{CO}$ 毒化影响, 往往需要负载Pt等贵金属催化剂, 导致PEMFCs的成本高昂, 阻碍了其商业 化应用. 为提高 $\mathrm{Pt}$ 贵金属的利用率, 通常将 $\mathrm{Pt}$ 负载在载体材料上来提高 $\mathrm{Pt}$ 的分散性以减少 $\mathrm{Pt}$ 颗粒集聚, 因此, 合适的载体材 料对于降低PEMFCs成本具有极大意义. 纳米碳材料由于具有高稳定性、可控的孔结构、可变的物理形态、可修饰的表面 化学以及低成本等特点, 是一种理想的催化剂载体材料, 已被广泛应用于PEMFCs电催化剂中.

本文综述了 PEMFCs电催化剂的纳米碳基载体的最新研究进展, 重点讨论了纳米碳的纳米结构和表面物理化学性质对 电催化剂性能的影响, 主要从孔结构、杂原子掺杂以及功能性碳基载体方面对其进行概述. 在孔结构方面, 纳米碳载体的 孔形貌和孔径大小能够显著地影响PEMFCs电催化剂的催化性能. 相比于无序孔, 有序孔能够减小反应物分子的传质阻力, 可使反应物分子更好地与载体孔道内的催化活性位点结合, 增加Pt催化剂的可及性, 从而提高反应活性. 合适的孔径不仅 能够使纳米碳载体具有足够的传质通道, 还能提供充足的用于电催化反应的高比表面积, 从而增加电催化剂的催化性能. 在杂原子掺杂方面, 向纳米碳载体中掺入氮、硫和磷等杂原子能够稳定碳载体结构, 并增加载体表面与金属纳米粒子之间 的结合位点, 提高金属纳米颗粒的分散性, 通过金属-载体之间的相互作用和协同作用提升电催化剂性能. 在功能性碳载体 方面, 通过对纳米碳载体进行有针对性地改性得到具有特定功能的碳化物载体, 改性后的功能性碳化物载体能够通过加速 $\mathrm{CO}$ 反应中间体氧化以增加电催化剂的抗 $\mathrm{CO}$ 毒化能力, 并能够通过降低燃料电池腐蚀电流的方式提升电催化剂的耐久性.

本文讨论了纳米碳载体的最新进展, 指出PEMFC电催化剂载体的未来发展方向, 为PEMFC催化剂的未来研究和设计 提供参考意见, 为推动PEMFC的市场化提供帮助.

关键词: 纳米碳载体; 质子交换膜燃料电池; 电催化剂; 氧还原反应; 甲醇氧化反应

收稿日期: 2020-10-05. 接受日期: 2020-11-29. 上网时间: 2021-04-05.

*通讯联系人. 电话/传真: (020)84113253; 电子信箱: wangyi76@mail.sysu.edu.cn

基金来源：国家自然科学基金(21978331，21975292，21905311)；广东省基础与应用基础研究基金(2020A1515010343); “广东特支 计划”科技创新青年拔尖人才(2016TQ03N322); 广州市科技计划项目(20170701007); 国家重点研究发展计划(2016YFB0101200); 中央高校基本科研业务费专项资金(19lgpy136, 19lgpy116); 博士后研究基金(2019M653142);

本文的电子版全文由Elsevier出版社在ScienceDirect上出版(http://www.sciencedirect.com/journal/chinese-journal-of-catalysis). 